Health Technology Assessment of

Assistance Dogs

and Dog-Assisted

Interventions

\title{
Martina Lundqvist
}
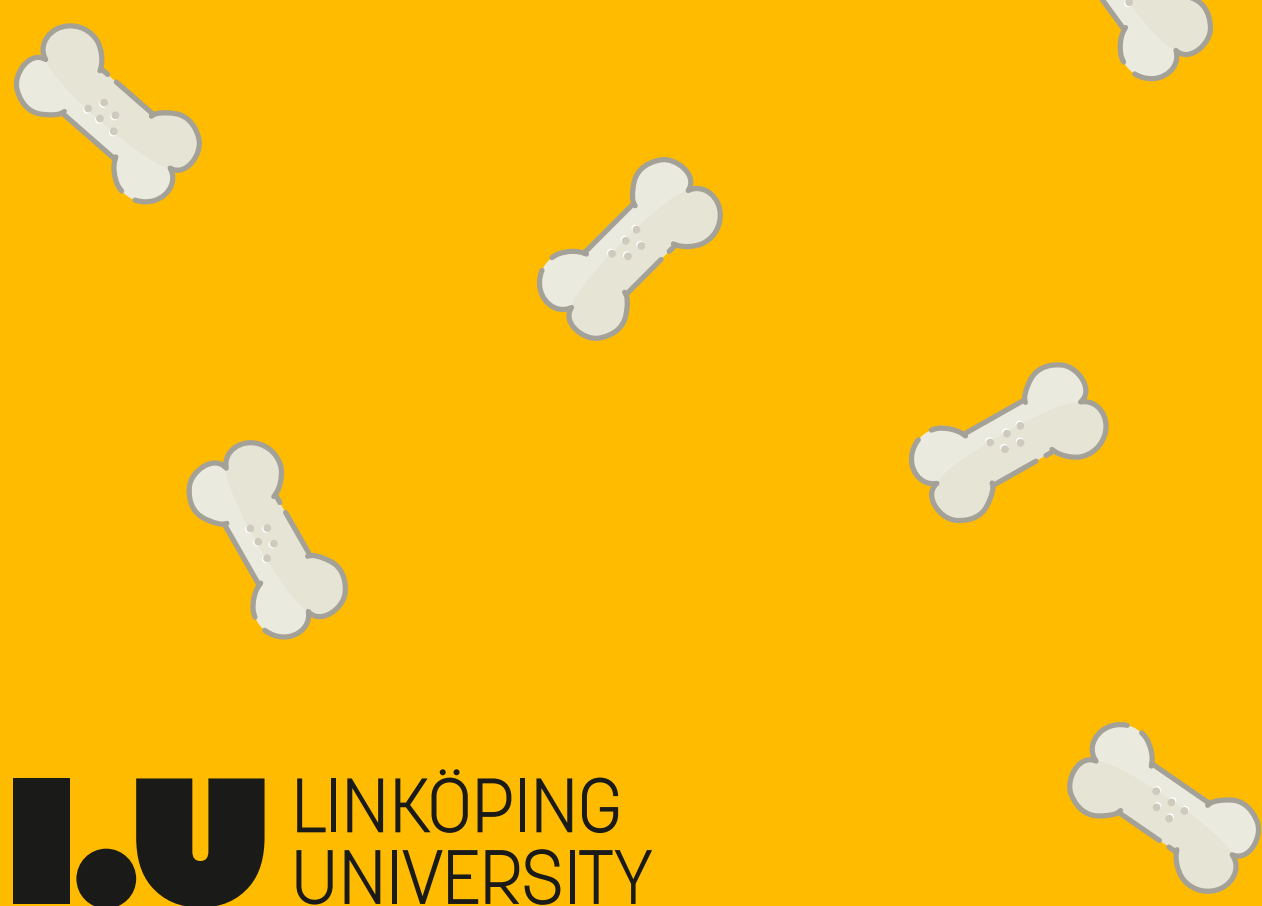


\title{
Health Technology Assessment of Assistance Dogs and Dog-Assisted Interventions
}

\author{
Martina Lundqvist
}

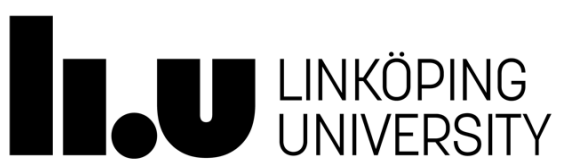

Department of Health, Medicine and Caring Sciences

Linköping University, Sweden

Linköping 2020 
(Martina Lundqvist, 2020

Cover Design: Adrian Berggren

Published articles have been reprinted with the permission of the copyright holders.

Printed in Sweden by LiU-Tryck, Linköping, Sweden, 2020

ISBN 978-91-7929-834-0

ISSN $0345^{-0082}$ 
To Hampus and Arvid. You mean the world to me! 



\section{CONTENTS}

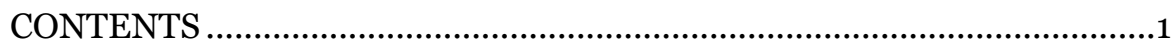

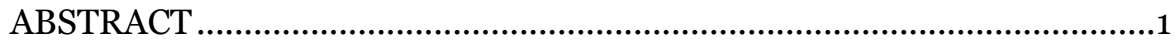

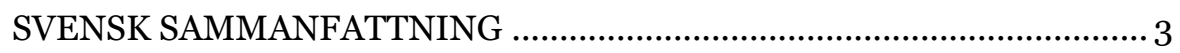

LIST OF PAPERS ....................................................................... 5

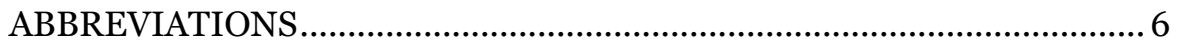

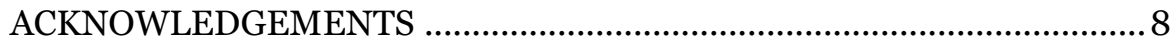

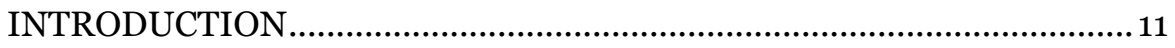

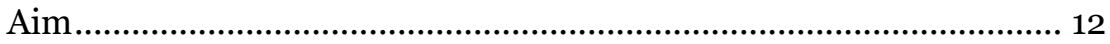

Research questions............................................................................... 12

Outline of thesis.....................................................................................13

BACKGROUND....................................................................................... 14

Health technology assessment............................................................... 14

Economic evaluation of healthcare......................................................... 14

Decision analytic modelling ................................................................ 16

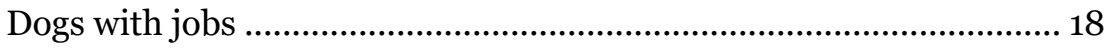

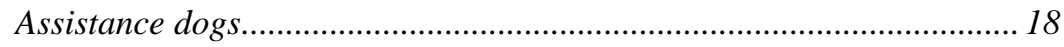

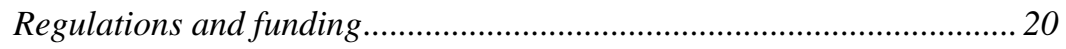

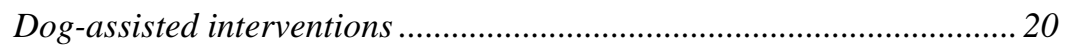

Risks associated with dogs when used in health and social care ............ 22

The Service and Hearing Dog Project.................................................... 23

METHODS .............................................................................................. 25

The design of the Service and Hearing Dog Project.............................. 25

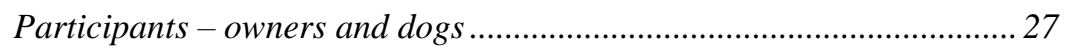

Paper I - To describe and explore what effects a service or hearing dog has on the owner .................................................................................. 32 Paper II - A thematic content analysis to explore service and hearing dog owners' experiences and gain a deeper understanding of the ownership 
Paper III - Long-term cost-effectiveness of physical service dogs and diabetes alert dogs

Sensitivity analyses

Paper IV - A systematic literature review to establish known effects and cost-effectiveness of dog-assisted interventions

Papers I and II - Effects and experiences of having a service or hearing dog

Describing and exploring potential consequences of having a service or hearing dog on HRQoL, well-being and activity level (paper I).....

Expectations and perceived experiences of having a certified service or hearing dog (paper II).

Paper III - Cost-effectiveness of having a physical service dog and a diabetes alert dog

Paper IV - Effects and cost-effectiveness of dog-assisted interventions

- a systematic review ............................................................................. 56

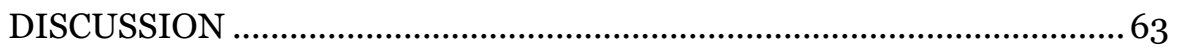

The value of using dogs as assistive aids and in healthcare..................63 63

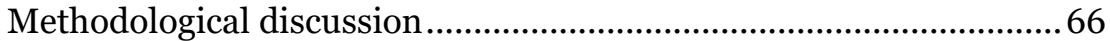

My reflections ..................................................................................

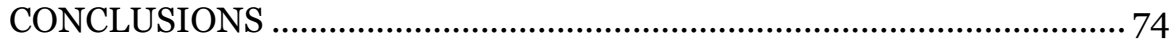

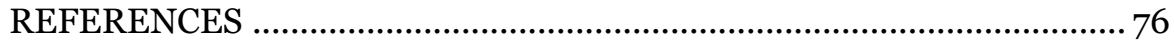

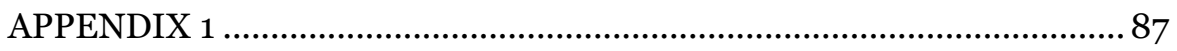

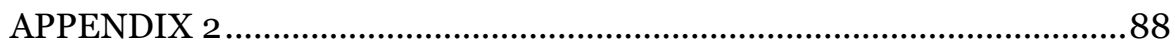

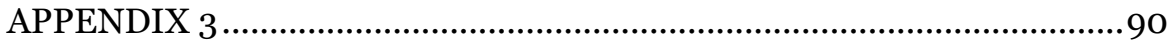




\section{ABSTRACT}

Dogs as an assistive aid for people with disabilities date as far back in time as the first century CE. Today, dogs are used in various settings to help and assist humans. 'Assistance dogs' is an umbrella term for guide dogs, hearing dogs and service dogs. They are custom trained to help and support their owners in their everyday life and thereby give them greater independence. Dogs who perform dog-assisted interventions are another type of working dog, where the dog and the owner work together as a team visiting people with various needs in different settings such as hospitals and nursing homes. These visits aim to strengthen people's inner motivation, using the dog as an external motivator. There is a lack of evaluations of working dogs in the health technology assessment context, and in the health economic evaluation context. Hence, there is a need for structured analyses that include both the short- and long-term effects and the costs of assistance dogs and dog-assisted interventions.

The overall aim of this thesis is to explore and assess the use of assistance dogs and dog-assisted interventions.

The research questions were investigated using a variety of methods. In paper I, inferential statistical analysis was used to analyse patient-reported outcomes measures. In paper II, a thematic content analysis was employed to explore the experiences of service and hearing dogs. To study the long-term cost-effectiveness of physical service dogs and diabetes alert dogs, a decision analytic model was used in paper III. The input data in studies I, II, and III was obtained from the Service and Hearing Dog Project. In paper III, the data was also supplemented with information from published literature and expert opinions. Paper IV investigated the effects and cost-effectiveness of dog-assisted interventions, and takes the form of a systematic review.

Paper I showed that a service or hearing dog have positive impact on its owner's health-related quality of life, well-being and activity level. Paper II showed that owners of service or hearing dogs experienced both positive physical and psychosocial effects from their dog. Negative experiences were also identified, for example being denied access to public places and negative attitudes from other people. Paper III showed that physical service dogs and diabetes alert dogs are cost-effective in comparison with regular companion dogs, resulting in both lower costs and a gain in QALYs. The one-way sensitivity analysis did not change the results, but the probabilistic sensitivity analysis showed that the results were uncertain. Synthesizing 
the results from the review in paper IV showed that dog-assisted interventions for therapeutic purposes led to minor to moderate effects in psychiatric conditions. Dog-assisted interventions as an activity had minor to moderate effects on cognitive disorders, and dog-assisted interventions for support purposes were beneficial in different types of medical interventions. Studies of cost-effectiveness were lacking. To conclude, assistance dogs are valuable and may be cost-effective for use as assistive aids and dog-assisted interventions render minor to moderate effects in certain situations in healthcare settings. 


\section{SVENSK SAMMANFATTNING}

Användning av hundar som hjälpmedel för personer med funktionsnedsättning går att spåra ändå tillbaka till första århundradet e.Kr. Idag används hundar i människans tjänst i en mängd olika sammanhang. Assistanshundar är ett samlingsbegrepp för ledarhundar, signalhundar och servicehundar. De är specialutbildade för att hjälpa och stödja sina ägare i deras vardag och på så vis ge dem möjlighet till att leva ett mer självständigt liv. Hundar som utför hundassisterade interventioner är en annan typ av tjänstehund, men deras jobb är inte att hjälpa sin ägare. Istället arbetar hundar som utför hundassisterade interventioner och deras ägare som ett team. Tillsammans besöker de personer med olika behov i olika miljöer som exempelvis sjukhus eller äldreboende. De arbetar med att stärka motivationen hos personerna de träffar. Idag saknas det övergripande utvärderingar som tittar på olika aspekter av den här typen av hundar. Det saknas även utvärderingar som specifikt studerar effekter och kostnader av assistanshundar och hundassisterade interventioner. Det finns därför ett behov av strukturerade analyser som inkluderar både kort- och långsiktiga effekter samt kostnader för denna typ av hundar och interventioner.

Det övergripande syftet med denna doktorsavhandling är att utforska och utvärdera användningen av assistanshundar och hundassisterade interventioner.

Frågeställningarna studeras med ett brett urval av metoder. I studie I analyseras patientrapporterade utfallsmått med statistiska metoder. I studie II genomförs en tematisk innehållsanalys för att undersöka förarnas upplevelser av service- och signalhundar. För att analysera den långsiktiga kostnadseffektiviteten av fysiska servicehundar och alarmerande diabeteshundar i studie III konstrueras en beslutsmodell. Datamaterialet i studie I, II och III hämtas från service- och signalhundsprojektet. I studie III kompletteras data med information från publicerad litteratur och med expertutlåtande. I studie IV studeras effekterna och kostnadseffektiviteten av hundassisterade interventioner genom en systematisk litteraturöversikt.

Studie I visade att en service- eller signalhund kan ha en positiv inverkan på deras ägares hälsorelaterade livskvalitet, välbefinnande och aktivitetsnivå. Resultaten från de tematiska analyserna i studie II påvisade att ägare av en service- eller signalhund upplevde både positiva fysiska och psykosociala effekter av sin hund. Negativa erfarenheter av hunden identifierades också, till exempel att hunden begränsade möjligheten att vistas i offentliga miljöer och andra personers negativa attityder. Studie III visade 
att fysiska servicehundar och alarmerande diabeteshundar är kostnadseffektiva i jämförelse med vanliga sällskapshundar, de var både kostnadsbesparande och innebar en QALY-vinst. Känslighetsanalyser av specifika parametrar påverkade inte resultaten, men den probabilistiska känslighetsanalysen visade att resultaten var osäkra. Resultaten från den systematiska litteraturöversikten i artikel IV visade att hundassisterad interventioner som ges i terapeutiskt syfte hade små till måttliga effekter vid psykiatriska tillstånd. Hundassisterade aktiviteter hade små till måttliga effekter vid kognitiva störningar och hundassisterade interventioner som gavs som stöd vid olika typer av medicinska insatser var fördelaktiga. Studier gällande kostnadseffektivitet av hundassisterade interventioner saknades. Sammanfattningsvis, assistanshundar som hjälpmedel ger positiva effekter i flera dimensioner för sina ägare och är sannolikt kostnadseffektiva. Hundassisterade interventioner uppvisar små till måttliga effekter i vissa situationer i hälso- och sjukvården. 


\section{LIST OF PAPERS}

I. Martina Lundqvist, Lars-Åke Levin, Kerstin Roback, Jenny Alwin. The impact of service and hearing dogs on health related quality of life and activity level: A Swedish longitudinal intervention study. BMC Health Services Research. 2018, 18(1).

II. Martina Lundqvist, Lars-Åke Levin, Jenny Alwin, Ann-Charlotte Nedlund. To live with a wagging tailed assistant - service and hearing dog ownership from the perspective of Swedish owners. Health \& Social Care in the Community, 2020.

III. Lundqvist M, Alwin J, Levin LA. Certified service dogs - A cost-effectiveness analysis appraisal. PLoS One. 2019;14(9):e0219911.

IV. Martina Lundqvist, Per Carlsson, Rune Sjödahl, Elvar Theodorsson, Lars-Åke Levin. Patient benefit of dog-assisted interventions in health care: a systematic review. BMC Complementary and Alternative Medicine, 2017, 17(1). 


\section{ABBREVIATIONS}

AAA Animal-assisted activity

AAI Animal-assisted intervention

AAT Animal-assisted therapy

CE Common Era

CEA Cost-effectiveness analysis

CEAC Cost-effectiveness acceptability curves

DAA Dog-assisted activity

DAI Dog-assisted intervention

DAS Dog-assisted support

DAT Dog-assisted therapy

EQ-5D EuroQoL-5 Dimension Questionnaire

EQ-VAS EuroQoL-Visual Analogue Scale

ICER Incremental cost-effectiveness ratio

HRQoL Health-related quality of life

HTA Health technology assessment

MFD The Swedish Agency for Participation

NICE The National Institute for Health and Care Excellence

NT The New Therapies Council

PRISMA Preferred Reporting Items for Systematic Review and MetaAnalysis

PRO Patient-reported outcome

PROM Patient-reported outcome measure

PSA Probabilistic sensitivity analysis

QALY Quality-adjusted life year

QoL Quality of life 
SAF The Swedish Association of Service Dogs

SBK The Swedish Working Dog Association

SBU The Swedish Agency for Health Technology Assessment and Assessment of Social Services

SD Standard deviation

SEK Swedish currency [Swedish crowns]

SF-36 Medical Outcomes Study (MOS) 36-Item Short-Form Health

Survey

SF-6D Short-Form Six-Dimension

SKK The Swedish Kennel Club

SVTH Skandinaviska Vård- och Terapihundsföreningen

TLV The Dental and Pharmaceutical Benefits Agency

UK United Kingdom

USA United States of America

USD US currency [US dollars]

WHO-5 The World Health Organization Five Well-Being Index

WTP Willingness to pay 


\section{ACKNOWLEDGEMENTS}

During these five years, many people have contributed in different ways in making this thesis possible. I would like to express my sincere gratitude to each one of you, and particularly to the following people:

Lars-Åke Levin, my supervisor, for generously sharing your great knowledge and experiences. For all the time you put into reading my work and guiding me forward. Your encouragement and praise have made me grow, both professionally and personally.

Jenny Alwin, my co-supervisor, for being genuinely supportive and for teaching me the importance of being accurate and transparent. Your door has always been open, and you have always shown great confidence in me. Thank you!

Kerstin Roback, my co-supervisor during the two first years, for your valuable support, and for your constructive and timely feedback. And perhaps most importantly, for sharing my interest in horses.

Ann-Charlotte Nedlund, my co-author of paper II, for sharing your wisdom about qualitative methods and for being supportive during the end stage of this thesis.

Per Carlsson, Elvar Theodorsson and Rune Sjödahl, my co-authors of paper IV, for your excellent collaboration and for generously showing an interest in my work and sharing your knowledge with me.

Magnus Husberg, my colleague, for helping me out with statistics and Excel troubles, even when you were no longer allowed to. For taking dog research to a whole new level, looking at 'Oh my good how cute' websites. And perhaps most importantly, for being impressed by my "bromsbacksfingrar".

Lars Valter, statistician at Region Östergötland and Linköping University, for kindly helping me with the statistical analyses and patiently answering all my constant questions about statistics.

Lars Bernfort, Mari Broqvist, Thomas Davidson, Ann-Charlotte Nedlund, Barbro Krevers and my PhD colleagues, for reading the final draft of this thesis and giving me constructive feedback. It really helped me move forwards.

Lena Hector, my colleague, for all your help with practical matters throughout these years. Your help has been invaluable. 
Thérèse Eriksson, my new life-long friend and $\mathrm{PhD}$ colleague, I am so lucky I found you. Together we have undertaken this journey throughout the ups and downs. Thank you for all the encouraging conversations and all the fun we have!

Mattias Aronsson, my former roommate and $\mathrm{PhD}$ colleague, for being the best roomie and friend one could ever imagine during my first years as a PhD student. For all the time you spent helping me out, teaching me everything I know about Markov models.

Jonathan Siverskog, my roommate and $\mathrm{PhD}$ colleague, for being an excellent roommate, for introducing 'Inte bara glögg' into my life and for sending me a wonderful Christmas card. Your hard work during these years has inspired me!

Lars Bernfort, my colleague and friend, for understanding the importance of taking timely 'fikapauser' and for all the great talks during these years.

All my colleagues at the Division of Health Care Analysis, current and former, for making my time as a PhD student so much more fun! For contributing to a stimulating scientific environment and for all the funny, weird and inspiring conversations during our breaks. These conversations have taught me about things I did not know I had to know.

Anne and Martin Lundqvist, my parents, for always believing in me and encouraging me to do my best. I am eternally thankful to you for always showing your devoted interest and great concern, no matter what. You are outstanding!

Thomas Lundqvist and Johanna Stenholm, my brother and sister, for always being by my side. Thomas, for being a genuinely kind person always helping me and everyone around you. Johanna, thank you for your way of being such a kind and strong woman, it inspires me.

My nephews, Alexander, Anton and Oscar Stenholm, for bringing me so much joy and love during these years. It has been amazing following you from birth till today. You have become the most wonderful young men one could ever imagine.

To all my girlfriends, for being you and for you always being there. For all the great girls' nights, talking about everything and nothing. For having coined the phrase 'Alla har sin skit'. You are hilarious!

Elin Wiklund, my best friend since forever, for always being a great listener and for always giving me good advice. Your way of being a person and a friend inspires me. And thank you for sharing my interest in horses. You are one of a kind!

Hampus and Arvid Tengelin, my lovely little family, you two are the best thing that ever happened to me. Hampus, thank you for being my best 
friend, for giving me daily comfort and for making me happy. Arvid, you changed our lives for the better. Your curiosity and your wonder at life make us smile every day. My love for you both is unconditional and eternal. 


\section{INTRODUCTION}

Dogs have been seen as man's best friend since the dawn of history. The domestication of dogs has been dated to between 13,000 and 17,000 years ago, and today they are a member of our herd and a beloved part of our lives [1]. Beyond playing an important role as four-legged family members, the value of dogs as livestock is high. Herding dogs, search and rescue dogs, sled dogs, detection dogs and assistance dogs are just a selection of different dog professions. Throughout history, numerous working dogs have become famous by showing great devotion, endurance or heroism. Balto the sled dog is a great example of a heroic dog. He led the final leg of the transportation of a diphtheria anti-toxin drug to a small Alaskan town in 1925 [2]. The town was isolated due to brutal winter conditions. In just six days, Balto - together with 150 other dogs - made the lifesaving delivery of the anti-toxin over ice and snow in temperatures below $-40^{\circ} \mathrm{C}$, travelling more than 1,00o kilometres in total [2]. Today, a statue of Balto can be seen in Central Park, New York City.

When exactly in history dogs became an assistive aid to people with disabilities is not known [3]. The earliest evidence is a fresco discovered in the ruins of the Roman city Herculaneum, that dates back to the first century $\mathrm{CE}[3,4]$ and depicts a blind man being led by a dog. However, the first known systematic attempt to train dogs to assist blind people, i.e. guide dogs, was conducted in a hospital in Paris in the 1780s [4]. It took until the 1930 s before the training of guide dogs started in Sweden [5]. Guide dogs are included in the term 'assistance dog'. This is an umbrella term that also includes hearing and service dogs [6]. Assistance dogs are custom trained to help and support their owners in their everyday life and thereby give them greater independence. The use of an assistance dog other than a guide dog first appeared in the USA in the 1960s [7], and in Sweden in the 1980s [8]. In Sweden today, approximately 90 trained assistance dogs other than guide dogs work as a supportive aid for their owner [9].

Dogs who perform dog-assisted interventions are another type of working dog, but their job is not to assist their owner. Instead, these dogs and their owner work as a team [10], visiting people with various needs in different settings like hospitals, nursing homes and schools. Their main task is to engage and interact with the people they meet, and thereby provide them with affection and comfort. The use of dogs to perform dog-assisted interventions can also be traced far back in time [11]. In Sweden, the first known dog-assisted intervention was conducted at a nursing home in the 1970s [12]. According to Skandinaviska Vård- och Terapihundsföreningen 
(SVTH), there are approximately 30 dogs conducting dog-assisted interventions in health and social care in Sweden [13]. However, this number is uncertain and probably an underestimation.

There is a lack of evaluations and evidence in relation to the effects of working dogs. Evaluations can be performed in different ways using different perspectives. One broad term is 'health technology assessment' (HTA), which is a systematic assessment of different aspects such as medical, social, ethical and - importantly - economic efficacy in terms of health economic evaluations. Health economic evaluations are a useful tool for helping healthcare decision-makers to make informed decision about which treatments should be funded [14]. In health economic analyses, the costs and health effects of different interventions are systematically weighed up against each other, making it possible to compare relevant interventions that may be funded in the health and social care sector. This is of great importance, since resources are scarce and optimal resource allocation is essential. As more treatment alternatives become available and needs are seemingly endless, priorities must be made. Further, applying economic evaluation methods makes it possible to examine the long-term effects (or consequences) of interventions through economic decision analytic modelling. Assistance dogs and dog-assisted interventions have been the target of previous studies [15-20]. There are, however, still large knowledge gaps that need to be filled. Using a broad evaluation strategy such as HTA is therefore an excellent tool for this task.

\section{Aim}

The overall aim of the thesis is to explore and assess the use of assistance dogs and dog-assisted interventions.

\section{Research questions}

- What effects does a service and hearing dog have on the owner's health-related quality of life, well-being and activity level? (Paper I)

- What are the dog owner's expectations and experiences of being assisted by a service or hearing dog? (Paper II)

- Are physical service dogs and diabetes alert dogs cost-effective in comparison to regular companion dogs? (Paper III)

- What are the health effects and cost-effectiveness of dog-assisted interventions for different categories of patients? (Paper IV) 


\section{Outline of thesis}

The outline of the thesis is as follows. In the background section, the reader will be introduced to the topics of this thesis that are necessary in order to understand and interpret the other sections, such as economic evaluations, assistance dogs and dog-assisted interventions. In addition, the reader will be familiarized with the Service and Hearing Dog Project.

The methods section will present the different methods used in the studies. The overall results based on the studies will be presented in the results section. Finally, I will discuss whether or not dogs can contribute as assistive aids and in health care, the study's strengths and limitations, and my own reflections. Last but not least, the conclusions of this thesis will be reported. 


\section{BACKGROUND}

In the background section, information about health technology assessment, health economic evaluations and the different working dogs evaluated in this thesis will be provided. In addition, the Service and Hearing Dog Project will be presented, data gathered in the project is used in three of the papers included in this thesis.

\section{Health technology assessment}

Health technology assessment (HTA) refers to a systematic way of evaluating properties, effects and/or impacts of a health technology [21]. There are several definitions of HTA in the literature, but a common feature of all definitions is that HTA aims to inform and support decision-making at different levels of the healthcare system in a systematic and transparent way $[21,22]$. The HTA process intends to summarize best available scientific evidence about the medical, social, economic and ethical issues related to a health technology [22].

\section{Economic evaluation of healthcare}

To make informed decisions regarding the choice between treatment alternatives, decision-makers need information about both the costs and the effects of the alternatives. Costs are important since resources are scarce and all investments have an alternative use. A new, costly health technology could end up doing more harm than good if it crowds out more value than it adds. Health economic evaluations are used to assess new and existing health technologies to ensure that the use of available resources is efficient [14]. Therefore, results from health economic evaluations are important input for priority setting.

Within health economics, the cost-effectiveness analysis (CEA) is the most common method used to analyse the relative costs and outcomes of different courses of action. In a CEA, the most preferred outcome measure - quality-adjusted life years (QALYs) - is often used when measuring the effect of an intervention. QALY combines the number of life years in a health state with the expected quality of life in that given state. Using a generic outcome allows for comparison between treatments under different conditions. In a CEA, as in other analyses, costs are measured in monetary terms [14]. A health economic analysis can be performed from different 
perspectives [23]. If applying a societal perspective, the analysis should include costs and effects outside the healthcare system. A narrower perspective is the healthcare sector perspective. In such an analysis, costs that do not come under the healthcare budget and effects that do not translate into QALY gains should be ignored.

The most common way to present the result of a health economic analysis is the incremental cost-effectiveness ratio (ICER). The ICER shows the differences between the cost of the investigated treatment and the alternative treatment, divided by the difference in the effects:

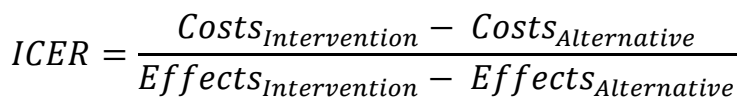

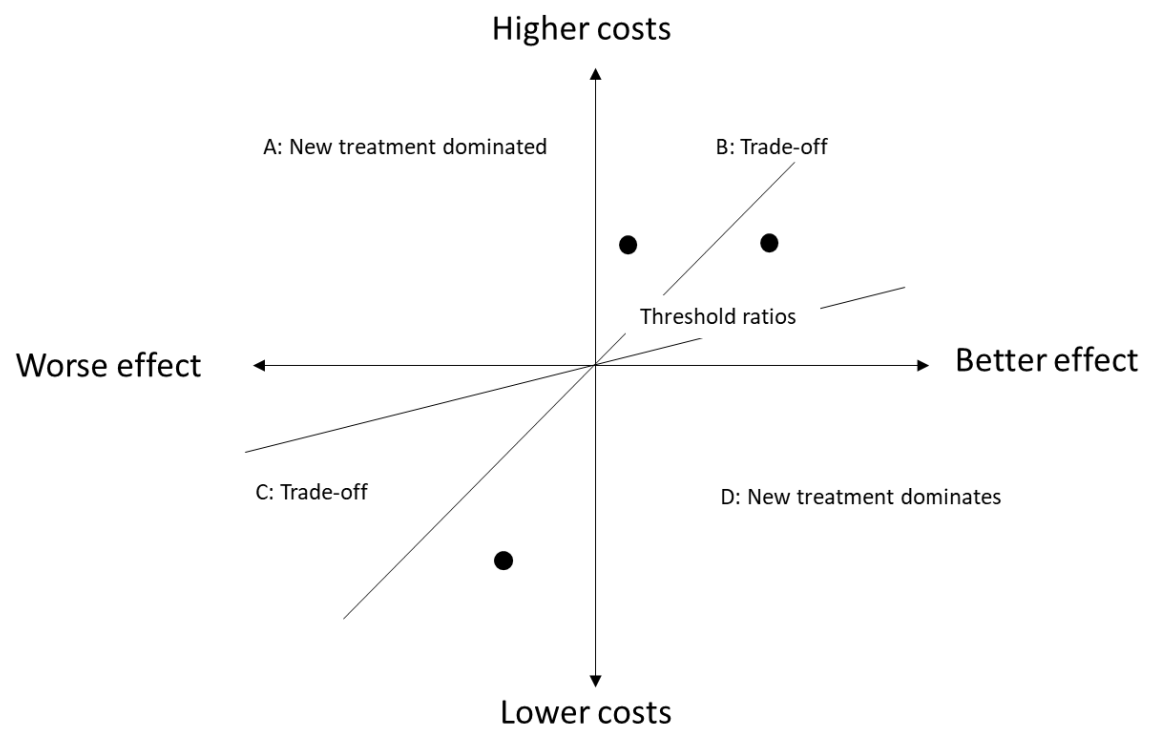

Figure 1. Cost-effectiveness plane

The ICER can be plotted in the cost-effectiveness plane (Figure 1). The cost-effectiveness plane consists of four quadrants (A-D) and is a tool to describe whether or not a treatment is cost-effective. If the new treatment implies higher costs and worse effects than the alternative treatment, the new treatment should never be implemented (quadrant A). If the new treatment instead implies lower cost and better effect than the alternative treatment, the new treatment should always be implemented (quadrant D). However, if the new treatment implies higher cost but also better effects than the alternative (quadrant B) or if the new treatment implies lower cost 
but worse effect than the alternative treatment (quadrant $\mathrm{C}$ ), the answer regarding which treatment to use is not straightforward. The choice of treatment will depend on what cost-effectiveness ratio is judged acceptable. This cut-off value is usually referred to as the threshold value. The threshold value represents how much gaining a QALY is worth and is illustrated with different lines in the cost-effectiveness plane in Figure 1. ICERs (presented as dots in the figure) located above the threshold should not be implemented, while ICERs located below the threshold should be implemented.

What we are willing to pay for a QALY varies between countries and healthcare systems. In Sweden, a number of attempts using different methods have been made to establish Swedish threshold values. Olofsson et al. estimated the value of a QALY based on people's willingness to pay (WTP). They determined that the threshold value for a QALY was close to

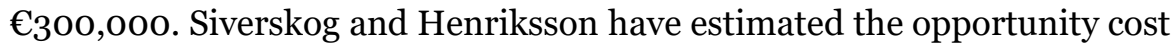
of re-allocating healthcare recourses. The authors suggested a cost per QALY of $€ 19,000$ [24]. In practice, empirical estimates have not been directly used in Swedish decision-making. Instead, $€_{50,000}$ is often used as a rule of thumb [25], but cost-effectiveness is not the only criterion that decisions are based on. In Sweden, the cost-effectiveness threshold is not viewed as a hard decision rule about which treatments to fund. It may be appropriate to fund cost-ineffective treatments due to equity considerations. Similarly, funding may be denied for highly cost-effective treatments for mild conditions. The ICER threshold in decision-making at the Dental and Pharmaceutical Benefits Agency (TLV) and the New Therapies Council (NT) involves balancing the cost-effectiveness criteria against other criteria and considerations such as severity of disease, rarity, magnitude of effect and uncertainty of the ICER estimation. The variation in the threshold has been confirmed in a study by Svensson et al. [25]. They looked at reimbursement decisions from TLV to study how cost-effectiveness combined with severity of disease had affected pharmaceutical reimbursement decisions. They showed that the implied value of a QALY, based on reimbursement decisions, was between $€ 80,000$ and $€ 135,000$ [25].

\section{Decision analytic modelling}

Decision analytic modelling aims to inform a decision problem based on the best available information. A decision model can be used to extrapolate costs and effects from short term to long term. Extrapolation of data may be necessary when evaluating an intervention where the trial data does not capture the costs and effects that the intervention causes in the long run. Basing an evaluation solely on data from a clinical trial often leads to erroneous conclusions because clinical trials often provide data in condi- 
tions that differ from real life. Further, another advantage of decision analytic modelling is the possibility to synthesize evidence from different sources since the trial may also lack data on costs and effects or may not be relevant to Swedish conditions. All these shortcomings can be addressed and mitigated by using decision analytic modelling techniques. Conducting a sensitivity analysis, i.e. testing the robustness of the results and having the opportunity to compare all relevant options if multiple options are available, is an additional advantage of decision models [26]. Hence, health economic decision modelling is an irreplaceable tool $[14,26]$. Two commonly used decision models are the decision tree model and the Markov model [26]. These can also be combined.

A decision tree is a simple form of decision model. It starts with a single node representing the choice between alternative options, e.g. treatment $\mathrm{A}$ and treatment B. Further possible events in the decision tree model are shown as branches emanating from chance nodes that represent outcomes outside the decision-maker's full control [26].

A Markov model is a stochastic model simulating a cohort of individuals or other objects over a finite set of outcomes, usually called states. Transitions between the states of health represent health changes and occur with fixed time intervals, called cycles. Based on an initial decision problem, an individual can remain in the same health state or move to another health state. The transition will be based on a set of probabilities. Future transitions in the model occur independently of previous events. Transitions will be repeated until the appropriate time horizon has been reached or when the individuals reach an absorbing state (death). When reached, it is possible to calculate long-term costs and QALYs by summing up the data for the simulated individuals in the model. Figure 2 illustrates a simple three-state Markov model where the ovals represent states and the arrows represent transition probabilities.

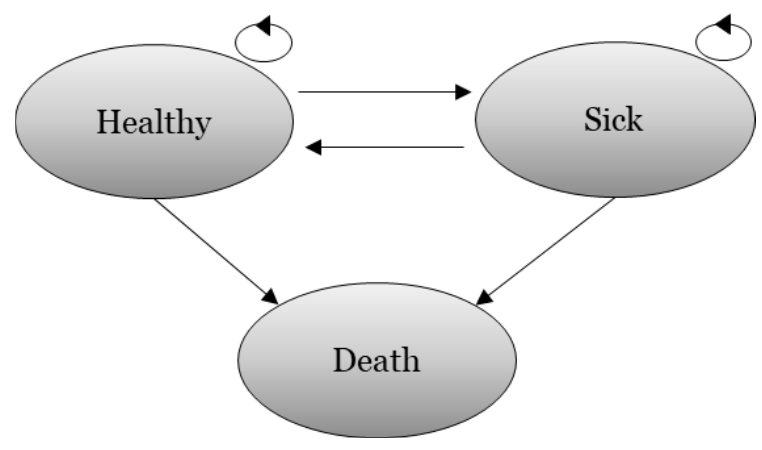

Figure 2. Structure of a simple Markov model. 
As mentioned, long-term extrapolation of health outcomes and costs should be considered a strength. However, it should be noted that models are simplifications of reality, and when evaluating an intervention beyond the duration of a trial this also involves an increased degree of uncertainty. There are two main kinds of uncertainty we must deal with: parameter uncertainty and model uncertainty. Parameter uncertainty is the statistical uncertainty in the input parameters represented in terms of, for example, the standard error of the mean [14]. To address uncertainty associated with the synthesis of many input parameters, simulation techniques such as a probabilistic sensitivity analysis (PSA) can be used [27]. In the PSA, the uncertainty from the individual parameters is propagated through the model using simulation techniques. In this way, the uncertainty in the costeffectiveness results indicates the uncertainty to implement a treatment strategy, rather than the uncertainty surrounding the individual parameters [28]. The results from the analysis can be plotted in a cost-effective plane illustrating the overall uncertainty and as cost-effectiveness acceptability curves (CEACs), presenting the probability that the intervention will be cost effective at different threshold values. Model uncertainty relates to assumptions caused by simplifications in the model. To deal with model uncertainty, the model can be re-run with an alternative assumption in deterministic sensitivity analyses. In this way, it is possible to see the effects of the alternative assumption compared to the base case assumption [14, 26].

\section{Dogs with jobs}

In this thesis, the focus is on studies of assistance dogs and dog-assisted interventions. There is an important distinction between these categories of dogs. Assistance dogs are specially trained to assist their owner due to a functional and/or health impairment. Dogs performing dog-assisted interventions work as an external motivation for different patients within a healthcare setting. Information about assistance dogs and dog-assisted interventions is presented in detail in the following section.

\section{Assistance dogs}

An assistance dog is trained to assist or aid its owner due to a functional and/or health impairment. The training of the dog is tailored to suit the needs of the owner, with the aim of helping in everyday life and thereby also achieving a more independent lifestyle. The term 'assistance dog' includes three types of dogs: guide dogs, hearing dogs and service dogs [6], see Figure 3. 


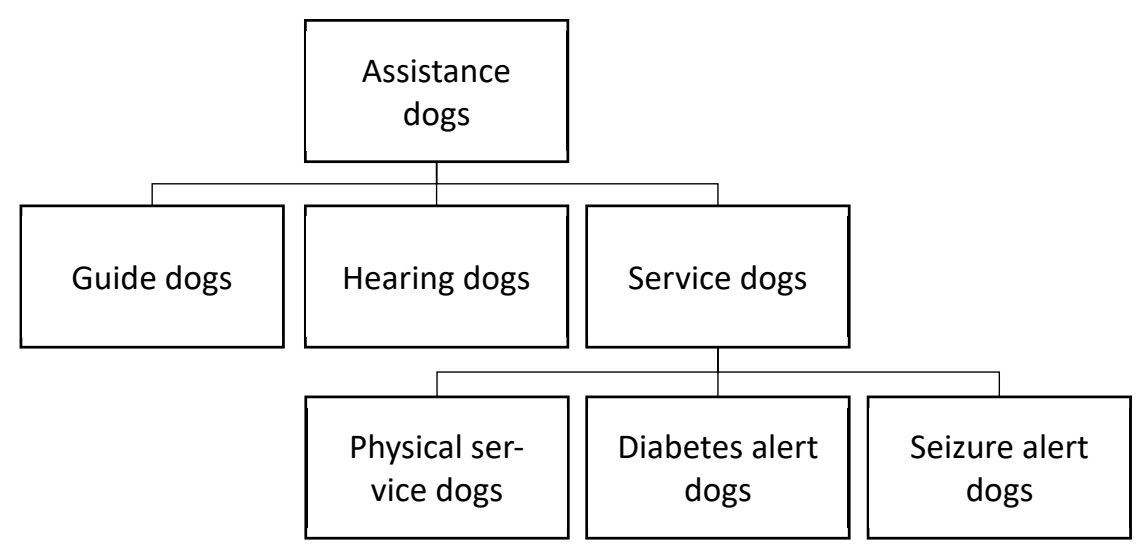

Figure 3. Illustration of the assistance dogs concept.

Guide dogs assist people who are blind or visually impaired. They navigate their owner to get around obstacles safely and confidently. The dogs obey commands from the owner but will disobey if the command is considered unsafe [29]. Hearing dogs assist people who are deaf or hard of hearing. Their primary task is to alert their owner to a variety of sounds, such as doorbells, smoke alarms, alarm clocks or a ringing telephone. Service dogs assist people with disabilities other than vision or hearing impairment [30]. The service dog concept can be divided into sub-categories such as physical service dogs, diabetes alert dogs and seizure alert dogs, see Figure 3. Physical service dogs are trained to assist people with physical and mobility impairments. They can help with a variety of tasks, for example picking up and retrieving objects, opening and closing doors, moving wheelchairs, and helping with balance and stability [30]. In addition, they can attract other people's attention in the event of an emergency or if the owner needs help. Diabetes alert dogs warn their owner of high and low blood sugar levels, while seizure alert dogs are trained to warn their owner of imminent epileptic seizures [30]. In this thesis, hearing dogs and service dogs (with all three subcategories) will be studied.

In Sweden, it is possible to obtain a trained service or hearing dog in three different ways. The owner of the dog can conduct the training in collaboration with a certified instructor. Between the instructor-led training sessions, the owner has to train the dog independently. It is also possible to purchase a dog that has already been trained by a certified instructor. In this case, a match between the dog and the intended owner is made based on a number of criteria. When the basic training is complete and the dog is ready to meet its new owner, the instructor trains the dog and the intended owner together for some time [31]. Lastly, the owner can train the dog independently. Regardless of how and by whom the dog is trained, the owner 
and the dog must undergo an examination together. On passing the examination, a vest ${ }^{1}$ is awarded as evidence of assistance dog certification [32]. To keep the vest and the certification, the dog and owner must pass an annual maintenance test. This is carried out to ensure that the dog and the owner maintain the necessary standards. The Swedish Working Dog Association is responsible for monitoring and assessing the quality of service and hearing dogs and their training [33]. Today, approximately 90 trained service and hearing dogs work as supportive aids for their owners. Of these, approximately 60 dogs have been owner trained and 30 have been trained by a certified instructor [34].

\section{Regulations and funding}

Sweden has three levels of government: national, regional and local. There are 21 regions, and there are 290 municipalities at local level. Both regions and municipalities have the right to tax citizens and have their own self-governing local authorities which are responsible for different activities in the community [35]. There are currently no national Swedish regulations regarding how to finance a service or hearing dog as a supporting aid. Further, there are no regulations or guidelines regarding service and hearing dog funding in the Swedish regions or municipalities [36]. If someone wants to train a service or hearing dog, it is in principal up to the individual owner to find a way to pay for the training, either through grants or with their own money. However, it is possible to receive financial support from the authorities. Swedish regions and municipalities are responsible for providing people with functional or health impairments individually adapted care and rehabilitation, and for a person with special needs this could mean a service or hearing dog [37].

The only current regulatory body regarding service and hearing dogs in Sweden is the Swedish Agency for Participation, which is responsible for financing and overseeing a support function that assesses the quality of service and hearing dogs and their training [33]. As mentioned above, this function is currently maintained by the Swedish Working Dog Association.

\section{Dog-assisted interventions}

'Dog-assisted intervention' (DAI) is an umbrella term for different interventions that are beneficial for humans, where a dog is the assisting animal. Unlike assistance dog, dogs working with dog-assisted interventions do not assist their owner. Instead, the dog and the owner or handler work as a team, visiting people in different settings with various needs with the

\footnotetext{
${ }^{1}$ Different terms are used in British and American English. Vest/jacket is used in British English and cape is used in American English.
} 
aim of strengthening their inner motivation by acting as an external motivator. Dog-assisted therapy (DAT), dog-assisted activity (DAA) and dogassisted support (DAS) are examples of different dog-assisted interventions that can be performed in healthcare settings [38]. Figure 4 illustrates the different interventions. As the figure shows, there are both distinctions and similarities between the interventions.

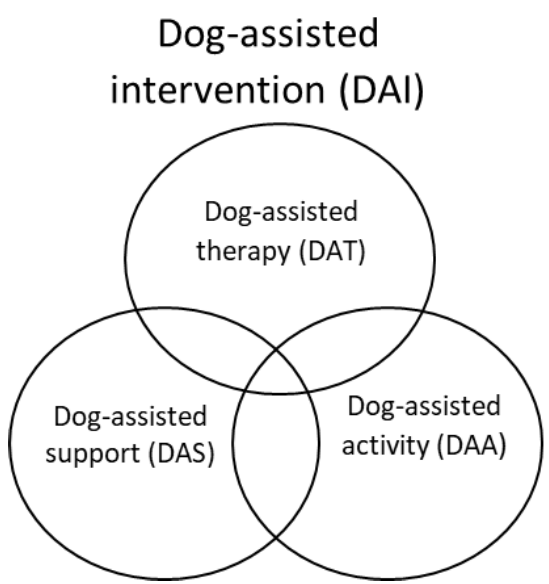

Figure 4. Dog-assisted interventions (DAI) in a healthcare setting comprise dogassisted therapy (DAT), dog-assisted activity (DAA) and dog-assisted support (DAS).

DAT is a goal-oriented and structured intervention that comprises multiple sessions focusing on improving the patient's health. Working with DAT requires the handler to be a health or human service professional with expertise within the scope of practice. DAT can be given to groups or individuals. Regardless, specific goals for the intervention should be set for each individual, and these goals should be included in professional documentation and evaluated over time. The dog can be used in various ways during DAT. The patient might, for example, have physical contact with the dog, grooming the dog, walking the dog, playing with the dog and training the dog, including practising obedience commands and basic agility skills $[39,40]$. DAAs have both similarities and differences compared with DAT. Unlike DAT, the DAA handler does not need training within health and human services. The activities have no therapeutic goal, instead focusing on improve the patient's well-being [38]. However, like DAT, the activities consist of multiple sessions. Examples of typical DAAs include feeding the dog, grooming the dog, petting the dog, throwing a ball to the dog and other activities that involve exercising minor motor skills [41, 42]. Another subcategory within the field of DAI is dog-assisted support (DAS). DAS is mainly conducted as single sessions to distract or reduce stress and anxiety 
during short-term diagnostic or therapeutic contexts [43]. The main tasks for a dog providing DAS are being present and accessible. There is no focus on activities.

In Sweden, the training of a dog with the aim of performing dog-assisted interventions can be carried out through different specialist organizations [13]. Professionals within health and human services can train a dog for therapeutic purpose [44]. Training a dog to conduct DAA or DAS can be done by anyone, as this does not require training within health and human services [45]. The training is normally paid for by the handler himself or herself.

\section{Risks associated with dogs when used in health and social care}

There are risks that need to be mentioned when dogs are used in a health and social care setting. Sweden's National Board of Health and Welfare has published a report discussing aspects that need to be considered when using dog-assisted interventions [46]. These aspects are also relevant to assistance dogs to some extent. The aspects are:

- Allergy

- The spread of infection and disease

- Physical injuries (for example dog bites)

- People's fear of dogs (cynophobia)

Allergy is a common chronic disease. In Sweden, 18 percent of the adult population and 7 percent of children and adolescents have a pet allergy [47]. All dogs produce allergens, which can be found in the dog's hair, dander, saliva and urine [48]. A common misconception is that a so-called hypoallergenic dog causes fewer allergies than other dogs, based on the argument that these dogs shed less hair and dander and therefore cause fewer symptoms for those who are allergic to dogs. However, no studies have verified this [49]. The allergen levels increase if the dog lives indoors, and are higher in rooms where the dog is allowed [50]. When performing dog-assisted interventions, it is therefore of great importance to try to reduce the levels of allergens. This can be achieved using air filters, carpet free spaces, regular cleaning, etc. It is also possible to restrict which rooms the dog has access to and thus reduce the allergen levels [46].

Allergies can also be a problem when bringing an assistance dog into public places or on public transportation. To reduce conflicts between assistance dog owners and people with allergies, an agreement between the Asthma and Allergy Association and the Swedish Association of the Visu- 
ally Impaired has been reached [51]. This takes the form of a policy document that says that both parties have the right to participate in the community and that society has a responsibility for everyone's participation. If there is a situation that needs to be resolved, the assistance dog owner and the allergic person shall try to solve the problem on their own as far as possible. If this is not possible, and if the problem has occurred for example on public transportation, it is the transport provider's responsibility to find a solution that works for both parties [51].

Another risk regarding dog-assisted interventions is the risk of spreading infections and diseases. To reduce the spread of infections, Sweden's National Board of Health and Welfare suggests preventive work such as cleaning, proper hand hygiene and, if necessary, personal protective equipment. If there is a suspicion that either the dog or the handler has an infection or a disease, all planned visits should be cancelled [46].

It has also been argued that there may be a risk of physical injuries when conducting dog-assisted interventions. To reduce the risk of physical injuries, appropriate preventive actions should be taken. For instance, the caregiver has a responsibility to ensure that fall injuries caused by the dog or its equipment can be avoided as far as possible. The same applies to physical injuries caused by dog bites. For those who have a fear of dogs, dog-assisted interventions may also cause unnecessary concern. This can be avoided by planning and announcing the dog visit so that individuals who are afraid of dogs do not have to interact with them [46].

\section{The Service and Hearing Dog Project}

The objective of the Service and Hearing Dog Project was to give people with different disabilities the opportunity to obtain a certified service or hearing dog. The project was initiated by the Swedish Government in 2008. It aimed to increase the number of service and hearing dogs in Sweden, and at the same time to study whether the use of service and hearing dogs had an impact on their owners' need for public support.

The project took place between 2009 and 2013, and a total of sixty-nine owners and their dogs were enrolled. The inclusion criteria were (1) $\geq 16$ years old, (2) having a companion dog and (3) needing a service or hearing dog (i.e. having a mobility impairment, diabetes, epilepsy or a hearing disorder). Those who were interested in participating in the project registered with the Swedish Association of Service Dogs (SAF). Initially, a veterinarian examined the dog. If the veterinarian examination was approved, the owner and the dog underwent a minor suitability test under the supervision of staff from SAF. The aim of this test was primarily to determine the dog's appropriateness, and to assess whether the owner was able to train the dog. 
Prior to starting the training, the dog and owner also underwent a major suitability test. This test determined the dog's responsiveness and obedience. The owner and the dog conducted the training in collaboration with a certified instructor appointed by SAF. They followed a customized training plan until they were considered to have reached a satisfactory level of training. At that time, a certification test took place. The certification test included several subtests to assess whether the dog had all the skills required. On passing the certification, the dog was provided with a vest that identified the dog as a certified service or hearing dog.

The project was led by the Swedish Institute of Assistive Technology, and the National Board of Health and Welfare was responsible for evaluating the project. The Centre for Medical Technology Assessment at Linköping University was responsible for designing a study and conducting the evaluation. 


\section{METHODS}

To explore and assess service and hearing dogs from an HTA perspective, a combination of quantitative and qualitative methods was used. The broad approach was considered suitable since working dogs are a nonmedical technology that is not traditionally evaluated in the health economic context. The qualitative study was used as an extension and a complement to the quantitative studies in order to gain a deeper understanding of the experiences of service and hearing dog ownership. When exploring the effects and cost-effectiveness of dog-assisted interventions, a systematic review was chosen to capture the current scientific evidence base. Table 1 gives an overview of papers I-IV.

Table 1. Overview of studies included in the thesis.

\begin{tabular}{|c|c|c|c|}
\hline Paper & Specific aim & Source of data & Methods of analysis \\
\hline I & $\begin{array}{l}\text { To describe and explore the poten- } \\
\text { tial consequences for HRQoL, well- } \\
\text { being and activity } \\
\text { level of having a certified service or } \\
\text { hearing dog }\end{array}$ & $\begin{array}{l}\text { The Service and Hear- } \\
\text { ing Dog Project }\end{array}$ & $\begin{array}{l}\text { Inferential statistical } \\
\text { analysis }\end{array}$ \\
\hline II & $\begin{array}{l}\text { To explore service and hearing dog } \\
\text { ownership from the owner's per- } \\
\text { spective by examining the owner's } \\
\text { expectations before training a dog, } \\
\text { and experiences after having a cer- } \\
\text { tified dog }\end{array}$ & $\begin{array}{l}\text { The Service and Hear- } \\
\text { ing Dog Project }\end{array}$ & $\begin{array}{l}\text { Thematic content anal- } \\
\text { ysis }\end{array}$ \\
\hline III & $\begin{array}{l}\text { To assess the cost-effectiveness of } \\
\text { a certified physical service dog and } \\
\text { a diabetes alert dog in comparison } \\
\text { with a regular companion dog }\end{array}$ & $\begin{array}{l}\text { The Service and Hear- } \\
\text { ing Dog Project, pub- } \\
\text { lished literature and ex- } \\
\text { pert opinions }\end{array}$ & $\begin{array}{l}\text { Decision analytic Mar- } \\
\text { kov model }\end{array}$ \\
\hline IV & $\begin{array}{l}\text { To conduct a systematic } \\
\text { literature review of quantitative } \\
\text { studies on dog-assisted } \\
\text { interventions in healthcare, with } \\
\text { the intention of assessing } \\
\text { the effects and cost-effectiveness } \\
\text { of the interventions } \\
\text { for different categories of patients }\end{array}$ & $\begin{array}{l}\text { Peer-reviewed litera- } \\
\text { ture search in the elec- } \\
\text { tronic databases Pub- } \\
\text { Med, AMED, CINAHL } \\
\text { and Scopus }\end{array}$ & Systematic review \\
\hline
\end{tabular}

\section{The design of the Service and Hearing Dog Project}

The Service and Hearing Dog Project was designed as a longitudinal interventional study with a pre-post design. The pre-post design was considered to be the only option due to the limited target group in combination with the fact that randomly assigning participants to a control group was 
not considered within the non-profit association involved in the project. The participants were asked if they would be willing to participate in the study when they passed the minor suitability test. Before the major suitability test or just before the training started, the participants gave their written informed consent and baseline data was collected.

Baseline data was collected through a telephone interview following a questionnaire and postal questionnaires. The telephone interview included questions about baseline characteristics, resource utilization, physical activity, time spent outside the home and time spent on social activities. Information on resource utilization was collected during the telephone interview by asking the participants how much healthcare they had used during the past three months and whether this healthcare was related to the reason for training a certified dog. Collecting data based on participants' recall has advantages and disadvantages, and the time period over which the participants have to remember details of their healthcare consumption is crucial in terms of how accurate the answers will be [52]. It has been shown that a recall period of six months or less is appropriate for remembering resource utilization that occurs frequently, and that a recall period of 12 months is suitable for remembering less frequent resource utilization [53, 54]. Recall periods longer than 12 months should be avoided since the level of agreement between patient's recall and medical records drops [53]. The recall period used in the present study was therefore carefully considered, and three months was considered to be a reasonable time for the participants to remember their healthcare consumption accurately. In addition to the telephone questionnaire, a postal questionnaire was sent to all participants including a number of self-assessment instruments and two openended questions. The baseline telephone interview was conducted on average 18 days (SD: 28.o days) before the major suitability test, and the baseline postal questionnaire was conducted on average 15 days (SD: 27 days) before the major suitability test. Four participants gave their baseline interview retrospectively, since the training of the dog had begun when the study enrolment started.

The training course took on average 1.5 years (range: 5 months -2 years and 10 months). Three months after the owner and the dog completed the training and the dog was certified, the first follow-up data was collected. The participants once again underwent a telephone interview answering the same questions as they did at baseline, with the addition of a question asking about the time they spent outside their home and the time they spent on social activities. The first follow-up postal questionnaire included the same self-assessment instruments as the baseline questionnaire, with the addition of six open-ended questions. The first follow-up telephone in- 
terview was conducted on average 95 days (SD: 22.7 days) after the certification of the dog, and the first follow-up postal questionnaire was answered on average 127 days (SD: 76 days) after the certification.

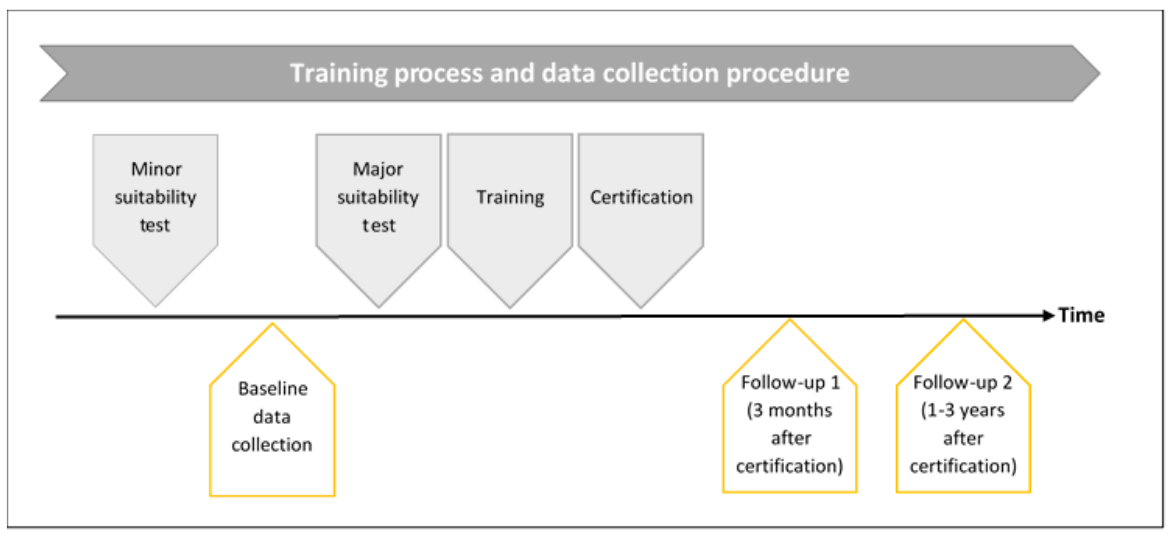

Figure 5. The training process and data collection procedure.

A second follow-up was conducted 1-3 years after certification. This follow-up was simultaneously sent to all participants who had completed the training, which meant that the study objects had different follow-up times. The second follow-up was a postal questionnaire that contained the same self-assessment instruments as the baseline and first follow-up questionnaire, no telephone interview were carried out at follow-up 2. It also contained the same open-ended questions as at the first follow-up. The training process and data collection procedure are presented in Figure 5.

The study was approved by the regional ethics board at Linköping University (No. 157/09) and retrospectively registered in clinicaltrial.gov, NCTo3270592, in September 2017.

\section{Participants - owners and dogs}

Out of sixty-nine enrolled participants, fifty-five completed the dog training and were thereby included in the study. Table 2 provides a summary of the participants' self-reported baseline characteristics. When joining the study, their average age was 44 years (range $17-68$ years). The most common diseases/functional impairments stated as the reasons for needing a certified service dog were diabetes, neurological disorders and musculoskeletal disorders. 
Table 2. Baseline characteristics of the participants.

\begin{tabular}{|c|c|}
\hline Baseline characteristics $(n=55)$ & \\
\hline \multicolumn{2}{|l|}{ Age (years) } \\
\hline Mean (SD) & $43.8(14.0)$ \\
\hline Min.-max. & $17-68$ \\
\hline \multicolumn{2}{|l|}{ Gender } \\
\hline Female & $47(85.5 \%)$ \\
\hline \multicolumn{2}{|l|}{ Education } \\
\hline Primary school & $6(10.9 \%)$ \\
\hline Secondary school & $15(27.3 \%)$ \\
\hline Post-secondary education & $12(21.8 \%)$ \\
\hline University degree & $22(40.0 \%)$ \\
\hline \multicolumn{2}{|l|}{ Main activity/professional status } \\
\hline Employed full-time & $5(9.1 \%)$ \\
\hline Employed part-time & $13(23.6 \%)$ \\
\hline Student & $4(7.3 \%)$ \\
\hline Sick leave & $4(7.3 \%)$ \\
\hline Retired & $2(3.6 \%)$ \\
\hline Disability pension & $23(41.8 \%)$ \\
\hline Other & $4(7.3 \%)$ \\
\hline Employed full-time & $5(9.1 \%)$ \\
\hline \multicolumn{2}{|l|}{ Household arrangement } \\
\hline Household more than 1 & $33(60.0 \%)$ \\
\hline Single & $22(40.0 \%)$ \\
\hline \multicolumn{2}{|l|}{ Disease/functional impairment } \\
\hline Diabetes & $20(36.4 \%)$ \\
\hline Neurological disorder & $15(27.3 \%)$ \\
\hline Musculoskeletal disorder & $12(21.8 \%)$ \\
\hline Deaf/hard of hearing & $3(5.5 \%)$ \\
\hline Epilepsy & $2(3.6 \%)$ \\
\hline Other & $3(5.4 \%)$ \\
\hline
\end{tabular}

Baseline characteristics of the 55 dogs in the study are presented in Table 3. The mean age of the dogs at baseline was 2 years (range 1-4 years). Thirty dogs were trained as physical service dogs, 20 as diabetes alert dogs, two as seizure alert dogs and three as hearing dogs. 
Table 3. Baseline characteristics of the dogs.

\begin{tabular}{lr}
\hline Baseline characteristics (n=55) & \\
\hline Age (years) & $2.2(0.7)$ \\
\hline Mean (SD) & $1.3-4.0$ \\
\hline Min.-max. & $27(49.1 \%)$ \\
\hline Gender & \\
\hline Bitch & $22.6(10.7)$ \\
\hline Weight (kg) & $3.2-52.0$ \\
\hline Mean (SD) & $49.8(11.7)$ \\
\hline Min.-max. & $19.0-67.5$ \\
\hline Height (cm) & $16(29.1 \%)$ \\
\hline Mean (SD) & \\
\hline Min.-max. & $30(54.5 \%)$ \\
\hline Neutered & $20(36.4 \%)$ \\
\hline Yes & $2(3.6 \%)$ \\
\hline Assistance dog type & $3(5.5 \%)$ \\
\hline Physical service dog & \\
\hline Diabetes alert dog & \\
\hline Seizure alert dog & \\
\hline Hearing dog &
\end{tabular}

Numerous breed categories were represented in the study. The two most common categories were 'Retrievers - flushing dogs - water dogs' and 'Sheepdogs and cattle dogs' (Figure 6).

\section{Breed categories}

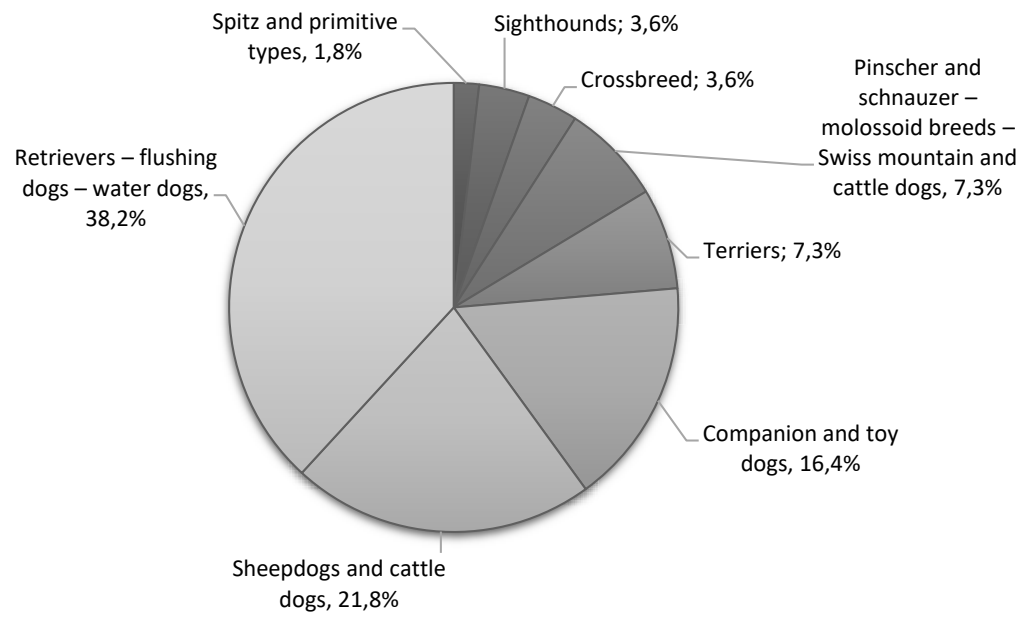

Figure 6. Breed categories according to Fédération Cynologique Internationale (FCI). [55] 
At the first follow-up the participants were asked to complete a checklist of the tasks that their dog carried out. This checklist was taken from a study conducted by Rintala et al. and translated into Swedish [56]. The tasks performed by the dogs after the certification are presented in Figure 7. The vast majority of the dogs picked up items from the floor, retrieved items, carried items in their mouths, helped take of clothes, etc. Tasks carried out by a small proportion of dogs were turning on the water tap, putting clothes in and out of a dryer, putting linen on or of a bed, giving payments to shop assistants, etc. 


\section{What the dogs helped with at first follow-up}

Pick items from floor

Retrieve items

Go get another person

Carry items in mouth

Take off clothes

Get items from shelves

Alert before a disease attack

Open/close drawers

Open/close cabinets

Open/close interior doors

Push automatic door button

Carry items in backpack

Clothes in/out basket

Clothes in/out washer

Help with housework

Bark in emergency

Give mobility support

Open/close exterior doors

Dry clothes in basket

Move mobility aid

Pull towels from rack

Carry items in bag

Helps you up if you have fallen

Help transfer

Give payment to clerk

Help maintain position

Put items on counter

Open/close refrigerator

Activate emergency alert

Clothes in/out dryer

Put linen on/off bed

Put on clothes

Basket room to room

Position for transfer

Button for dryer/towels

Push button for soap

Turn on water tap

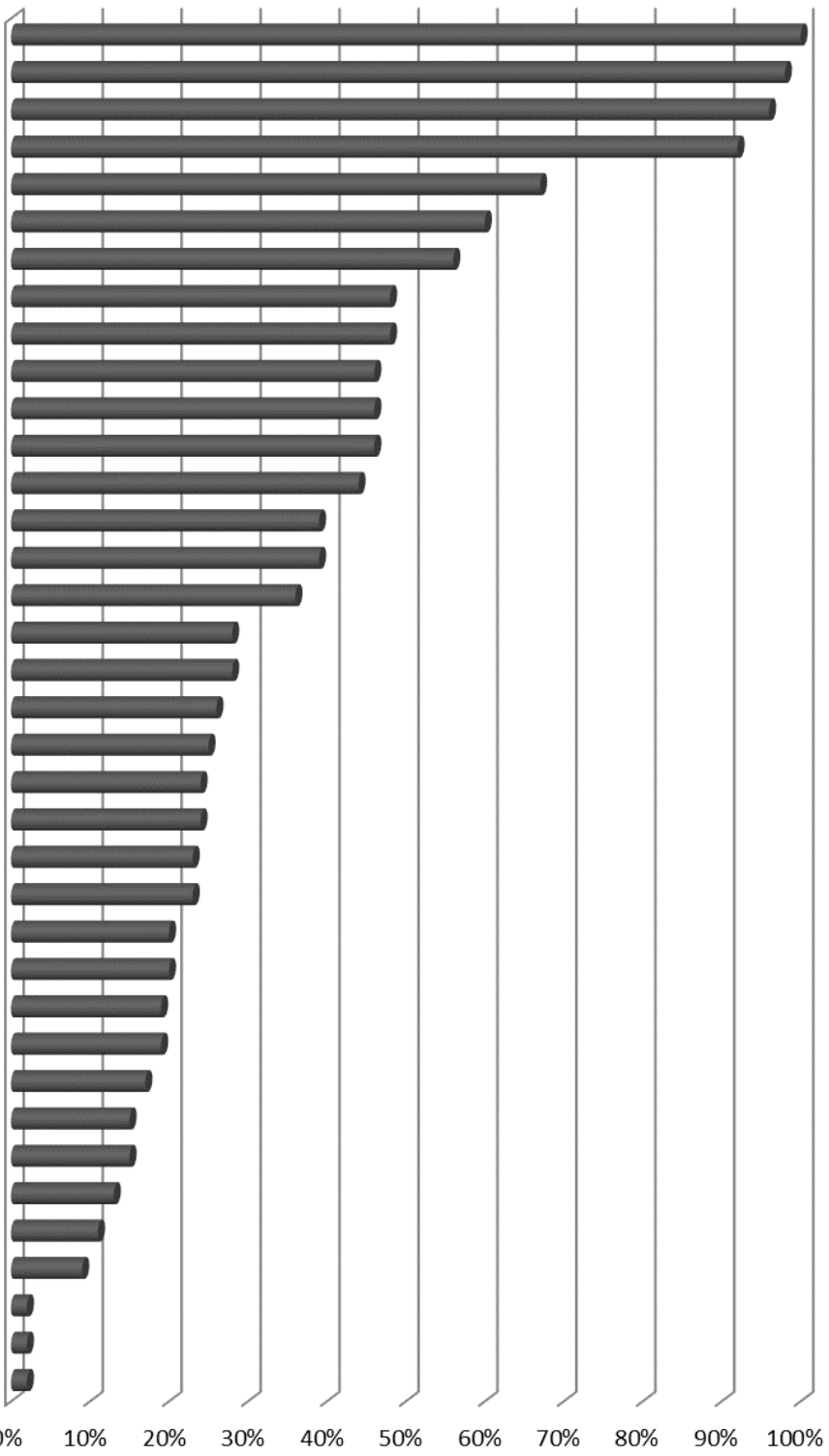

- First follow-up

Figure 7. Tasks that the dogs carried out at the first follow-up. 


\section{Paper I - To describe and explore what effects a ser- vice or hearing dog has on the owner}

Different generic instruments were included in the postal questionnaires in the Service and Hearing Dog Project, and these were analysed in paper I. The instruments capture different aspects of the chosen outcomes.

The EQ-5D instrument was used to capture the participants' HRQoL. EQ-5D includes the EQ-5D descriptive system and the EQ-VAS [57]. The EQ-5D contains five dimensions: mobility, self-care, usual activities, pain/discomfort and anxiety/depression. The EQ-5D-3L version was used in the project, meaning that for each dimension the answers are reported on a three-level ( $3 \mathrm{~L})$ ordinal scale: "no problems", "some problems" or "severe problems". The EQ-5D-3L was converted to a single index using the UK value set developed by Dolan et al. [57]. The index score based on the UK value set ranges from -0.594 to 1 , where o corresponds to death and 1 corresponds to perfect health, and negative values indicate health states worse than death. The EQ-VAS is a vertical $20 \mathrm{~cm}$ visual analogue scale. Individuals rate their current HRQoL status on a scale with the endpoints of o (worst health you can imagine) and 100 (best health you can imagine).

To get a more holistic assessment of the participants' HRQoL, RAND36 was also used. The questionnaire includes thirty-six questions across eight dimensions - physical functioning (PF), physical role functioning (RP), bodily pain (BP), general health (GH), vitality (VT), social functioning (SF), emotional role functioning (RE) and mental health (MH) - and the health transition scale (HT). The health transition scale is a single item question that provides an indication of perceived change in health. Each dimension is transferred to a scale from o (worst imaginable health state) to 100 (best imaginable health state) [58]. The distinctions between RAND36 and the traditionally used SF-36 are minor. They differ in the scoring procedure for the dimensions BP and GH, and RAND-36 does not have an algorithm for calculating a mental and physical component summary score [59]. To provide a single index score from RAND-36, the SF-6D was used. [60]. The SF-6D ranges between 0.291 and 1 , where 1 represents perfect health. The SF-6D was computed using the algorithm provided by Brazier et al. [61].

To measure the participants' well-being, the World Health Organization - Five Well-Being Index (WHO-5) was used. It contains five items: feeling cheerful and in good spirits, feeling calm and relaxed, feeling active and vigorous, feeling fresh and rested, and meaningful daily life. The items are scored from 5 (all of the time) to o (none of the time). It is recommended that the obtained score, ranging from o to 25, is multiplied by 4 to translate it into a percentage scale from $o$ (absence of well-being) to 100 
(maximal well-being), thus making it comparable with other scales which traditionally range from o to 100 [62].

Self-esteem was measured using the Rosenberg Self-Esteem Scale. It includes ten statements, each of which is answered on a four-point Likert scale - from "Strongly agree" to "Strongly disagree". The scale ranges from o to 30, with 30 being the highest score possible [63]. The questionnaire was translated using a translation-back translation procedure [64] since no Swedish version was available.

Questions about physical activity and time spent were also analysed in paper I. These were asked in the telephone questionnaire.

The participants' level of physical activity was assessed using a question from the Public Health Agency of Sweden's Lifestyle Report 2008 [65]. The participants rated how much they had moved around and exerted themselves physically in their leisure time during the last three months, on a four-point scale ranging from "sedentary leisure time" to "regular exercise and training". Sedentary leisure time meant they spent most of their time carrying out very calm, non-physical activities, such as reading and watching television, etc. and moved around for less than two hours per week, while regular exercise meant they were engaged in strenuous physical activity at least three times per week, for 30 minutes each time.

The participants were also asked whether the amount of time spent outside their home and the amount of time spent on social activities had changed (decreased, stayed the same or increased) since the dog was certified. These questions were developed by the research group, as these aspects were not captured in the other measurements. The questions were only asked at the first follow-up interview.

Pre-post comparisons of EQ-5D, RAND-36, WHO-5 and the Rosenberg Self-Esteem Scale with paired sample t-tests were carried out. The studied population's HRQoL results for the EQ-5D-3L and SF-6D were compared with the HRQoL values estimated using EQ-5D-3L for the general population [66] and the population norms for SF-6D [67]. Additionally, the RAND-36 results were compared with Swedish general population estimates based on SF-36 [68].

Two subgroup analyses were conducted. The participants were divided into groups depending on the type of dog, either (1) a physical service dog or (2) a diabetes alert dog. To test for differences between the subgroups, independent t-tests were performed.

A sample size of 47 participants was considered the minimum. This was determined using a power calculation based on the minimal important difference (MID) in the SF-6D. A Type I error rate of $\alpha=0.05$, a statistical power of 0.80 , an MID of 0.041 for the SF-6D [69] and an assumed standard deviation change of 0.01 were used to calculate the power. All analyses 
were performed using the statistics software package SPSS version 23.0 [70].

\section{Paper II - A thematic content analysis to explore ser- vice and hearing dog owners' experiences and gain a deeper understanding of the ownership}

In paper II, qualitative data from the postal questionnaires used in the Service and Hearing Dog Project was analysed to gain a deeper understanding of service and hearing dog ownership.

In the project, the participants answered two open-ended questions at baseline. The questions concerned the participants' expectations of training a certified service or hearing dog and their thoughts about how the dog would influence their situation after becoming certified.

1. What are your expectations of training a certified service or hearing dog?

2. How do you think the dog will influence/affect your situation after becoming certified?

At the first follow-up, the participants answered six open-ended questions. The same questions were answered by those participating in the second follow-up and was sent to thirty-three participants. Twenty-one of them returned the questionnaire. The questions concerned their experience of their certified dog.

1. What does your certified dog mean for your social situation?

2. What does your certified dog mean for your well-being?

3. How does your certified dog affect your ability to perform activities?

4. Has the dog had any significance influence on your medical situation and your perceived illness?

5 . Has the dog given you negative experiences?

6. Is there anything else you want to add?

The intention of asking these questions was to give the participants the opportunity to elaborate on their reasons for training a service or hearing dog and to explore their experiences. The construction of open-ended ques- 
tion might influence the answers [71]. To reduce the risk of this, the participants also had the opportunity to add other aspects of owning a service and hearing dog in question six.

The questions were analysed using a thematic content analysis in accordance with Braun and Clark [72]. An interlay inductive approach was used when analysing the data. All quotations were colour-coded before being separated from the questions. This was done to reduce the risk of the analysis being driven by the question, while still allowing the quotation to be linked back to the question if necessary. To identify relevant aspects in the data, ML initially read the answers several times. The identified patterns formed the themes. The relationship between the themes made it possible to create overreaching themes. When reviewing the identified themes and sub-themes, some of them were separated into new themes. Further, refining the themes also made it possible to distinguish different sub-subthemes. To ensure transparency and to minimize the risk of the analysis being influenced by ML's perceptions, the analytic process was constantly discussed with A-CN. The initial analysis was also reviewed by the research group. This was done to ensure that all potential themes and sub-themes had been identified, and to see how they fitted together. The 'workshop' where the research group validated the analysis can be seen as a form of triangulation [71]. The group also discussed the naming of the themes. All quotations were anonymized and translated from Swedish into English.

\section{Paper III - Long-term cost-effectiveness of physical service dogs and diabetes alert dogs}

Paper III was based on a decision-analytic model, enabling a health economic evaluation of physical service and diabetes alert dogs to be carried out. The model was populated with data from the Service and Hearing Dog Project, supplemented with data from published literature and expert opinions. The results from paper I showed that the service and hearing dog population was a heterogenous group. This motivated estimating the costeffectiveness of physical service dogs and diabetes alert dogs separately.

The cost-effectiveness analysis of physical service dogs and diabetes alert dogs was based on a decision-analytic Markov model. The model analysed a cohort of 1,00o hypothetical individuals who matched the population of the participants in the Service and Hearing Dog Project. The starting age of the cohort (44 years) was based on the mean age of the study population. The starting age of the dog was set to two years. The dog was assumed to retire when it reached ten years of age, since the useful life of a 
service dog is estimated at 8-9 years [37]. The base case analysis was conducted from a societal perspective. The time horizon used was set to ten years. Cost and QALYs were discounted by 3 percent annually.

The model structure is illustrated in Figure 8. Part 1, the one-year decision tree model, visualizes the training procedure. Owners who wish to train a dog must undergo and pass initial tests together with their dog. To receive the certification they must pass a final exam, at which point they move to the 'Dog certified' state (part 2, Figure 8). Owners who do not pass the minor and major suitability tests, those who do not pass the final exam and those who do not intend to train their dog to become a certified dog (owners of regular companion dogs) move directly to the 'Companion dog' state (part 2, Figure 8). After the initial decision tree, a Markov model with annual cycles runs for nine years (part 2). The time horizon is based on how long the dog is expected to be used as a certified dog. Each year, owners of a certified dog can move from the 'Dog certified' state to the 'Dog retired' state or, if they do not pass the annual certification maintenance test, to the 'Dog not certified' state (part 2, Figure 8). Both owners and dogs have an annual risk of death, which can transfer them to the 'Owner dead' or 'Dog dead' state. Owners of a regular companion dog can only move from the 'Companion dog' state to the 'Owner dead' state or the 'Dog dead' state.

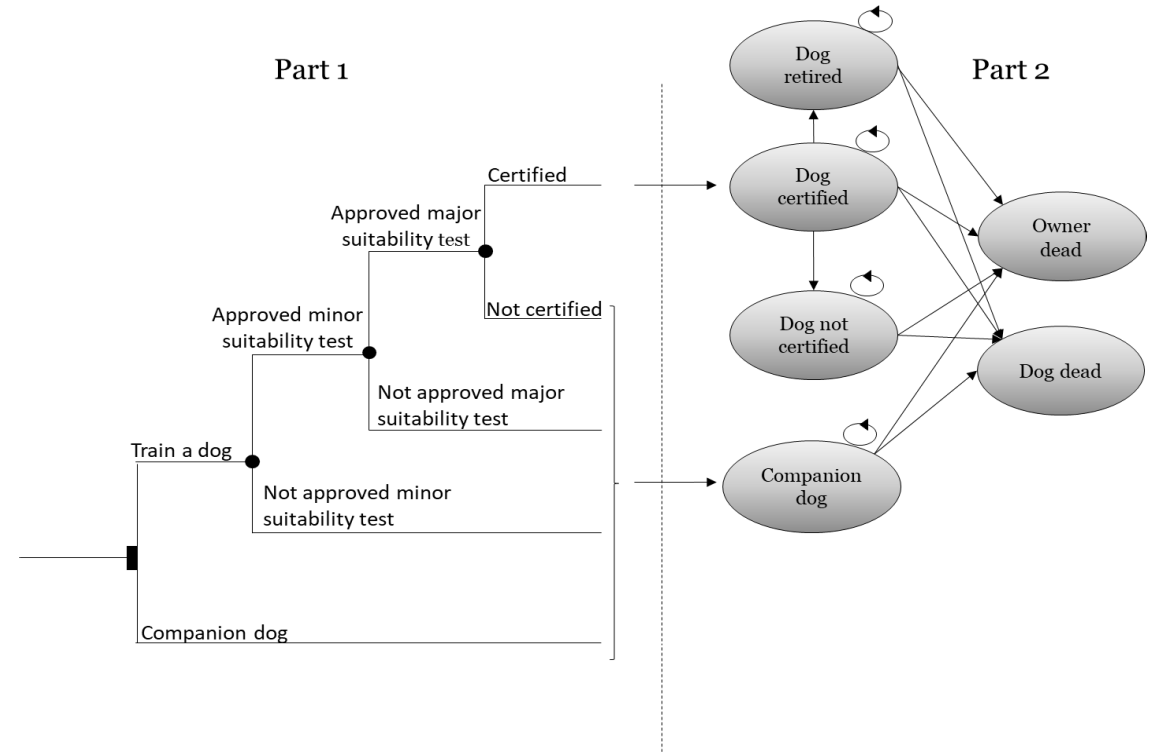

Figure 8. Structure of the decision-analytic Markov model.

The decision whether or not to train a certified dog is shown in part 1. Part 2 describes how a certified dog can retire or lose its certification, and that the owner and the dog have an annual risk of dying. Owners of a companion dog can move from the 'Companion dog' state to the 'Owner dead' or the 'Dog dead' state. 
Costs. Data on resource utilization was obtained from the telephone questionnaire in the Service and Hearing Dog Project and included:

- Hospitalization

- emergency care

- ambulance use

- visit to physician at hospital

- visit to physician (in primary care)

- home visit from physician

- visit to nurse

- home visit from nurse

- visit to physiotherapist

- home visit from physiotherapist

- visit to occupational therapist

- home visit from occupational therapist

- visit to other care giver and home visit from other care giver

It also included consumption of municipal services:

- use of home-help services

- personal assistance

- escort/accompanying person

- use of transportation service and use of other services

The participants detailed their quarterly resource utilization and stated whether or not this was related to the reason for training a service or hearing dog. The quarterly resource utilization was multiplied by units costs from regional pricing lists [73, 74].

Other health-related costs included and collected through the telephone questionnaire were:

- Informal care

- Sick leave

Data about informal care was obtained by participants estimating how much informal care they received during a typical week and if the informal caregiver needed to take time off from work. Informal care was valued based on loss of leisure time, where one hour was valued as 35 percent of average gross wage [75, 76]. The participants reported short- and long- 
term episodes of sick leave that reduced their work ability. Productivity loss due to sick leave was valued as gross wage including payroll taxes [77].

In the project, the participants stated the purchase cost of the dog and their costs for insurance, food, veterinary visits and other possible expenditure related to the dog. Resource use relating to training was gathered from SAF. This included costs for the instructor and administration costs relating to training. Productivity loss relating to training was calculated based on self-reported data, where the participants estimated the amount of time they and the people accompanying them (where applicable) had to take off work to be able to participate in the training.

Cost estimates for the regular companion dog state were based on the baseline data from the Service and Hearing Dog Project. Cost estimates for the certified dog state were based on data from the first follow-up. If the dog lost its certification or retired, we assumed that the owner obtained a mean cost in between the cost for a regular companion dog state and the cost for a certified dog state. If the dog died, costs were estimated based on the baseline data. In the base case analysis, only costs for healthcare utilization stated by the participants as related to the reason for having a certified dog were included. To estimate annual costs, the quarterly costs were multiplied by four. The estimates are presented in Tables 4 and 5, depending on the study population. Unit costs used are presented in Appendix 1.

The costs were calculated in Swedish kronor (SEK) and converted to US dollars (USD) using an exchange rate of 1 USD $=8.538$ SEK (2017 mean exchange rate).

Quality-adjusted life years. QALY weights for the regular companion dog state were based on HRQoL data from baseline, while QALY weights for the certified dog state were obtained from HRQoL data from the first follow-up in the Service and Hearing Dog Project. For owners of a dog that lost its certification or retired, we assumed a QALY weight between the estimate for owners of a regular companion dog and owners of a certified dog. If the dog died, QALY weights were based on HRQoL data from baseline. The QALY weights were based on the EQ-5D instrument using the UK value set [57]. The QALY weights used in the model for the different study populations are presented in Tables 4 and 5 .

Probabilities. The probabilities for passing the minor and major suitability tests and for passing the examination were based on data from the Service and Hearing Dog Project, Table 4. The probabilities for transferring between the states were based on assumptions determined in consultation with SAF, Table 4 . The probabilities presented in Table 4 apply to both physical service dogs and diabetes alert dogs. 
Mortality. The model used age-based standard mortality rates for the general population in Sweden [78] and mortality rates for dogs from a study conducted by Egenvall et al. [79].

Table 4. Parameters used in the model for physical service dog owners

\begin{tabular}{|c|c|c|c|}
\hline Model parameter & $\begin{array}{l}\text { Regular companion dog } \\
\text { (alfa, beta) }\end{array}$ & $\begin{array}{l}\text { Certified dog } \\
\text { (alfa, beta) }\end{array}$ & $\begin{array}{c}\text { Retired } \\
\text { dog/dog that } \\
\text { lost certifica- } \\
\text { tion status } \\
\text { (alfa, beta) }\end{array}$ \\
\hline \multicolumn{4}{|l|}{ Annual costs*/owner (USD) } \\
\hline \multicolumn{4}{|l|}{ Healthcare } \\
\hline Hospitalization & 617 & 378 & 497 \\
\hline Emergency care & 1,500 & 833 & 1,167 \\
\hline Ambulance & 101 & - & 50 \\
\hline Visit to physicians (hospital) & 528 & 793 & 661 \\
\hline Visit to physicians (health centre) & 925 & 691 & 808 \\
\hline Home visit physicians & 69 & - & 34 \\
\hline Visit to nurse & 338 & 987 & 663 \\
\hline Home visit nurse & 507 & 507 & 507 \\
\hline Visit to physiotherapist & 1,791 & 1,360 & 1,576 \\
\hline Home visit physiotherapist & - & 100 & 50 \\
\hline Visit to occupational therapist & 391 & 287 & 339 \\
\hline Home visit occupational therapist & 417 & 313 & 365 \\
\hline Visit to other caregiver & 1,743 & 1,282 & 1,513 \\
\hline Home visit other caregiver & - & - & - \\
\hline Total & $8,928(27,704)$ & $7,530(23,703)$ & $\begin{array}{r}8,229(25 \\
702)\end{array}$ \\
\hline \multicolumn{4}{|l|}{ Municipal services } \\
\hline Home-help services & 648 & 626 & 637 \\
\hline Personal assistants & 40,042 & 42,879 & 41,461 \\
\hline Escort/accompanying person & 811 & 1,060 & 935 \\
\hline Transportation service & 2,449 & 2,357 & 2,403 \\
\hline Other service & 638 & 708 & 673 \\
\hline Total & $44,588(10,9596)$ & $\begin{array}{r}47,630(9 \\
11232) \\
\end{array}$ & $\begin{array}{r}46,109(9 \\
10408) \\
\end{array}$ \\
\hline Informal care & $4,768(20,501)$ & $3,503(26,283)$ & $\begin{array}{r}4,135(23 \\
391)\end{array}$ \\
\hline Sick leave & $66,901(228,627)$ & $\begin{array}{r}63,859(147 \\
926) \\
\end{array}$ & $\begin{array}{r}65,380(182 \\
768) \\
\end{array}$ \\
\hline \multicolumn{4}{|l|}{ Dog costs year 1} \\
\hline Purchase dog & $1,151(308,32)$ & $1,151(308,32)$ & $\begin{array}{r}1,151(308, \\
32) \\
\end{array}$ \\
\hline Annual costs** & $1,332(92,10)$ & $1,332(92,10)$ & $1,332(92,10)$ \\
\hline Suitability tests & - & 193 & - \\
\hline Total & 2,482 & 2,676 & 2,482 \\
\hline
\end{tabular}




\begin{tabular}{|c|c|c|c|}
\hline \multicolumn{4}{|l|}{ Dog costs year 2} \\
\hline Annual costs** & $1,332(92,10)$ & $1,332(92,10)$ & $1,332(92,10)$ \\
\hline Dog training & - & 7,746 & - \\
\hline Cost of vests & - & 211 & - \\
\hline Total & 1,332 & 9,288 & 1,332 \\
\hline \multicolumn{4}{|l|}{ Dog costs following years } \\
\hline Annual costs** & $1,332(92,10)$ & $1,332(92,10)$ & $1,332(92,10)$ \\
\hline Annual certification maintenance test & - & 88 & - \\
\hline Annual health declaration & - & 59 & - \\
\hline Total & 1,332 & 1,478 & 1,332 \\
\hline QALY weights $¥$ & $0.226(14,39)$ & $0.351(29,53)$ & 0.309 \\
\hline \multicolumn{4}{|l|}{ Probabilities } \\
\hline Pass minor suitability test & & & 0.71 \\
\hline Pass major suitability test & & & 0.99 \\
\hline Pass examination & & & 0.80 \\
\hline \multicolumn{4}{|l|}{ Transition probabilities } \\
\hline Dog certified $\rightarrow$ Dog certified & & & 0.90 \\
\hline Dog certified $\rightarrow$ Dog not certified & & & 0.01 \\
\hline Dog certified $\rightarrow$ Dog retired & & & 0.09 \\
\hline Dog not certified $\rightarrow$ Dog not certified & & & 1 \\
\hline Dog retired $\rightarrow$ Dog retired & & & 1 \\
\hline
\end{tabular}

Table 5. Parameters used in the model for diabetes alert dog owners

\begin{tabular}{lrrr}
\hline Model parameter & $\begin{array}{c}\text { Regular companion dog } \\
\text { (alfa, beta) }\end{array}$ & $\begin{array}{c}\text { Certified dog } \\
\text { (alfa, beta) }\end{array}$ & $\begin{array}{r}\text { Retired } \\
\text { dog/dog that } \\
\text { lost certifica- } \\
\text { tion status } \\
\text { (alfa, beta) }\end{array}$ \\
\hline Annual costs*/owner (USD) & 1,770 & 3,017 & 2,393 \\
\hline Healthcare & 3,250 & 750 & 2,000 \\
\hline Hospitalization & 831 & 151 & 491 \\
\hline Emergency care & 1,633 & 1,427 & 1,530 \\
\hline Ambulance & 309 & 566 & 437 \\
\hline Visit to physicians (hospital) & - & - & - \\
\hline Visit to physicians (health centre) & 994 & 1,015 & 1,004 \\
\hline Home visit physicians & - & - & - \\
\hline Visit to nurse & 75 & 1,567 & 821 \\
\hline Home visit nurse & 100 & - & 50 \\
\hline Visit to physiotherapist & & 1,055 & 527 \\
\hline Home visit physiotherapist & - & & \\
\hline Visit to occupational therapist & & & \\
\hline
\end{tabular}


Methods

\begin{tabular}{|c|c|c|c|}
\hline Home visit occupational therapist & 78 & - & 39 \\
\hline Visit to other caregiver & 437 & 454 & 446 \\
\hline Home visit other caregiver & - & - & - \\
\hline Total & $9,475(5,3752)$ & $\begin{array}{r}10,001(12 \\
1805)\end{array}$ & $\begin{array}{r}9,738(8) \\
2677)\end{array}$ \\
\hline \multicolumn{4}{|l|}{ Municipal services } \\
\hline Home-help services & - & - & - \\
\hline Personal assistants & 3,474 & 3,040 & 3,257 \\
\hline Escort/accompanying person & - & - & - \\
\hline Transportation service & 25 & 38 & 32 \\
\hline Other service & 28 & 17 & 23 \\
\hline Total & $3,528(1,7292)$ & $3,095(1,6417)$ & $\begin{array}{r}3,312(1, \\
6855)\end{array}$ \\
\hline Informal care & $2,414(12,432)$ & $1,168(13,198)$ & $\begin{array}{r}1,791(12 \\
315)\end{array}$ \\
\hline Sick leave & $28,900(15,4178)$ & $\begin{array}{r}27,829(12 \\
4822)\end{array}$ & $\begin{array}{r}28,364(13, \\
4491)\end{array}$ \\
\hline \multicolumn{4}{|l|}{ Dog costs year 1} \\
\hline Purchase dog & $1,151(308,32)$ & $1,151(308,32)$ & $\begin{array}{r}1,151(308, \\
32)\end{array}$ \\
\hline Annual costs** & $1,332(92,10)$ & $1,332(92,10)$ & $1,332(92,10)$ \\
\hline Suitability tests & - & 193 & - \\
\hline Total & 2,482 & 2,676 & 2,482 \\
\hline \multicolumn{4}{|l|}{ Dog costs year 2} \\
\hline Annual costs** & $1,332(92,10)$ & $1,332(92,10)$ & $1,332(92,10)$ \\
\hline Dog training & - & 7,746 & - \\
\hline Cost of vests & - & 211 & - \\
\hline Total & 1,332 & 9,288 & 1,332 \\
\hline \multicolumn{4}{|l|}{ Dog costs following years } \\
\hline Annual costs** & $1,332(92,10)$ & $1,332(92,10)$ & $1,332(92,10)$ \\
\hline Annual certification maintenance test & - & 88 & - \\
\hline Annual health declaration & - & 59 & - \\
\hline Total & 1,332 & 1,478 & 1,332 \\
\hline QALY weights $¥$ & $0.656(36,19)$ & $0.674(24,12)$ & 0.665 \\
\hline
\end{tabular}

\section{Sensitivity analyses}

A probabilistic sensitivity analysis (PSA) was employed to examine the statistical uncertainty in the model [28]. The result is presented in the costeffectiveness plane and as cost-effectiveness acceptability curves. The costeffectiveness acceptability curves reports the probability of a certified dog being cost-effective at different threshold values [80].

To test the robustness of the results, one-way sensitivity analyses were carried out for different discount rates, the life span of the dog, the dog's 
retirement age, the cost of purchasing a fully trained dog, the costs and QALY estimates of having a retired dog, the inclusion of healthcare utilization unrelated to training a certified dog (i.e. all healthcare utilization), excluding productivity losses and changing the perspective of the analysis to a narrower healthcare perspective. The values used for the different oneway sensitivity analyses are presented in the results sections in Table 15.

\section{Paper IV - A systematic literature review to establish known effects and cost-effectiveness of dog-assisted interventions}

Paper IV was a systematic literature review. Reviewing the literature is an appropriate first step in order to synthesize and summarize the current knowledge of the effects and cost-effectiveness of dog-assisted interventions. To minimize biases in all steps of the review process, the Preferred Reporting Items for Systematic Review and Meta-Analysis guidelines (PRISMA) were followed.

Studies were identified by searching the electronic databases PubMed, AMED, CINAHL and Scopus from their inception date through to January 2017. In addition, reference lists from included studies and other systematic reviews were manually searched. All searches were conducted by one of the authors (ML). The search strategy used is presented in Table 6.

Table 6. Search strategy.

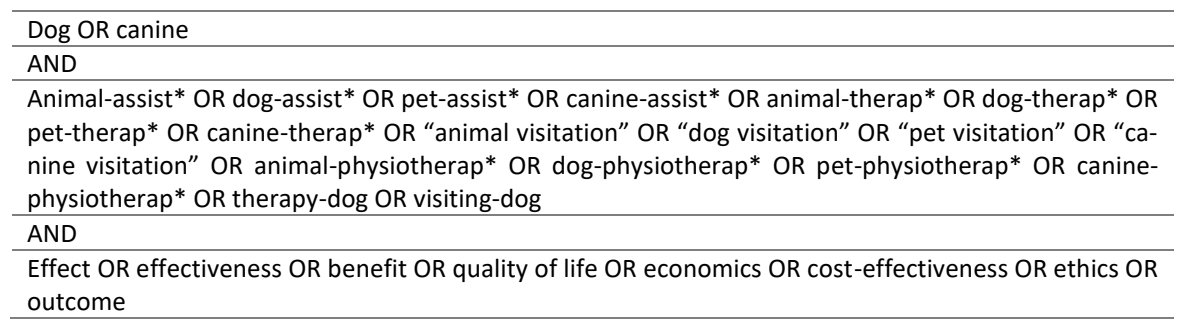

The research group determined the inclusion criteria applied in the review. The initial four criteria were determined after setting the research question and the latter three criteria were determined as basic quality criteria to be fulfilled. All criteria were determined before the initial search was conducted. A study had to fulfil all inclusion criteria to be included. 
The inclusion criteria are presented below:

- Studies of dog-assisted interventions (DAI) performed in healthcare settings including nursing homes and home care.

- Studies collecting primary data.

- Quantitative studies (i.e. measuring outcomes with numerical scales).

- Separate result presentation of effects.

- At least 20 study subjects.

- Existence of a control.

- Published articles from peer-reviewed journals with full text in English.

In total, after duplication removal, 1,445 studies were identified through database research. An additional 28 studies were identified through other sources. Titles and abstracts from the identified studies were screened to determine their relevance. Studies with a title or an abstract that did not meet the inclusion criteria were excluded (1,402 in total). Studies with insufficient information in the title and abstract were passed on to the next stage of the review process. The studies that remained after the initial selection were screened in full to confirm eligibility and to determine quality ( $\mathrm{n}=71)$.

To assess eligibility and to determine the quality of the studies that passed the above requirements, pairs of authors independently read the articles in full. The criteria applied for judging scientific quality were: adequate control group(s), control of confounders, randomization, adequately described experimental design and relevant measured outcome variables $[81,82]$. The quality of the studies was rated as high, moderate or low. A study classified as being of high quality had to fulfil all the above mentioned criteria, while a study classified as being of moderate quality had to fulfil most of the abovementioned criteria. When a study was classified as being of low quality, several of the criteria were not fulfilled or major shortcomings in some of the criteria had been found. Studies classified as being of low quality were excluded. In total, fifty-three studies were excluded during the last stage: twenty-eight for not meeting the inclusion criteria and twenty-five due to low quality (see Appendix 2). The different phases of the systematic review are illustrated in the flow chart in Figure 9. 


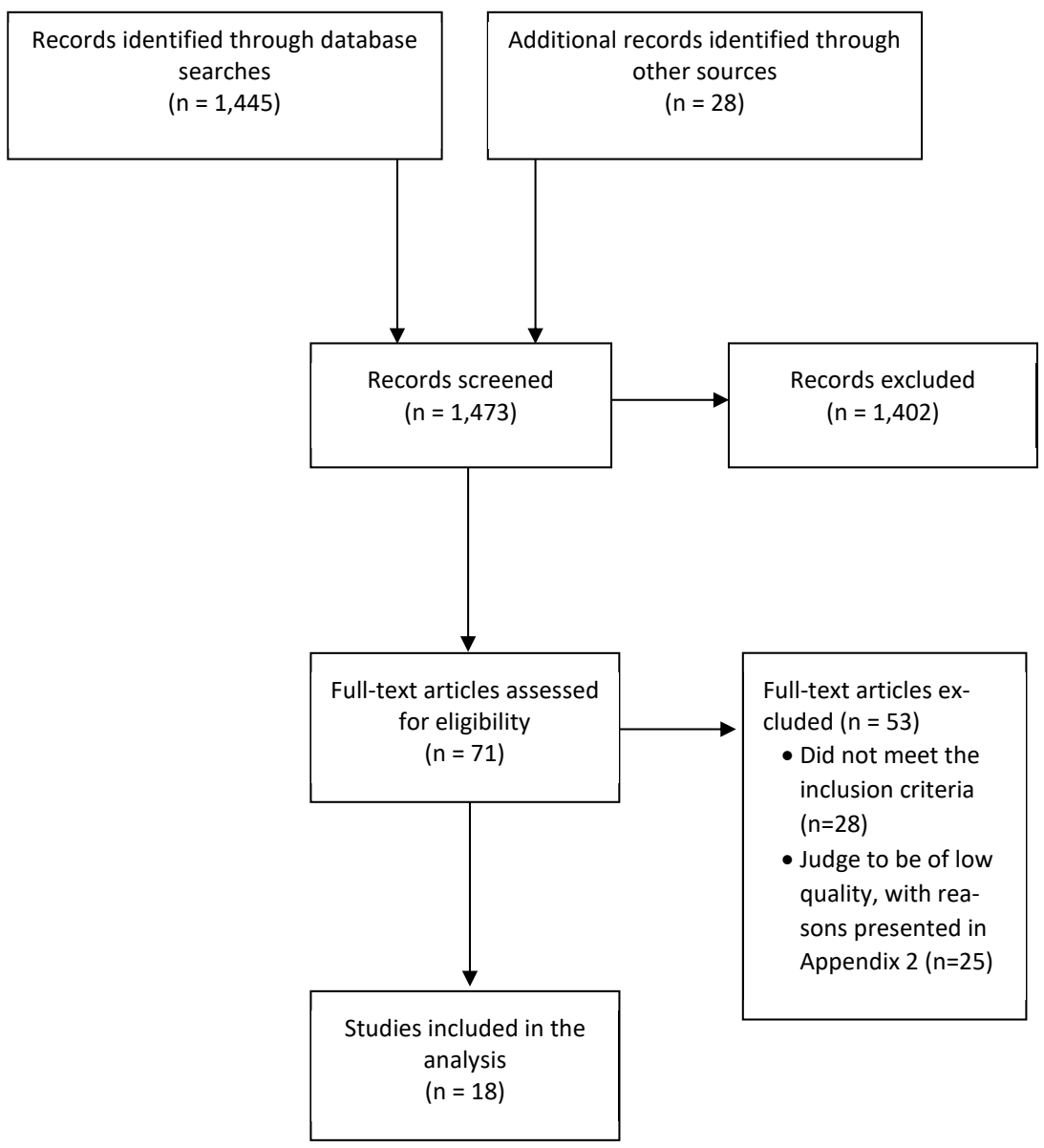

Figure 9. Flow chart of the work process. PRISMA 2009 Flow Diagram.

The 18 studies included in the review were published during the time period 1997-2016. Most of the studies were randomized controlled trials. Two studies were cohort studies with a pre-post intervention. One study adopted a within-subject, time series design and one used a crossover design. Appendix 3 summarizes data from the included studies.

To establish the contexts in which DAIs have effects, the authors categorized the interventions as therapeutic (DAT), activating (DAA) or supportive (DAS) interventions. This categorization was based on the criteria presented in Table 7. The criteria for DAT and DAA were compiled based on published literature $[38,83]$. When reviewing the literature, several interventions could not be categorized into the existing categories. To fill this gap, the research group constructed the DAS sub-category. 
Table 7. Criteria for categorization of interventions.

\begin{tabular}{clll}
\hline & Dog-assisted therapy & Dog-assisted activity & Dog-assisted support \\
\hline $\begin{array}{clll}\text { Intervention } \\
\text { Aim of action } \\
\text { Content of activity } \\
\text { Amount of activity }\end{array}$ & Goal-orientated & No specific goals & No specific goals \\
Multiple sessions & Multiple sessions & Single session \\
\hline Treatment integration & High & Low & High \\
\hline Dog handler/therapist & Educated & Volunteer & Volunteer \\
& Professional & Not professional & Semi-professional \\
\hline Effect/focus & Health & Well-being & Distraction \\
& & & Stress reduction \\
\hline
\end{tabular}




\section{RESULTS}

In this section, the results from papers I-IV will be presented. The results from the studies contribute to further knowledge about the effects of service and hearing dogs. Taking a long-term perspective into account, the results also contribute to knowledge about the cost-effectiveness of physical service dogs and diabetes alert dogs. By reviewing the literature, it has been possible to summarize the knowledge about the effects and cost-effectiveness of dog-assisted interventions.

\section{Papers I and II - Effects and experiences of having a service or hearing dog}

\section{Describing and exploring potential consequences of having a service or hearing dog on HRQoL, well-being and activity level (paper I)}

The participants included in the study had low HRQoL compared to the general population. For the total study population, a significant improvement from baseline to first follow-up was shown in the EQ-VAS. The other index scores also indicated improvement even if the changes were not statistically significant, Table 8.

Table 8. HRQoL measures for the general population in Sweden and HRQoL measures for the total study population at baseline and first follow-up.

\begin{tabular}{lclllll}
\hline Instrument & $\mathbf{n}$ & $\begin{array}{l}\text { General popu- } \\
\text { lation† } \\
\text { years) }\end{array}$ & Baseline (SD) & Follow-up (SD) & Diff. & p-value \\
\hline $\begin{array}{l}\text { EQ-5D single } \\
\text { index }\end{array}$ & 53 & 0.86 & $0.441(0.363)$ & $0.491(0.339)$ & 0.050 & 0.234 \\
\hline EQ-VAS & 53 & 87 & $55.15(21.125)$ & $62.62(19.450)$ & 7.472 & $0.007^{*}$ \\
\hline SF-6D & 52 & 0.79 & $0.639(0.126)$ & $0.650(0.126)$ & 0.011 & 0.441 \\
\hline
\end{tabular}

*Statistically significant at a p-value level of 0.05 +General population: index $n=588$ [66], VAS $n=556$ [66], SF-6D n=22,166 [67].

The participants had low RAND-36 scores in all domains in comparison to the SF-36 domains scores for the Swedish general population, Table 9. Significant improvements between baseline and first follow-up were seen in two of the eight RAND-36 domains - Physical Role functioning (RP) and Emotional Role functioning (RE) scores (Table 9) - as well as for the summary score Health Transition (HT). 
Table 9. Mean SF-36 score (SD) estimates for the general population in Sweden and mean RAND-36 scores for the total study population at baseline and first follow-up.

\begin{tabular}{llllll}
\hline $\begin{array}{l}\text { HRQoL } \\
\text { score } \\
(\mathbf{n = 5 4 )}\end{array}$ & $\begin{array}{l}\text { SF-36 general popu- } \\
\text { lationt (SD) [68] }\end{array}$ & Baseline (SD) & $\begin{array}{l}\text { First follow-up } \\
\text { (SD) }\end{array}$ & Diff. & p-value \\
\hline PF & $87.9(19.6)$ & $47.8(32.6)$ & $45.5(35.1)$ & -2.31 & 0.329 \\
\hline RP & $83.2(31.8)$ & $34.3(40.1)$ & $50.6(40.7)$ & 16.36 & $0.003^{*}$ \\
\hline BP & $74.8(26.1)$ & $55.3(31.2)$ & $56.3(30.4)$ & 1.02 & 0.728 \\
\hline GH & $75.8(22.2)$ & $46.0(24.2)$ & $43.1(22.8)$ & -2.99 & 0.212 \\
\hline VT & $68.8(22.8)$ & $41.0(25.0)$ & $46.2(23.5)$ & 5.28 & 0.051 \\
\hline SF & $88.6(20.3)$ & $63.4(27.3)$ & $66.7(23.8)$ & 3.30 & 0.352 \\
\hline RE & $85.7(29.2)$ & $59.3(41.3)$ & $75.3(40.0)$ & 16.05 & $0.013^{*}$ \\
\hline MH & $80.9(18.9)$ & $67.0(20.2)$ & $71.8(19.8)$ & 4.83 & 0.057 \\
\hline HT & & $42.1(25.2)$ & $52.3(25.4)$ & 10.19 & $0.020^{*}$
\end{tabular}

PF=Physical Function; RP=Role Physical; BP=Bodily Pain; GH=General Health; VT=Vitality; SF=Social Function; RE=Role Emotional; $\mathrm{MH}=$ Mental Health; $\mathrm{HT}=$ Health Transition score. *Statistically significant at a $p$-value level of 0.05 . $+n=8,930$

The participants' well-being improved significantly between baseline and follow-up, Table 10. No change in self-esteem was found.

Table 10. Well-being and self-esteem for the total study population.

\begin{tabular}{lccllll}
\hline Instrument & $\mathbf{n}$ & Baseline (SD) & $\begin{array}{l}\text { First follow-up } \\
\text { (SD) }\end{array}$ & Diff. & p-value \\
\hline WHO-5 & 53 & $48.38(22.631)$ & $54.72(17.919)$ & 6.340 & $0.030^{*}$ \\
\hline Rosenberg Self-Esteem Scale & 53 & $17.75(6.260)$ & $18.94(6.792)$ & 1.189 & 0.068 \\
\hline *Statistically significant at a p-value level of 0.05 & & & \\
\hline
\end{tabular}

At baseline, 24 percent of the participants stated that they regularly exercised and trained during their leisure time. By first follow-up, this had increased to 33 percent. The improvement was statistically significant (pvalue: 0.021$)$. Most of the participants also stated that the proportion of time spent outside their home had increased (67 percent) and that they spent more time on social activities (61 percent).

\section{Physical service dogs and diabetes alert dogs}

Sub-group analyses were conducted to study whether the results differed based on dog type. Owners of physical service dogs had a low HRQoL measured with EQ-5D single index, EQ-VAS and SF-6D. Owners of diabetes alert dogs reported higher HRQoL (Table 11). The tendency of improve- 
ment seen in both groups at the first follow-up was not statistically significant. However, the improvement between the subgroups from baseline to first follow-up measured with EQ-5D differed (p-value: 0.045). This indicates that physical service dog owners benefited more from a certified dog than diabetes alert dog owners in terms of HRQoL.

Table 11. HRQoL measures for the general population in Sweden and HRQoL measures for physical service dog owners and diabetes alert dog owners at baseline and follow-up.

\begin{tabular}{lllllll}
\hline Instrument & $\mathbf{n}$ & $\begin{array}{l}\text { General } \\
\text { popula- } \\
\text { tiont (40- } \\
\text { 49 years) }\end{array}$ & Baseline (SD) & $\begin{array}{l}\text { First follow-up } \\
\text { (SD) }\end{array}$ & Diff. & p-value \\
\hline Physical service dogs & & & & & \\
\hline EQ-5D single index & 29 & 0.86 & $0.266(0.323)$ & $0.351(0.282)$ & 0.086 & 0.201 \\
\hline EQ-VAS & 29 & 87 & $52.97(22.301)$ & $60.93(17.625)$ & 7.966 & 0.058 \\
\hline SF-6D & 28 & 0.79 & $0.590(0.093)$ & $0.610(0.088)$ & 0.020 & 0.282 \\
\hline Diabetes alert dogs & & & & & \\
\hline EQ-5D single index & 19 & 0.86 & $0.656(0.277)$ & $0.674(0.336)$ & 0.017 & 0.741 \\
\hline EQ-VAS & 19 & 87 & $56.00(20.685)$ & $63.89(23.120)$ & 7.895 & 0.075 \\
\hline SF-6D & 19 & 0.79 & $0.699(0.143)$ & $0.719(0.143)$ & 0.020 & 0.424 \\
\hline *Statistically significant at a p-value level of $0.05 .+$ General population: index $n=588[66]$, VAS n=556 \\
[66], SF-6D n=22,166 [65].
\end{tabular}

Owners of physical service dogs had low RAND-36 domain scores compared to the general population. However, a statistically significant improvement was found in the Physical Role functioning (RP) and Emotional Role functioning (RE) domains, and in the Health Transition score (HT). No differences were found in any of the RAND-36 domain scores between baseline and first follow-up for owners of diabetes alert dogs or between the subgroups.

Studying change in physical activity within the subgroups showed that a larger proportion of the physical service dog owners conducted 'moderate but regular exercise during leisure time' (27\%) at follow-up, compared to baseline (10\%). The greatest difference in how diabetes alert dog owners rated their physical activity between baseline and first follow-up was seen in the item 'Moderate exercise during leisure time'. Those who previously rated their exercise level as 'moderate exercise during leisure time' now took part in 'moderate but regular exercise during leisure time' or 'regular exercise and training'. Figure 10 presents the distributions. 
How much have you moved about and exerted yourself physically in your leisure time in the last 3 months?

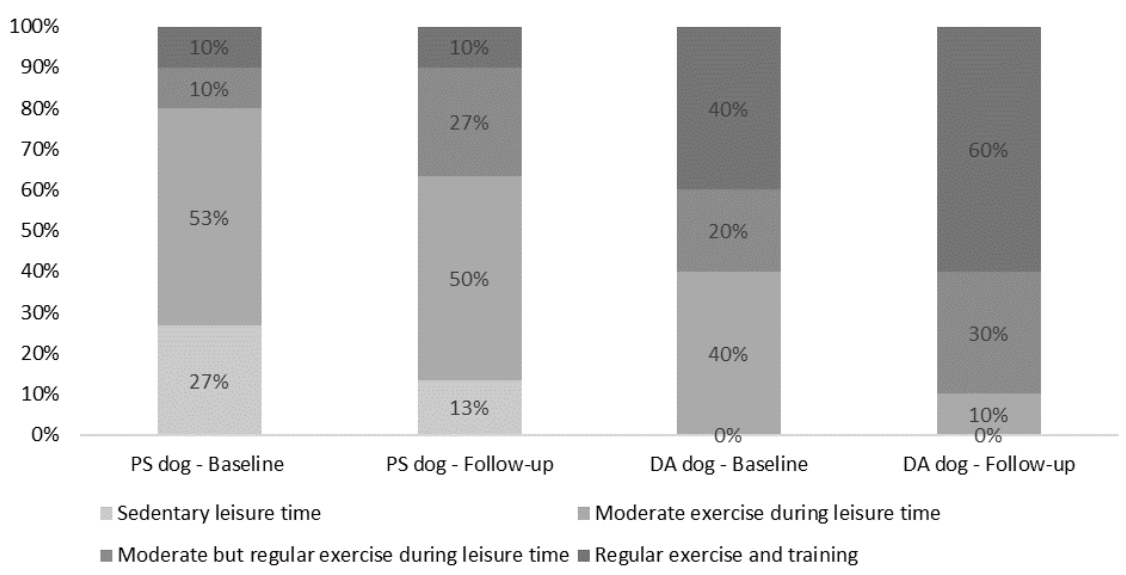

Figure 10. Distribution of physical activity during leisure time in the last three months for owners of physical service dogs (PS dog) and diabetes alert dogs (DA $\operatorname{dog})$.

At the first follow-up, 84 percent of the physical service dog owners stated that they had increased the time they spent outside their home and 79 percent stated that they had increased the time they spent on social activities. The corresponding figures for the diabetes alert dog owners were 53 and 42 percent, respectively.

\section{Expectations and perceived experiences of having a certified service or hearing dog (paper II)}

When analysing the open-ended questions from the project with a thematic content analysis, two main themes were identified: expectations expressed before training a service or hearing dog, and experiences of having a service or hearing dog. The identified expectations were categorized in four sub-themes: the skills of the dog, security and independence, the training, and overall life changes. The experiences of having a certified dog, in both the short and long terms, were divided into positive and negative experiences followed by different of sub-themes and sub-sub themes. Table 12 summarizes the findings. 
Table 12. Themes, sub-themes and sub-sub themes identified in the thematic content analysis.

\begin{tabular}{|c|c|c|}
\hline Themes & Sub-themes & Sub-sub-themes \\
\hline \multirow[t]{4}{*}{ Expectations } & The skills of the dog & $\begin{array}{l}\text { - Alarm for low and high blood sugar levels } \\
\text { - Assistance in everyday life } \\
\text { - Epileptic seizure }\end{array}$ \\
\hline & Security and independence & $\begin{array}{l}\text { - General security } \\
\text { - Specific security }\end{array}$ \\
\hline & The training & $\begin{array}{l}\text { - The importance of the instructor } \\
\text { - The training of the dog } \\
\text { - Support and help to train my dog }\end{array}$ \\
\hline & Overall life changes & \\
\hline \multirow[t]{5}{*}{$\begin{array}{l}\text { Positive experiences at } \\
\text { short-term follow-up }\end{array}$} & Health status & $\begin{array}{l}\text { - Impact on general condition } \\
\text { - Prevents epileptic seizures } \\
\text { - Stable blood sugar levels } \\
\text { - Less anxiety } \\
\text { - Mobility } \\
\text { - I can save my physical resources, it gives } \\
\text { me less pain }\end{array}$ \\
\hline & Being active & $\begin{array}{l}\text { - I'm more active, I have to because of the } \\
\text { dog } \\
\text { - The dog has made it possible for me to be } \\
\text { more active } \\
\text { - No difference }\end{array}$ \\
\hline & Security and independence & $\begin{array}{l}\text { - General security } \\
\text { - Specific security } \\
\text { - I don't have to rely on others } \\
\text { - The environment has been enlarged }\end{array}$ \\
\hline & Social relationships & $\begin{array}{l}\text { - Positive } \\
\text { - No impact at all }\end{array}$ \\
\hline & $\begin{array}{l}\text { The dog is the best thing } \\
\text { that has happened to me }\end{array}$ & - Life changing \\
\hline \multirow{5}{*}{$\begin{array}{l}\text { Negative experiences } \\
\text { at short-term follow- } \\
\text { up }\end{array}$} & Negative attitudes & - Offensive comments \\
\hline & $\begin{array}{l}\text { Limited access to public } \\
\text { places }\end{array}$ & - We are not welcome everywhere \\
\hline & Reduced freedom & - Self-perceived obstacles \\
\hline & Feeling stressed & - Someone else to take care of \\
\hline & The training & \\
\hline \multirow[t]{3}{*}{$\begin{array}{l}\text { Positive experiences at } \\
\text { long-term follow-up }\end{array}$} & Health status & $\begin{array}{l}\text { - Decreased mental illness } \\
\text { - Stable blood sugar levels } \\
\text { - Reduced pain and reduced use of analge- } \\
\text { sics } \\
\text { - Fewer epileptic seizures } \\
\text { - Less drugs }\end{array}$ \\
\hline & Being active & $\begin{array}{l}\text { - My service dog makes my life so much } \\
\text { more active } \\
\text { - Dog exercises - I exercise }\end{array}$ \\
\hline & Security and independence & \\
\hline
\end{tabular}




\begin{tabular}{|c|c|c|}
\hline & Social relationships & $\begin{array}{l}\text { - Positive } \\
\text { - No impact at all }\end{array}$ \\
\hline & Support & - The dog makes it easier \\
\hline & Care & - Someone to cherish \\
\hline & The training & - Good trainers \\
\hline \multirow[t]{3}{*}{$\begin{array}{l}\text { Negative experiences } \\
\text { at long-term follow-up }\end{array}$} & Negative attitudes & $\begin{array}{l}\text { - Other people's lack of knowledge about } \\
\text { these dogs }\end{array}$ \\
\hline & $\begin{array}{l}\text { Limited access to public } \\
\text { places }\end{array}$ & - I have had to leave shops \\
\hline & Controlling the dog & $\begin{array}{l}\text { - The dog is hard to control in certain situa- } \\
\text { tions }\end{array}$ \\
\hline
\end{tabular}

\section{Expectations}

The participants' expectations in terms of what a certified dog would contribute were high. They expected the dog to be able to help relieve problems related to their functional or health impairments. They also wanted the dog to make them feel more secure and reduce their dependence on others. Further, the participants hoped that assistance from the dog would change their lives.

The dog brings so much joy and company. I hope he [the dog] will be able to alert me when my blood sugar levels fall out of normal range. That he will be able to trigger my alarm if I go into diabetic coma at home. That he [the dog] can get help if I end up helpless outside my home. (D32)

With help from a physical service dog, I will become more independent and will have the chance to strengthen my self-confidence and become more independent. I believe it will improve my living conditions, I will have a life that is simply better. (P35)

The participants also had expectations on the training itself. They hoped the training course would help them train the dog properly, and that it would mean growth and development for themselves.

\section{Positive experiences}

The participants' perceived experiences responded to their expectations in many ways. Most participants perceived positive effects on their health status. For example, patients with diabetes found that the dog gave them the opportunity to avoid blood sugar spikes and drops. Patients with epilepsy expressed that the dog was able to avert epileptic seizures. The 
participants also felt that they had become more mobile and that the dog prevented anxiety.

Buddy [fictitious dog name given by authors] helps me control my blood sugar levels. It makes it easier for me to keep my blood sugar within the "frames". It is a huge benefit for my health and well-being. I feel better when I'm with my dog and when I have my dog with me. Also, my attitude is better: It works! (D65)

She [the dog] prevents my seizures by warning me in time. (S29)

The participants perceived that they had become more active as a result of the dog. This was due to the dog's need for activities and exercise, but also since the dog enabled them to go outdoors. For participants who used a wheelchair, outdoor activities had also become easier.

He [the dog] makes activities outdoors much easier, especially in the winter when he can help me get through the snow. (P60)

A dog increased the participants' sense of security and independence. The participants also stated that being able to take care of themselves gave them an incredible feeling of freedom. Further, being assisted by the dog was perceived as life changing in many ways. The dog had become their best friend, and having someone to look after had enriched their lives.

\begin{abstract}
Having a physical service dog has meant a new life for me. Before I only thought of the practical things the dog could help me with. The practical things are important, but I had so much more, being outside strengthens the immune system, I became healthier, social contact is easier and I am never alone. (P23)
\end{abstract}

He [the dog] is the best thing that has happened to me. (P2O)

The participants also stated that the dog had given them the opportunity to make new friends. In addition, they felt that they interacted more with people in general. The same positive experiences of the dog were generally highlighted in the long-term follow-up. The dog was still seen as a great support, and they found it meaningful to have someone to look after. The dog had no impact on their owner's social interactions and opportunities to exercise if this was not perceived as a problem before having a dog. 


\section{Negative experiences}

Before the training, none of the participants expected anything negative to come out of training a service or hearing dog. However, in both the short and long terms the participants brought up negative experiences relating to the dog. The most common negative experiences were restrictions on bringing the dog into public places and negative comments from other people which were perceived as offensive.

Since service/hearing dogs are so important for those of us with various disabilities, it is necessary to have a more open society that allows us to bring the dog everywhere, for example to restaurants, into shops, etc. (H1)

The only negative experience is the inaccessibility when I can't bring him with me. (P61)

Not being able to give the dog enough exercise was perceived as stressful. In addition, the participants sometimes felt that the dog gave them reduced freedom due to situations where they perceived the dog as an obstacle.

Limited social situation. Can't visit allergic friends etc.

(D300)

Some participants also said that they had to travel long distances to participate in the training course. They also wished that the training had been more tailored to their previous knowledge. The training course was perceived as very time-consuming, and had infringed on one of the participant's job. At the long-term follow-up, the participants also stated that the dog made the house dirty and that the dog caused greater wear on furniture, clothes, etc. Other negative experiences brought up at the long-term follow-up were in line with what was mentioned at the first follow-up.

\section{Paper III - Cost-effectiveness of having a physical service dog and a diabetes alert dog}

The analysis shows that, over a time horizon of ten years, owners of both physical service and diabetes alert dogs use less resources in terms of healthcare and informal care, and that their productivity loss is reduced compared to owners of a regular companion dog, Table 13. Owners of a diabetes alert dog also use fewer municipal services. 
Table 13. Costs divided into different categories for certified dog owners and regular companion dog owners. The costs are estimated over a ten-year time horizon.

\begin{tabular}{lrrr}
\hline & Certified dog & Regular companion dog & $\begin{array}{r}\text { Certified dog - regu- } \\
\text { lar companion dog }\end{array}$ \\
\hline Physical service dog & & & \\
\hline Costs (USD) & 72,804 & 84,394 & $-11,590$ \\
\hline Healthcare costs & 431,484 & 421,479 & 10,005 \\
\hline Municipal services & 40,909 & 45,068 & $-4,159$ \\
\hline Informal care & 622,396 & 632,399 & $-10,004$ \\
\hline Productivity loss & 16,536 & 13,740 & 2,796 \\
\hline Dog & $1,184,128$ & $1,197,080$ & $-12,952$ \\
\hline \multicolumn{1}{|l}{ Total costs } & & & $-13,118$ \\
\hline Diabetes alert dog & & & $-1,422$ \\
\hline Costs (USD) & 76,448 & 89,566 & $-4,098$ \\
\hline Healthcare costs & 31,926 & 33,348 & $-3,523$ \\
\hline Municipal services & 18,720 & 22,818 & 2,796 \\
\hline Informal care & 269,658 & 273,181 & $-19,365$ \\
\hline Productivity loss & 16,536 & 13,740 & \\
\hline Dog & 413,288 & 432,653 & \\
\hline Total costs & & & \\
\hline
\end{tabular}

Compared to a regular companion dog, a physical service dog results in both lower costs [-6,00o USD] and a gain in QALYs [0.28]. Similar results apply for a diabetes alert dog [-4,500 USD, o.06 QALYs]. As a result, both physical service dogs and diabetes alert dogs are dominant alternatives, see Table 14 .

Table 14. Cost-effectiveness of a physical service dog and a diabetes alert dog compared to a regular companion dog.

\begin{tabular}{|c|c|c|c|c|c|}
\hline & Costs (USD) & $\begin{array}{l}\Delta \text { Cost } \\
\text { (USD) }\end{array}$ & QALY & DQALY & $\begin{array}{r}\text { Cost per } \\
\text { QALY } \\
\text { gained }\end{array}$ \\
\hline \multicolumn{6}{|l|}{ Physical service dog } \\
\hline Certified & $1,191,121$ & $-5,959$ & 2.79 & 0.28 & Dominant \\
\hline Regular companion & $1,197,080$ & & 2.51 & & \\
\hline \multicolumn{6}{|l|}{ Diabetes alert dog } \\
\hline Certified & 428,137 & $-4,516$ & 6.26 & 0.06 & Dominant \\
\hline Regular companion & 432,653 & & 6.20 & & \\
\hline
\end{tabular}

The probabilistic sensitivity analysis for physical service dogs and diabetes alert dogs reveals that the results are uncertain, Figure 11 (panels A and C). Investigating the joint distribution of the incremental costs and QALYs shows that a physical service dog is associated with a decrease in costs in 52 percent of the simulations and a gain in QALYs in 87 percent of the simulations. A diabetes alert dog is associated with a decrease in costs 
in 54 percent of the simulations and a gain in QALYs in 57 percent of the simulations. The probability of a physical service dog being cost-effective increases as the threshold increases, Figure 11 (panel B). The probability that a diabetes alert dog will be cost-effective is approximately 55 percent irrespective of the threshold value, Figure 11 (panel D).
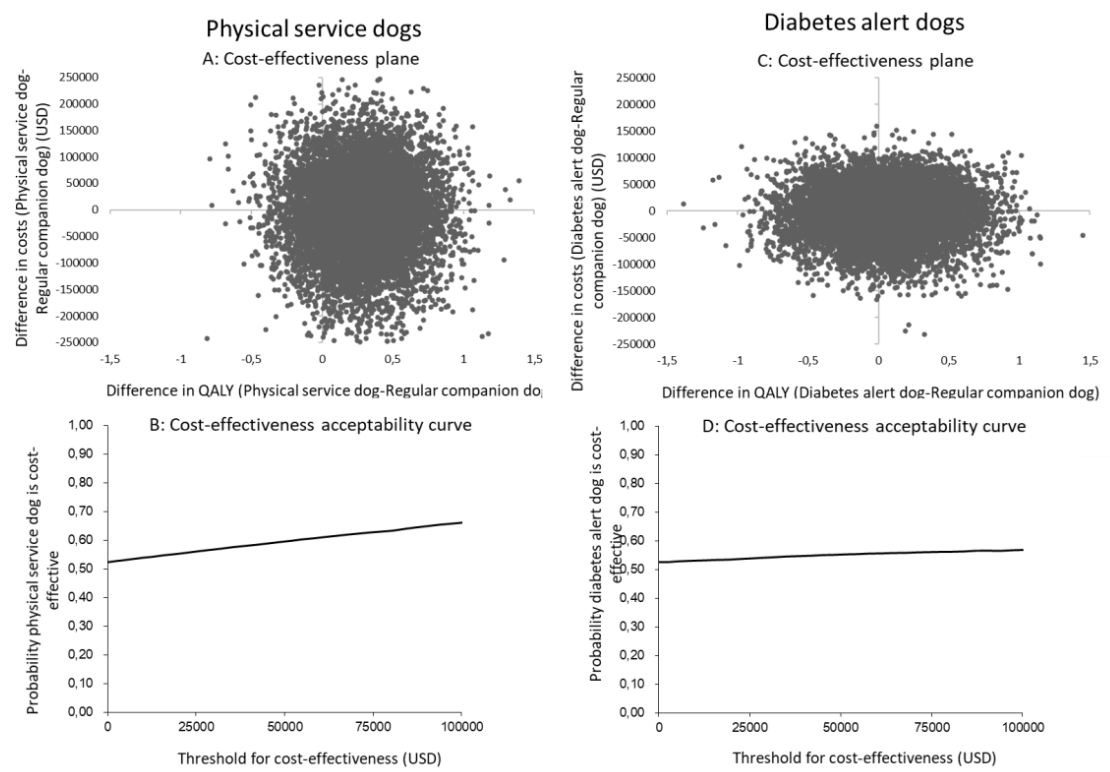

Figure 11. Result of probabilistic analysis for physical service dogs and diabetes alert dogs.

Panels A and C: Cost-effectiveness plane based on 10,000 iterations illustrating the distribution of the ICERs. Panels B and D: Cost-effectiveness acceptability curves showing the probability of a certified physical service dog and diabetes alert dog being cost-effective at different thresholds for cost-effectiveness.

Assuming that owners with a retired physical service dog had a higher resource utilization and suffer from a greater decrease in HRQoL than the base case results gives an incremental cost of approximately 23,000 USD, Table 15. Calculating the cost-effectiveness of a physical service dog from a healthcare perspective gives an ICER of approximately 24,000 USD. None of the deterministic sensitivity analyses change the results for diabetes alert dogs compared to the base case analysis, Table 15 . 
Table 15. Results of sensitivity analyses for physical service dogs and diabetes alert dogs, both in comparison to a regular companion dog.

\begin{tabular}{|c|c|c|c|c|c|c|c|}
\hline \multicolumn{2}{|c|}{ Scenario } & \multicolumn{3}{|c|}{ Physical service dogs } & \multicolumn{3}{|c|}{ Diabetes alert dogs } \\
\hline & & $\begin{array}{l}\Delta \text { Cost } \\
\text { (USD) }\end{array}$ & $\triangle Q A L Y$ & ICER & $\begin{array}{l}\Delta \text { Cost } \\
\text { (USD) }\end{array}$ & $\begin{array}{r}\triangle Q A \\
\text { LY }\end{array}$ & ICER \\
\hline 1 & $\begin{array}{l}\text { Discount rate (cost and } \\
\text { QALYs): } 0 \%\end{array}$ & $-7,519$ & 0.32 & Dominant & $-5,869$ & 0.07 & Dominant \\
\hline 2 & $\begin{array}{l}\text { Discount rate (cost and } \\
\text { QALYs): } 5 \%\end{array}$ & $-5,105$ & 0.26 & Dominant & $-3,779$ & 0.05 & Dominant \\
\hline 3 & Short life span of the dog $\neq$ & $-4,730$ & 0.26 & Dominant & $-3,422$ & 0.05 & Dominant \\
\hline 4 & Long life span of the dogr & $-6,499$ & 0.30 & Dominant & $-4,983$ & 0.06 & Dominant \\
\hline 5 & Dog retires at the age of 8 & $-6,012$ & 0.27 & Dominant & $-4,649$ & 0.05 & Dominant \\
\hline 6 & Dog retires at the age of 12 & $-5,926$ & 0.29 & Dominant & $-4,434$ & 0.06 & Dominant \\
\hline 7 & $\begin{array}{l}\text { Cost increase and HRQoL } \\
\text { decrease for owners with a } \\
\text { retired dog* }\end{array}$ & 5,783 & 0.25 & 22,763 & -420 & 0.00 & Dominant \\
\hline 8 & $\begin{array}{l}\text { Analysis including related } \\
\text { and unrelated costs (all } \\
\text { costs) }\end{array}$ & $-22,913$ & 0.28 & Dominant & $-1,643$ & 0.06 & Dominant \\
\hline 9 & $\begin{array}{l}\text { Purchasing a fully trained } \\
\operatorname{dog}(17,569 \text { USD) }\end{array}$ & $-109,766$ & 0.40 & Dominant & $-21,998$ & 0.08 & Dominant \\
\hline 10 & Healthcare perspective & 6,643 & 0.28 & 23,587 & 1,543 & 0.06 & Dominant \\
\hline 11 & $\begin{array}{l}\text { Societal perspective with- } \\
\text { out productivity losses }\end{array}$ & -170 & 0.28 & Dominant & $-5,209$ & 0.06 & Dominant \\
\hline $\begin{array}{l}* U \\
\ddagger 30 \\
r 10\end{array}$ & $\begin{array}{l}\text { ing an exponential cost increa } \\
\text { percent of the dogs have diec } \\
\text { percent of the dogs have diec }\end{array}$ & $\begin{array}{l}\text { ind expone } \\
\text { the age of } \\
\text { the age of }\end{array}$ & $\begin{array}{l}\text { tial HRQC } \\
1 \\
1\end{array}$ & L decrease & & & \\
\hline
\end{tabular}

In summary, the results from the study indicate that both physical service dogs and diabetes alert dogs are cost-effective for people with a functional or health impairment.

\section{Paper IV - Effects and cost-effectiveness of dog-as- sisted interventions - a systematic review}

The systematic literature review showed that the effects of dog-assisted interventions were inconsistent, and studies assessing the cost-effectiveness of dog-assisted interventions were lacking. In general, the included studies were fraught with numerous obstacles and confounding factors. Despite this, the overall assessment indicated minor to moderate effects of the interventions.

Dog-assisted interventions were applied in four identified conditions: cognitive disorders, psychiatric disorders, stress and mood, and pain.

Cognitive disorders. Studies on cognitive disorders dominated the selected studies [18, 20, 41, 42, 84-86]. In all these studies, the dog-assisted intervention was categorized as an activity. Apart from that, the studies differed in several ways, such as disease severity, number of sessions used for 
the intervention, length of sessions and control group treatments, see Appendix 3. Given these differences, using a dog-assisted activity as a treatment for cognitive disorders in a nursing home setting resulted in some positive effects on health and well-being.

Two of the studies showed that patients who received dog-assisted activities improved in depression-specific instruments [20,42]. Patients who received dog-assisted activities also significantly improved their QoL in two studies [20, 41]. However, the results from one of these studies were confounded by an outbreak of gastroenteritis with subsequent significant decreases in QoL in the comparison group [20]. Further positive effects of dog-assisted activities for patients with cognitive disorders were seen on the Alzheimer's Disease Assessment Scale, showing that the progression of Alzheimer's disease slowed down [85] and the profile of mood states improved [18]. In two studies, the effects of the dog-assisted activity did not differ from the comparative interventions $[84,86]$.

Psychiatric disorders. Three of the included studies investigated the use of dog-assisted interventions in child and adolescent psychiatry [39, 40, 87], and one in adult psychiatry [88]. In all studies, the dog-assisted intervention was categorized as therapeutic, and all studies showed significant reductions in psychiatric symptoms and higher programme adherence.

Improvements in global functioning, school attendance and self-reported emotional-behavioural symptoms were seen in children and adolescents hospitalized at a psychiatry unit for acute mental disorders receiving dog-assisted therapy compared to those receiving standard treatment [40, 87]. Children with ADHD who received a cognitive-behavioural intervention delivered with dog-assisted therapy achieved a greater reduction in the severity of ADHD symptoms compared to children who solely received a cognitive-behavioural intervention [39]. When assessing dog-assisted therapy as an adjunct to, and in comparison with, conventional psychosocial rehabilitation for adult inpatients with schizophrenia, patients receiving dog-assisted therapy had higher adherence to the programme and reduced cortisol levels.

Stress and mood. Six trials studied patients in situations where they were exposed to stress or where their mood could be affected. The dog-assisted intervention was categorized as supportive in four of these trials [8992], and as an activity in two [93, 94]. In summary, significant positive effects were seen in four studies. These findings suggest that dog-assisted support may reduce stress and positively affect the mood.

Receiving dog-assisted support during physical examinations or when undergoing venepuncture reduced children's stress levels [89, 90, 92]. In 
the same situations, positive effects of dog-assisted support were also identified in relation to mean arterial and systolic blood pressure, heart rate, behavioural distress and levels of serum cortisol plasma [89, 92]. Older adults who received a visit that incorporated a dog-assisted activity had a greater decrease in systolic blood pressure and a decrease in heart rate compared to when they received a visit that not was accompanied by a dog [94]. No significant effects were seen when studying dog-assisted support for children undergoing a dental procedure [91]. Further, no effects of a dog-assisted activity were found in adults undergoing non-palliative radiation therapy when the group who received the intervention was compared with one control group who received visits from a human and one where the patients read magazines [93].

Pain. One study examined whether the use of dog-assisted interventions had effects on patients' pain levels after total joint arthroplasty [95]. The intervention was categorized as supportive. Patients in the intervention group reported a significant reduction in pain measured with the visual analogue scale (VAS), compared to the control group [95]. Common to this and the other studies categorized as supportive interventions reporting positive effects, the intervention consisted of few and short sessions. Table 16 summarizes the conditions studied, the intervention type, the outcomes used and the author's conclusions. 


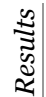

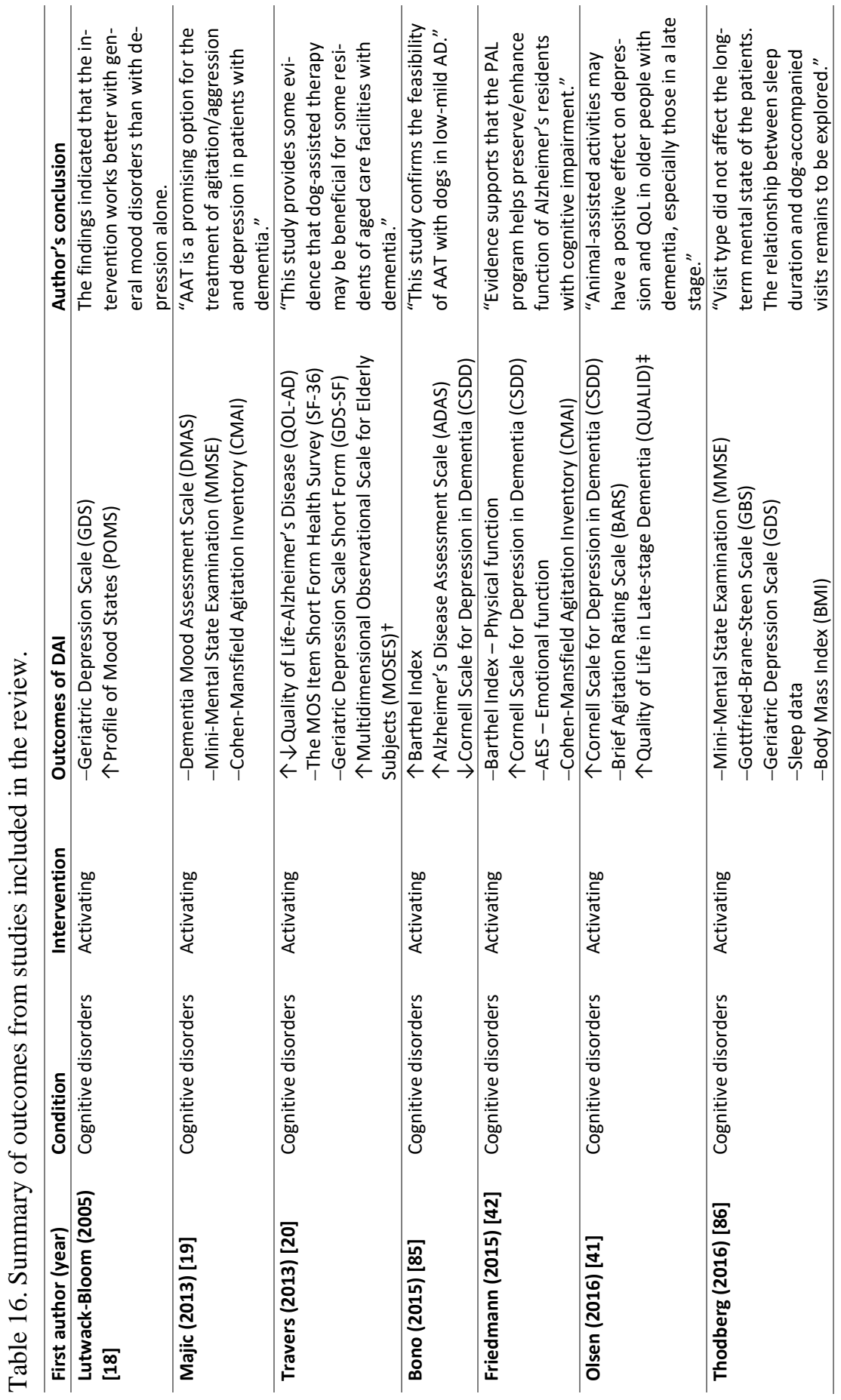




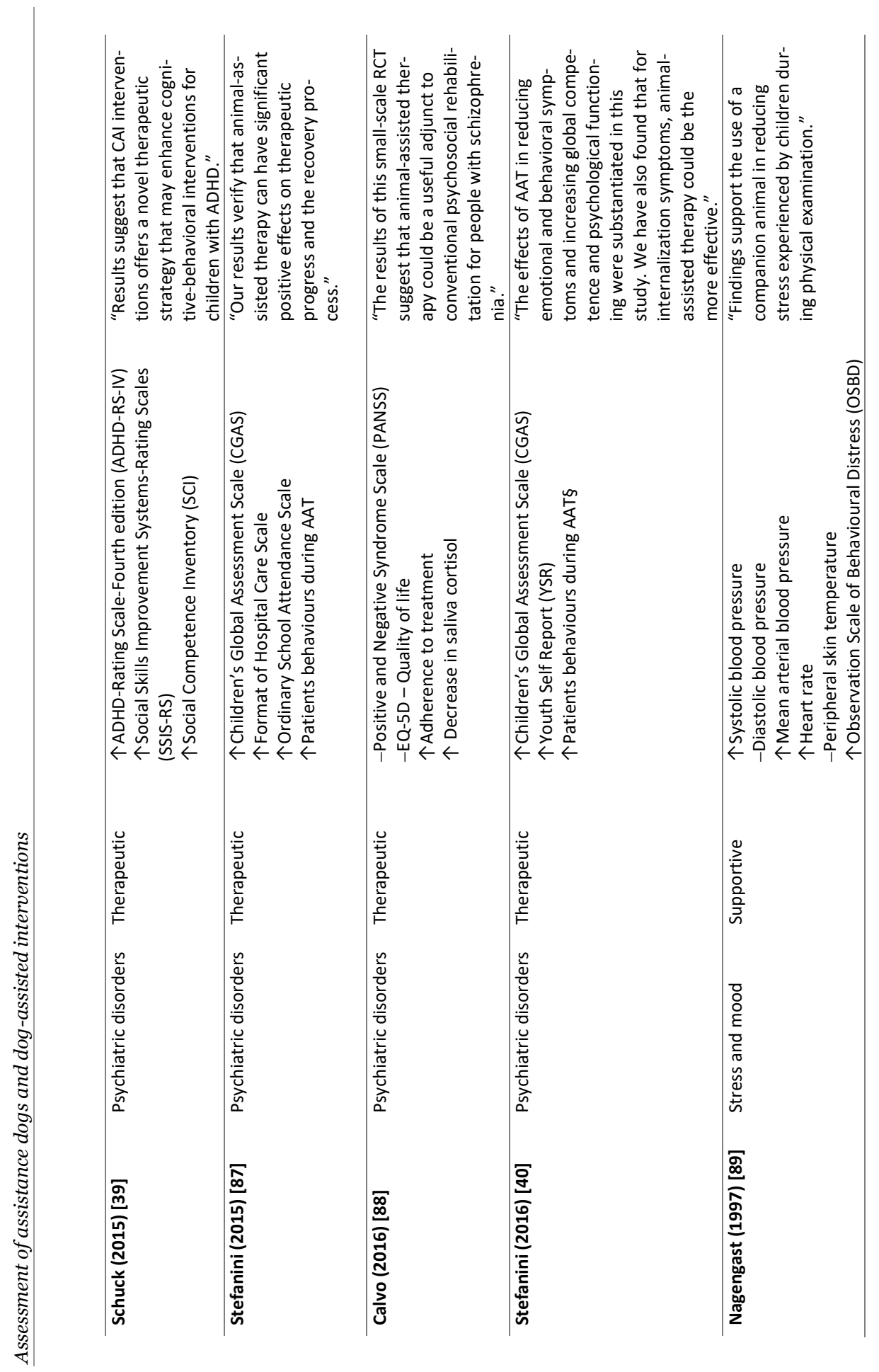




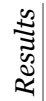

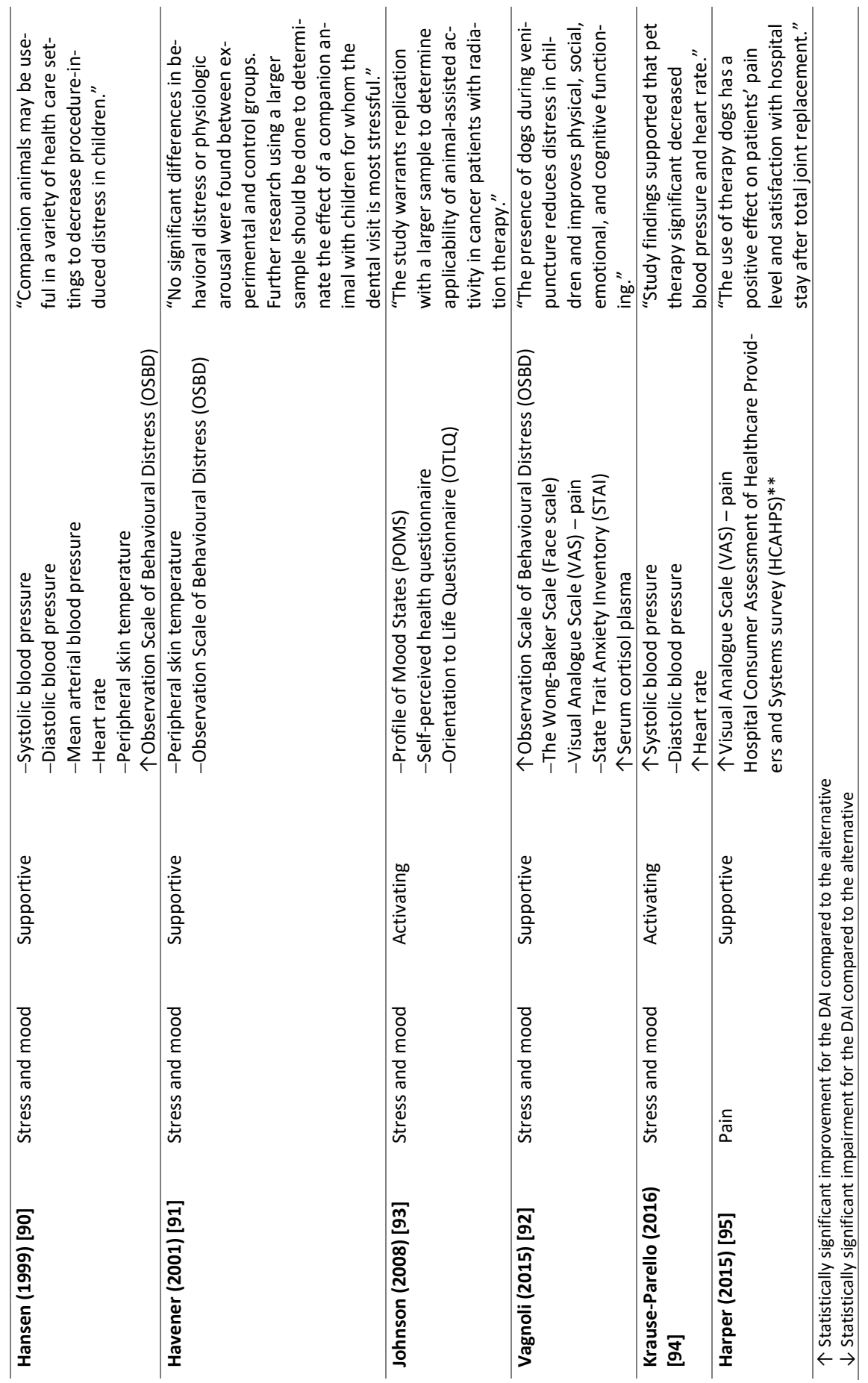




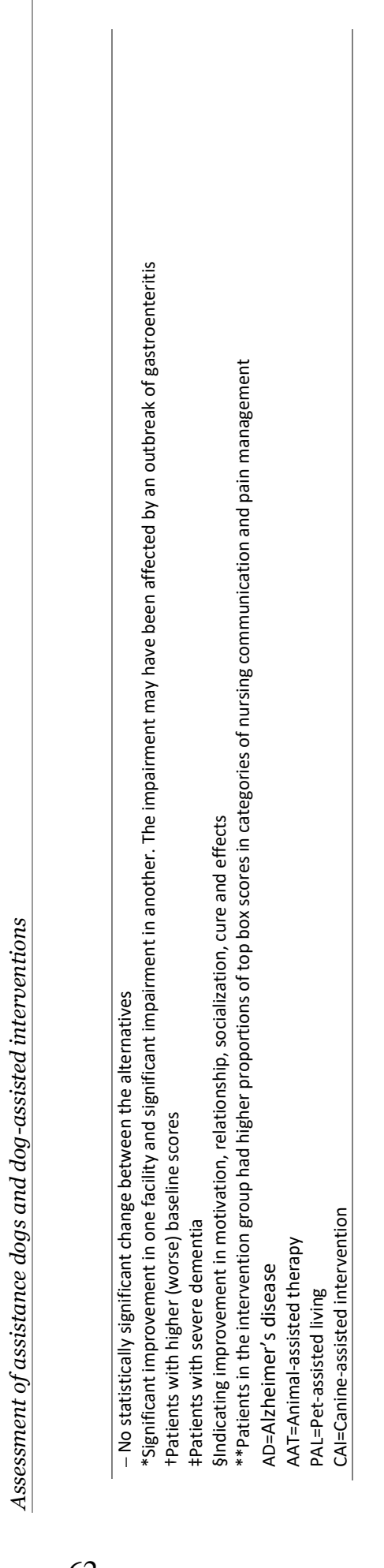




\section{DISCUSSION}

In this thesis, I have explored and evaluated the use and experiences of assistance dogs and dog-assisted interventions.

Initially, I would like to make a reflection regarding the evaluation of a non-medical technology. The HTA approach used in this thesis are not traditionally used in the working dog context, which leads us to the following questions: Is it a good idea to assess working dogs by applying the toolkit commonly used to evaluate medical technologies? Is it suitable? Will the results contribute something of interest? I would answer yes to all of these questions. If implementing assistance dogs and dog-assisted interventions in a healthcare context in general and if prescribing assistance dogs as a supportive aid in particular, it is important for decision-makers to be as informed as possible. Decisions that have implications for the overall performance of the healthcare system need to be informed, otherwise other essential care may be ruled out. So, even though this type of information and analysis is not traditionally requested in the working dog context, I believe it is of great value and necessary to develop methods for this purpose. The latter also leads us to discuss how this thesis has contributed to the field of health economics.

\section{The value of using dogs as assistive aids and in healthcare}

The results presented in paper I showed that there may be positive consequences of having a certified service dog in terms of HRQoL, well-being and activity level. Despite the improvements seen in the results, the HRQoL scores for the study population were considerably lower than the HRQoL data for the general population [66, 67]. The results of the sub-group analyses showed that physical service dog owners had lower HRQoL scores than diabetes alert dog owners. However, the results showed that physical service dog owners benefited more from the dog than diabetes alert dog owners, in terms of HRQoL. Previous studies examining assistance dogs' impact on HRQoL have shown various results. Shintani et al. used the SF36 v2 instrument and found improvements in the role function (RE), physical function (PF) and mental component summary subscales for service dog owners compared to the control group [16]. Hubert et al. studied service dogs' impact on QoL in individuals using wheelchairs and found no significant change between baseline and follow-up [15]. In compliance with 
other studies, the results from our study were uncertain. It is hard to draw firm conclusions when studying small populations without being able to control for confounders. However, the results were consistent. As in our study, a few other studies have also measured the impact of service dogs on their owners' self-esteem. Collins et al. was not able to determine that service dogs had any impact on self-esteem. Allen et al., however, found that individuals with severe ambulatory disabilities experienced improved selfesteem when receiving a service dog [17]. The results of our study also indicated an improvement in self-esteem, but the improvement was not statistically significant. In addition, the participants in our study reported that they had increased the time they spent outside their home and the time they spent on social activities. This was in line with previous research [96, 97]. Further, our participants had improved their well-being and increased their degree of physical activity during leisure time.

In paper II, the dogs were studied based on the owner's expectations and experiences. The participants perceived that the certified dog had positive effects on both their physical and mental well-being. For instance, the participants felt safer and more independent in their everyday life after the dog was certified. The participants also felt that the dog had a positive impact on their health condition. Several people also brought up the fact that the dog was the best thing that had happened to them. Before training the dog, none of the participants expected anything negative to come out of having a certified dog. Even though not everything relating to the dog was positive, none of the participants said it was not worth it. Several of the identified themes in our study are consistent with themes identified in other studies [96, 98, 99]. Camp et al. explored five physical service dog owners' experiences of their dog through an ethnographic approach. The authors concluded that the dogs enhanced independence and contributed to improvements in psychosocial functioning [96]. Rodriguez et al. conducted a cross-sectional open-ended survey. A total of 91 participants were included. In concordance with Camp et al. and our study, they identified psychosocial benefits of having a service dog. The participants perceived that the dog also contributed to drawbacks such as public access, lifestyle adjustments and negative attitudes from other people [98]. Herlache-Pretzer et al. used a qualitative descriptive methodological to identify experiences of having a service dog. Four participants were interviewed. They reported that the dog had a positive impact on their everyday life and that the dog gave them the ability to perform activities independently. Identified challenges were the need to educate people who did not understand the role of a service dog, high expenses associated with the dog and fluctuations in the dog's performance [99]. Both the benefits and the drawbacks identified in the different studies are in line with our results. 
Paper I and paper II contribute to knowledge about the short-term effects and experiences of having a service or hearing dog. Paper III was carried out to take long-term effects and cost-effectiveness into account. Constructing a Markov model made it possible to calculate the long-term costeffectiveness of having a physical service dog or a diabetes alert dog compared to a regular companion dog. The results from the analysis in paper III were consistent. The cost-effectiveness analysis of a physical service dog compared to a regular companion dog showed that a physical service dog is a dominant alternative, i.e. the physical service dogs achieved both lower costs [-6,00o USD] and a gain in QALYs [0.28]. Similar results were achieved when assessing the cost-effectiveness of having a diabetes alert dog compared to a regular companion dog [-4,500 USD, 0.06 QALYs]. When conducting one-way sensitivity analyses, assuming that owners with a retired physical service dog had a higher resource utilization and suffered a larger HRQoL decrement than in the base case analysis and calculating the cost-effectiveness of a physical service dog from a healthcare perspective gave ICERs of 23,000 USD and 24,000 USD respectively. These values are, however, within the range of what is traditionally considered as costeffective based on the rule of thumb. However, as mentioned in the background section, other aspects such as the severity of the condition, uncertainty of results and implications for the overall healthcare budget should also be taken into consideration when making decisions regarding the allocation of healthcare resources. In our cost-effectiveness analysis with statistically uncertain results, those other aspects should be considered when making policy decisions on whether or not to publicly fund service and hearing dogs. Since the participants in our study reported a HRQoL that was remarkably low compared to the general population [66] the severity of the condition is worth highlighting in the discussion of this thesis as well. For example, at baseline the mean EQ-5D single index value of owners of physical service dogs was 0.266 and at the first follow-up 0.351. These are below the EQ-5D single index values reported for a range of different disease groups (diabetes, depression, hypertension, ischemic heart disease, stroke, asthma, low back pain) in the general population in Sweden [100]. To our knowledge, this was the first attempt to analyse the cost-effectiveness of having a physical service dog or a diabetes alert dog, and further research is in the pipeline. Wester et al. have recently published a study protocol with the intention to study the cost-effectiveness of seizure dogs for people with medically refractory epilepsy in the Netherlands [101].

The compilation of studies exploring the effects of DAIs conducted in paper IV showed that there were substantial differences in terms of where dog-assisted interventions were applied. Further, firm conclusions regarding the effects of dog-assisted interventions based on the review are hard 
to draw and studies of cost-effectiveness are lacking. However, some promising results were seen. DAIs given for therapeutic purposes were positive in the treatment of psychiatric disorders for both young and adult patients. Further, DAIs given as activities had some positive effects on health and well-being. In addition, DAAs had effects on depression and QoL for patients with severe cognitive disorders. The review also identified DAIs given as support. These interventions seemed to have positive effects on patients' stress and mood. Previous systematic reviews were in line with the results presented in our review. They showed that the use of DAIs in healthcare settings had some evidence of patient benefits [102-104]. Berry et al. reviewed the use of therapy dogs for children with autism spectrum disorders, and based on four studies they concluded that the use of DAIs is encouraging but that additional research is needed [105]. O'Haire also studied patients with autism spectrum disorders. Out of fourteen included studies, seven involved dogs. These studies showed positive effects of DAIs, but they were all connected with methodological weaknesses [103]. Most reviews included a mix of animals and focused on a single condition or a specific population. This makes the inclusion of articles studying the effects of DAIs stricter and thereby the limits the possibility to compile and assess the effects of these interventions. Unlike previous reviews, our review was not limited to studying a specific condition, but only included results based on interventions using dogs as the assisting animal.

\section{Methodological discussion}

The study design used in the Service and Hearing Dog Project is a topic for discussion due to its known methodological weaknesses [106]. The prepost design (also referred to as a single-arm trial) means that a target group of individuals is given an intervention and then followed over time. The patients serve as their own controls, comparing data from before the intervention with data from after the intervention. The most frequently discussed limitation, and probably the most important, is the lack of control group and thereby the lack of opportunities to control for confounders. This makes it difficult to determine whether observed effects arise as an effect of the intervention, a placebo effect, the natural course of the disease or other time-varying factors, or whether those who are included in the study are representative of the target population [106, 107]. The observed effects can also occur due to the Hawthorne effect. The Hawthorne effect arises when participants change their behaviour when observed. As a result, the researcher needs to interpret the effects of single-arm studies with caution [106]. The main reason for using this design in our study was that the target group was limited and it was thereby difficult to find enough participants for a control group. The overall aim of the Service and Hearing Dog Project 
was to increase the number of certified dogs which meant that all eligible participants were offered the intervention. The pre-post design was therefore deemed to be the best and perhaps the only way to implement the project. Due to the weaknesses of the study design, the results should be interpreted with care.

The method used to gather data in the project also needs to be discussed, since self-reported data can contribute to uncertainty in the data. Data collection based on patient recall is a common method used in many trials [108]. A commonly mentioned advantage of this method is the possibility to tailor questionnaires to request specific information. Data from medical records regarding resource utilization rarely contains all the data necessary to conduct an economic analysis from a societal perspective [52, 109]. In addition, the use of questionnaires allows the researcher to control the data [52]. It can be difficult to access data extracted from medical records in a timely and cost-effective manner, and the researcher has to rely on a third party to be granted access [109]. Furthermore, a questionnaire is a relatively cheap way to gather data. However, there are also disadvantages of using self-reported data collection. The answers can become distorted or biased due to inaccurate recall. In the literature, it is stated that the time period is crucial for patients' ability to remember their healthcare consumption [52]. Six months or less has been deemed appropriate to remember frequent utilization [53, 54]. To minimize the recall bias, we limited the recall period to three months. Three months was considered to be an entirely reasonable time for the participants to remember their healthcare consumption accurately. The choice of method for collecting the data also matters. By using diaries that participants complete on a daily basis, it is possible to reduce recall bias [110]. On the other hand, using questionnaires has been shown to give a higher response rate [111]. Comparing the methods, the use of questionnaires has been showed to be equivalent to diaries for recall periods of up to six months [110]. Both approaches have pros and cons, and there is insufficient evidence to favour one of the approaches [111]. As stated in the methods section, we used postal questionnaires instead of diaries when collecting parts of the data. In addition, we conducted telephone interviews. Regardless of which data collection method is favoured, using a combination of telephone questionnaires and postal questionnaires was very successful in our study in terms of response rates. There were hardly any missing values at all for the participants who completed the study.

To study service and hearing dog ownership from a broad perspective, we used several different methods. In paper I, a number of generic instruments were used to explore the potential effects of having a certified dog. Using both EQ-5D and RAND-36 to measure HRQoL was considered to give a more holistic view of the participants' HRQoL. Today, these are the 
two most commonly used patient-reported outcome measures for measuring HRQoL, both nationally and internationally. However, they differ regarding both the health state descriptions and the methods used to infer societal values. The fact that the EQ-5D-3L only contains five dimensions with answers on a three-level scale may reduce the instrument's responsiveness [112]. It was therefore considered interesting to include RAND-36 as well. Further, while some of the dimensions are conceptually similar, others are different. For example, RAND-36 contains attributes for role limitation, social functioning and vitality [6o, 113]. These are not represented in the EQ-5D. We also chose to present the SF-6D score. Disparities seen between the EQ-5D and the SF-6D measures usually depends on variations in the health state descriptive system and scoring algorithm [114]. It has also been shown that EQ-5D is more sensitive to health gains for patients with severe conditions and the SF-6D more sensitive to health gains for patients with mild conditions. In addition to the HRQoL measurements, we also chose to present other outcomes, such as well-being and self-esteem. Our intention with these instruments was to capture other aspects of service and hearing dog ownership that could not be captured in the HRQoL instruments, and since the study aim was to describe and explore the consequences of having a certified service or hearing dog, this was considered to be justified. In summary, it is interesting to look into different outcome measures and thereby make the results from our study comparable with other studies using different outcome measures. A thematic content analysis was used to gain a deeper understanding of service and hearing dog ownership. One limitation associated with open-ended questions is the potential influence of the question design on the participants' answers [71]. In our study, the participants had the opportunity to add aspects other than those asked about in the questions, thus reducing the risk for this influence. Secondly, an inductive approach was used when analysing the data. This requires the researcher to process the data without any preconceptions [71]. To reduce this risk, the answers were separated from the questions. The analysis was also reviewed by the research group in order to ensure that all potential themes had been identified.

In paper III, a decision analytic model was used to estimate the longterm effects of physical service dogs and diabetes alert dogs. Although the extrapolation increases the relevance of the results for decision-making, it also introduces more uncertainty [26]. Using three-month data when modelling a time horizon of ten years will make the results uncertain. Like other models, our model contained assumptions and simplifications. To minimize the uncertainty, the analysis was built upon conservative assumptions. The impact of uncertainty was studied using sensitivity analyses. These analyses studied both the parameter (statistical) uncertainty and the 
model uncertainty. The methods used to study uncertainty are widely accepted within the field and will generate information about uncertainty in connection with implementing certified dogs [26]. The comparator used in the model was having a regular companion dog. This was determined to be the best option in order to solely evaluate the cost-effectiveness of certification. This could also be the most conservative comparator design. The effect of having a certified dog would probably be greater if the owner went from not having a dog at all to being assisted by a certified dog. This would be the case when the owner obtained a fully trained dog. Obtaining a fully trained dog is, however, a more costly alternative. We conducted a sensitivity analysis accounting for the costs of a fully trained dog. This did not affect the results, but since the other data was not based on a fully trained dog in comparison to not having dog at all, this analysis should only be seen as a first attempt at evaluating a fully trained dog. Further, in our base case analysis we only included healthcare utilization that the participants reported as being related to the reason for having a dog. This may have introduced uncertainty into our analysis, as it may be difficult to draw a strict distinction between healthcare utilization that is related versus unrelated to the reason for having a dog. Testing whether it affected the results was therefore carried out via a one-way sensitivity analysis. The analysis showed that this had no effect since the differences between the related and unrelated healthcare utilization were small. Another interesting methodological aspect of our model is the incorporation of two mortality rates for two different species: one for humans (owners) and one for dogs. This is an exclusive scenario. The dog's mortality rate has an indirect impact on both the owner's HRQoL and costs. The effects of the dog's own gained or lost QALY were excluded from the analysis.

A systematic review is used to summarize knowledge about a specific topic. The specific methodology of a systematic review is constructed to make it replicable and to minimize the risks of bias in all steps of the process. However, there are potential biases that should be considered during the process and when interpreting the results. In our review, a number of potential biases were identified. Studies included in the review were associated with methodological weaknesses. The samples were small, there were difficulties with randomization, and it was thereby hard to control for confounding factors. Due to the methodological weaknesses identified in the included studies, it is hard to draw firm conclusions from the review. Besides methodological weaknesses with the studies included in the review, the review itself had limitations. Firstly, the conclusions were based on only 18 studies. The limited number of included studies may depend on to strict inclusion criteria applied by the research group. Further, not including studies with fewer than 20 participants may have contributed to us excluding studies that could have been judged to be of at least moderate 
quality. In addition, we only included articles from peer-reviewed journals in full-text English. As stated initially, the limitations mentioned above are known drawbacks with a systematic review. Hence, to reduce these drawbacks we followed the PRISMA guidelines throughout the review process. The transparency of the process also makes it possible to replicate the review, which increases its trustworthiness.

As has been noted, several different methods have been used in this thesis to study the effects, experiences and cost-effectiveness of assistance dogs and dog-assisted interventions. I consider using a mixed method approach when studying a non-medical technology used by a complex patient population to be a strength. However, there is an ongoing debate regarding the compatibility versus the incompatibility of quantitative and qualitative methods [71]. A main argument for the methods not being appropriate to mix is the differences in their philosophical and methodological origins [71]. By contrast, these differences are also an argument for bringing them together. Further, it has been argued that a researcher within the field of health economics needs to be aware of ontological, epistemological and methodological issues when incorporating qualitative methods in their research [115]. As a health economist, I am interested in both quantitative and qualitative research, and using different methods within the field can be both useful and appropriate [115]. Since I am more interested in addressing the most appropriate research method to answer my research questions than my degree of philosophical coherence associated with the different research methods I will take the position of being a pragmatist [71]. Taking this view, quantitative and qualitative methods are not seen as competing or contradictory.

\section{My reflections}

The idea for this thesis arose during the Service and Hearing Dog Project. The project took a total of five years to complete. Initially, parts of the results were presented in a report published by the National Board of Health and Welfare [116]. At the same time, the research group also presented the results in the report to the client, the Ministry of Health and Social Affairs. The presentation of the results coincided with a parliamentary crisis in 2014. Whether that, or something else, was the reason why the project did not result in any action is hard to say. The Service and Hearing Dog Project had no immediate impact on Swedish policy. One change that has taken place since the project was completed is the introduction of an organization for coordination and quality assurance of the assistance dogs training and certification. Previously, the most important actor in the service dog market was a non-profit organization. Today, the Swedish Agency 
for Participation (MFD) has contracted the Swedish Working Dog Association (SBK) to control and assess the quality of service and hearing dogs and their training until the end of 2020 [142, 67]. Which organization will maintain the support function from 2021 onwards is unknown at the time of writing. The control over the training and certification of service and hearing dogs has thereby been centralized. However, no decision has been made regarding financing and subsidization at national level. Nor is there any policy decision on the role of dogs in Swedish healthcare and who should have access to service dogs. The absence of national guidelines regarding service and hearing dogs as a supportive aid may contribute to differences between Swedish regions and municipalities. Some regions and municipalities prescribe and subsidize dogs while others choose not to. By extension, this can lead to regional inequity. The project's meagre contribution to influencing Swedish policy was one reason for conducting further research on service and hearing dogs. It also increased the interest of looking into the effects and cost-effectiveness of dog-assisted interventions. The research presented in this thesis brings the use of working dogs in a healthcare context to light. Although the results are uncertain to some degree, they are consistent.

The research presented in this thesis also contributes to the field of health economics. It shows that it is appropriate to carry out an economic evaluation of a non-medical technology. These types of interventions also need to be evaluated if they are under consideration for public funding, or are already publicly funded. The thesis contributes to making health economists aware of the importance and relevance of combining quantitative methods with qualitative methods when evaluating a technology that is not typically evaluated within the field of HTA. When little is known about a new technology or if the technology studied is rare or complex, quantitative findings can be enriched by qualitative findings. In this thesis, paper II adds information that reinforces the positive effects of the dog. The experiences that the participants described can thereby reduce the uncertainty in the input parameters used in the cost-effectiveness analysis to some degree. Paper II also reduces the uncertainty in the long-term extrapolation, since the participants' long-term experiences suggest that the effects of the dog are long-lasting. An additional positive aspect of the qualitative analysis is the possibility to identify values that are not captured in our other studies. The value of having someone to care for was an aspect and effect of the dog that was highlighted in paper II. It is a value that I believe was not captured when using standardized instruments, and therefore is not included in our cost-effectiveness analysis. Further, the research presented in this thesis also raises awareness of something interesting. In the simulation model, which assesses the cost-effectiveness of physical service dogs and diabetes alert dogs, mortality rates for two different species need to be 
included. To my knowledge, this has not been done before. As mentioned previously, the dog's mortality rate had an indirect impact on both the owner's HRQoL and costs, but the dog's own gained or lost QALYs were excluded from the analysis. It would be interesting to see how including these would affect the analysis.

In future research, to increase knowledge about the use of assistance dogs, it would be valuable to conduct studies focusing exclusively on the different assistance dog subgroups. Studying larger samples of these subgroups could increase knowledge about which individuals benefit the most from being assisted by these dogs. In addition, it would be interesting to map how prescriptions and subsides for assistance dogs could be managed in Sweden. One possible way to generate further input about this would be to study how this is done in other countries. It would also be interesting to study dogs trained by the owner in collaboration with a certified instructor contra professionally trained dog. In Sweden, the most common way to receive a service or hearing dog is to train the dog in collaboration with a certified instructor. To my knowledge, this is not the case elsewhere. In addition, research has shown that owners of a service dog who are professionally trained experienced less burden than those who had trained a dog themselves [117]. It would be interesting to find out whether this is also the case in Sweden and, by extension, to study the effects and cost-effectiveness of instructor-trained service and hearing dogs. Regarding dog-assisted interventions, to further increase knowledge, studies need to be conducted beyond the pilot research phase, using larger samples and adequate control groups.

Finally, as mentioned in the introduction, approximately 90 trained assistance dogs other than guide dogs currently provide supportive aid in Sweden. This number is probably lower than it could be because owners have to find a way to pay for the training themselves. To view this number in relation to how many people have the potential to benefit from a trained assistance dog, we have roughly estimated the potential need for the two most commonly used assistance dogs: physical service dogs and diabetes alert dogs. According to Statistics Sweden (SCB), 158,000 people between 16-64 years have an impairment which interferes with or limits their mobility [118]. In addition, approximately 3,00o people have type 1 diabetes that is hard to manage [119]. Of these, approximately 18 percent have a pet allergy [120] and 10 percent have a fear of dogs (cynophobia) [121], and an assistance dog would therefore not be appropriate for them. We can also assume that an additional 50 percent would not be interested in having a dog for other reasons. Our rough estimate results in a figure of 60,000 people who could benefit from a physical service dog or a diabetes alert dog. Comparing this figure with the 90 trained dogs in service today suggests that there is need of more assistance dogs in Sweden. Looking at the results 
from the studies included in this thesis, society would probably benefit from having more wagging tails in assistance roles. 


\section{CONCLUSIONS}

Specific conclusions for studies I-III relating to the use of service and hearing dogs:

- The target group for service and hearing dogs has an overall low health-related quality of life compared to the general population, especially among owners of physical service dogs.

- Being assisted by a service or hearing dog may have had a positive impact on the owner's health-related quality of life, well-being and activity level.

- Asking service and hearing dog owners about their expectations before having a trained dog and their experiences after the dog was certified highlighted both positive and negative aspects of ownership. They felt that the dog had a positive impact on their health status and gave them ability to be more independent and active, but in particular they perceived the dog to be an invaluable source of help in their everyday life. Drawbacks of service and hearing dog ownership included restrictions regarding public access and other people's negative attitudes towards the dog.

- Our model-based long-term cost-effectiveness analysis showed that physical service dogs and diabetes alert dogs used by individuals with a functional impairment and/or a health impairment are costeffective.

Specific conclusions for study IV related to dog-assisted intervention performed in a healthcare setting:

- The systematic literature review of studies estimating the effects and cost-effectiveness of dog-assisted interventions showed that there are substantial differences in terms of how and to whom the interventions are applied.

- An assessment of the studies indicates minor to moderate effects of dog-assisted interventions conducted for therapeutic purposes for patients with psychiatric conditions. Further, dog-assisted interventions given as activities indicate minor to moderate effects for patients with cognitive disorders, and dog-assisted interventions given as support indicate minor to moderate effects on the patient's stress and mood when carrying out different types of medical interventions. Studies assessing the cost-effectiveness of dog-assisted interventions are lacking. 
- Further studies using larger samples with adequate control groups are needed to move beyond the pilot research phase and thereby establish firm conclusions about dog-assisted interventions.

General conclusions:

- This work provides an insight into the possibility of performing a proper health economic evaluation of a non-medical technology.

- It shows that combining quantitative and qualitative methods when evaluating a technology that is not typically evaluated within the field is beneficial. 


\section{REFERENCES}

1. Driscoll CA and Macdonald DW. Top dogs: wolf domestication and wealth. Journal of Biology, 2010. 9(2): p. 10.

2. Aboul-Enein BH, et al. The 1925 Diphtheria Antitoxin Run to Nome Alaska: A Public Health Illustration of Human-Animal Collaboration. J Med Humanit, 2019. 40(3): pp. 287-296.

3. History. Assistance Dogs: Learning New Tricks for Centuries. https://www.history.com/news/assistance-dogs-learning-newtricks-for-centuries. Accessed February 10, 2020.

4. International Guide Dog Federation. History of Guide Dogs. https://www.igdf.org.uk/about-us/facts-and-figures/history-ofguide-dogs/. Accessed February 10, 2020.

5. Nationalencykolpedin Ab. Ledarhund. https://www.ne.se/uppslagsverk/encyklopedi/l\%C $3 \%$ A5ng/ledarh und. Accessed February 10, 2020.

6. Assistance Dogs International. Types of Assistance Dogs. https://www.assistancedogsinternational.org/about-us/types-ofassistance-dogs. Accessed January 10, 2018.

7. National Education for Assistance Dog Services. The History of the Service Dog, Part II - From the Seeing Eye to hearing, mobility and autism service dog.

https://assistancedogs.wordpress.com/2013/08/06/the-historyof-the-service-dog-part-ii-celebrating-international-assistance-dogweek/. Accessed February 10, 2020.

8. Bergh ÅT. Civila tjänstehundar: en bok om hundar i konkret mänsklig tjänst. 2006: Eget bevåg.

9. Myndigheten För Delaktighet. Uppföljning stödfunktion assistanshundar 2019. Årsredovisning stödfunktion 2019, 2020.

10. Alliance of Therapy Dogs. Whats is the difference between a therapy dog vs a service dog? https://www.therapydogs.com/differencetherapy-dog-vs-service-dog/. Accessed March 9, 2018.

11. Fine AH. Handbook on animal-assisted therapy: foundations and guidelines for animal-assisted interventions. Fifth ed. 2019: Academic Press

12. Hallgren A. Hunden i våra hjärtan och i vårt samhälle. 1989: ICAförlaget $\mathrm{AB}$.

13. Skandinavika Vård- och Terapihundsföreningen. Utibildare anslutna till skandinaviska vård- och terapihundsföreningen. http://svth.se/utbildare/. Accessed May 28, 2020.

14. Drummond M, et al. Methods for the Economic Evaluation of Health Care Programmes. Third ed. 2008: Oxford University Press, Oxford. 
15. Hubert G, et al. Effect of service dogs on manual wheelchair users with spinal cord injury: a pilot study. J Rehabil Res Dev, 2013. 50(3): pp. 341-50.

16. Shintani M, et al. The effect of service dogs on the improvement of health-related quality of life. Acta Med Okayama, 2010. 64(2): pp. 109-13.

17. Allen K and Blascovich J. The value of service dogs for people with severe ambulatory disabilities. A randomized controlled trial. JAMA, 1996. 275(13): pp. 1001-6.

18. Lutwack-Bloom $\mathrm{P}$, et al. Effects of pets versus people visits with nursing home residents. Journal of Gerontological Social Work, 2005. 44(3/4): pp. 137-159.

19. Majić T, et al. Animal-assisted therapy and agitation and depression in nursing home residents with dementia: A matched case control trial. American Journal of Geriatric Psychiatry, 2013. 21(11): pp. 1052-1059.

20. Travers $\mathrm{C}$, et al. An evaluation of dog-assisted therapy for residents of aged care facilities with dementia. Anthrozoös, 2013. 26(2): pp. 213-225.

21. World Health Organization. Health technology assessment Definitions. https://www.who.int/health-technologyassessment/about/Defining/en/. Accessed February 18, 2020.

22. European Network for Health Technology Assessment. HTA at the European level. https://eunethta.eu/frequently-asked-questionsfor-the-pharmaceutical-industry/. Accessed February 18, 2020.

23. Byford S and Raftery J. Perspectives in economic evaluation. BMJ (Clinical research ed.), 1998. 316(7143): pp. 1529-1530.

24. Siverskog J and Henriksson M. Estimating the marginal cost of a life year in Sweden's public healthcare sector. The European Journal of Health Economics, 2019. 20(5): pp. 751-762.

25. Svensson M, et al. Reimbursement Decisions for Pharmaceuticals in Sweden: The Impact of Disease Severity and Cost Effectiveness. Pharmacoeconomics, 2015. 33(11): pp. 1229-36.

26. Briggs A, et al., Decision Modelling for Health Economic Evaluation. 2006: Oxford University Press.

27. Doubilet $\mathrm{P}$, et al. Probabilistic sensitivity analysis using Monte Carlo simulation. A practical approach. Med Decis Making, 1985. 5(2): pp. 157-77.

28. Claxton K, et al. Probabilistic sensitivity analysis for NICE technology assessment: not an optional extra. Health Economics, 2005(4): p. 339.

29. Sveriges Ledarhundsförare. Vad är en ledarhund? https://ledarhund.nu/. Accessed January 20, 2020.

30. The Swedish Kennel Club. Assistenthund som hjälpmedel https://www.skk.se/sv/hundagande/fokuspa/assistanshundar/vad-ar-en-assistanshund/. Accessed February 21, 2020. 
31. The Swedish Working Dog Association. Två vägar till assistanshund https://www.brukshundklubben.se/assistanshund/utbildaassistanshund/ Accessed February 13, 2020.

32. The Swedish Working Dog Association. Två vägar till assistanshund. https://www.brukshundklubben.se/assistanshund/utbildaassistanshund/. Accessed March 21, 2020.

33. The Swedish Agency for Participation. Assistance dogs https://www.mfd.se/kunskapsomraden/assistanshundar/. Accessed January 13, 2020.

34. The Swedish Working Dog Association. Personal communication, June 23, 2020.

35. Swedish Association of Local Authorities and Regions. Municipalities and regions.

https://skr.se/tjanster/englishpages/municipalitiescountycouncils andregions.1088.html. Accesssed June 12, 2020.

36. 1177 Vårdguiden. Ledarhundar och assistanshundar.

https://www.1177.se/Ostergotland/behandling--

hjalpmedel/hjalpmedel/olika-typer-av-

hjalpmedel/syn/ledarhundar-och-assistanshundar/. Accessed January 10, 2020.

37. The Swedish Working Dog Association. Info till kommuner \& regioner. https://www.brukshundklubben.se/assistanshund/infotill-kommuner-regioner/. Accessed January 10, 2020.

38. International Association of Human-Animal Interaction Organizations. IAHAIO White Paper 2014 - The IAHAIO definitions for animal assisted intervention and animal assisted activity and guidelines for wellness of animals involved. . http://www.iahaio.org/new/fileuploads/4163IAHAIO\%20WHITE \%20PAPER-\%20FINAL\%20-\%20NOV\%2024-2014.pdf. Accessed February 17, 2017.

39. Schuck SE, et al. Canine-assisted therapy for children with ADHD: preliminary findings from the positive assertive cooperative kids study. J Atten Disord, 2015. 19(2): pp. 125-37.

40. Stefanini MC, et al. The effect of animal-assisted therapy on emotional and behavioral symptoms in children and adolescents hospitalized for acute mental disorders. European Journal of Integrative Medicine, 2016. 8(2): pp. 81-88.

41. Olsen C, et al. Effect of animal-assisted interventions on depression, agitation and quality of life in nursing home residents suffering from cognitive impairment or dementia: a cluster randomized controlled trial. Int J Geriatr Psychiatry, 2016. 31(12): pp. 13121321.

42. Friedmann E, et al. Evaluation of a pet-assisted living intervention for improving functional status in assisted living residents with mild to moderate cognitive impairment: a pilot study. Am J Alzheimers Dis Other Demen, 2015. 30(3): pp. 276-89. 
43. Lundqvist M, et al. Patient benefit of dog-assisted interventions in health care: A systematic review. BMC Complementary and Alternative Medicine, 2017. 17(1).

44. Svenska Terapihundskolan. Hundassisterad terapi. https://terapihundskolan.se/terapihund-vardhundhundassisterad-terapi/. Acessed May 28, 2020.

45. Svenska Terapihundskolan. Hundassisterad aktivitet. https://terapihundskolan.se/besokshund-djurassisterad-aktivitet/. Accessed May 28, 2020.

46. Socialstyrelsen. Hundar i vård och omsorg - Vägledning till gällande regelverk 2014.

47. Astma Och Allergiförbundet. Allergifakta 2016.

48. Polovic N, et al. Dog saliva - an important source of dog allergens. Allergy, 2013. 68(5): pp. 585-592.

49. Nicholas CE, et al. Dog allergen levels in homes with hypoallergenic compared with nonhypoallergenic dogs. American Journal of Rhinology \& Allergy, 2011. 25(4): pp. 252-256.

50. Nicholas C, et al. Dog characteristics and allergen levels in the home. Ann Allergy Asthma Immunol, 2010. 105(3): pp. 228-33.

51. Asthma and Allergy Association. Policy document - Överenskommelse om ledarhundar. https://astmaoallergiforbundet.se/wpcontent/uploads/2016/06/Policydokument---verenskommelseom-ledarhund.pdf, 2017.

52. Franklin M and Thorn J. Self-reported and routinely collected electronic healthcare resource-use data for trial-based economic evaluations: the current state of play in England and considerations for the future. BMC Medical Research Methodology, 2019. 19(1): p. 8.

53. Bhandari A and Wagner T. Self-Reported Utilization of Health Care Services: Improving Measurement and Accuracy. Medical Care Research and Review, 2006. 63(2): pp. 217-235.

54. Ritter PL, et al. Self-reports of health care utilization compared to provider records. Journal of Clinical Epidemiology, 2001. 54(2): pp. 136-141.

55. Federation Cynologique Internationale. FCI breeds nomenclature. . http://www.fci.be/en/nomenclature/. Accessed January 12, 2018.

56. Rintala DH, et al. Effects of assistance dogs on persons with mobility or hearing impairments: a pilot study. J Rehabil Res Dev, 2008. 45(4): pp. 489-503.

57. Dolan P. Modeling Valuations for EuroQol Health States. Medical Care, 1997. 35(11): pp. 1095-108.

58. Hays RD, et al. The RAND 36-Item Health Survey 1.o. Health Econ, 1993. 2(3): pp. 217-27.

59. Orwelius L, et al. The Swedish RAND-36 Health Survey - reliability and responsiveness assessed in patient populations using Svensson's method for paired ordinal data. Journal of PatientReported Outcomes, 2018. 2(1): p. 4. 
6o. Andersson A, et al. Är "RAND-6D" ett alternativ för de nationella kvalitetsregistren. Report from FoU-enheten för närsjukvården. Region Östergötland, 2015.

61. Brazier J, et al. The estimation of a preference-based measure of health from the SF-36. J Health Econ, 2002. 21(2): pp. 271-92.

62. Psychiatric Research Unit MHCNZ, Denmark. WHO-five Well-being Index (WHO-5). https://www.psykiatri-regionh.dk/who5/Pages/default.aspx. Accessed April 4, 2017.

63. Rosenberg M. Society and the adolescent self-image. $3 \mathrm{rd}$ ed. Princeton: Princeton University Press: 1972.

64. Maneesriwongul W and Dixon JK. Instrument translation process: a methods review. Journal of Advanced Nursing, 2004. 48(2): pp. $175-186$.

65. The Public Health Agency of Sweden. National public health survey, Health on equal terms - 2008.

https://www.folkhalsomyndigheten.se/nationellafolkhalsoenkaten/. Accessed March 21, 2017.

66. Burström K, et al. A comparison of individual and social time tradeoff values for health states in the general population. Health Policy, 2006. 76: pp. 359-370.

67. Van Den Berg B. SF-6D population norms. Health Economics (United Kingdom), 2012. 21(12): pp. 1508-1512.

68. Sullivan M, et al. The Swedish SF-36 Health Survey--I. Evaluation of data quality, scaling assumptions, reliability and construct validity across general populations in Sweden. Soc Sci Med. 1995;41(10): pp. 1349-58.

69. Walters SJ and Brazier JE. Comparison of the minimally important difference for two health state utility measures: EQ-5D and SF-6D. Qual Life Res, 2005. 14(6): pp. 1523-32.

70. Ibm Corp. Released 2015. IBM SPSS for Windows, Version 23.o. Armonk, NY: IBM Corp.

71. Ritchie J, et al. Qualitative research practice: A guide for social science students and researchers. Second ed. 2014: SAGE.

72. Braun V and Clarke V. Using thematic analysis in psychology. Qualitative Research in Psychology, 2006. 3(2): pp. 77-101.

73. Södra Regionvårdsnämnaden. Regionala priser och ersättningar för Södra sjukvårdsregionen 2017.

http://sodrasjukvardsregionen.se/avtal-priser/regionala-priseroch-ersattningar-foregaende-ar/. Accessed November 15, 2017.

74. Sydöstra Sjukvårdsregionen. Priser och ersättningar för Sydöstra sjukvårdsregionen 2017.

https://plus.rjl.se/info files/infosida41089/prislista 2017 slutver sion 10 o.pdf. Accessed December 18, 2017.

75. Statistics Sweden (SCB). Average monthly salary, gender and year [dataset].

http://www.statistikdatabasen.scb.se/pxweb/sv/ssd/START AM AMo110 AMo110B/LoneSpridSektorYrkA/table/tableViewLay 
out1/?rxid=7f178888-aooe-4e65-b38d-ca80424de359. Accessed December 18, 2017.

76. Johannesson M, et al. The costs of treating hypertension-an analysis of different cut-off points. Health Policy, 1991. 18(2): pp. 141-50.

77. European Commission Eurostat. Hourly labour costs.

http://ec.europa.eu/eurostat/statistics-

explained/index.php/Hourly labour costs. Accessed October 23, 2017.

78. Statistics Sweden (SCB). Lifetime table 2010-2014, divided into men and women [dataset].

http://webcache.googleusercontent.com/search?q=cache:bfeKo3iq j30J:www.scb.se/Statistik/BE/BE0101/2014A01G/Be0101Livslang dstabeller-14.xlsx+\&cd=1\&hl=en\&ct=clnk\&gl=se. Accessed June 14, 2017.

79. Egenvall A, et al. Mortality in over 350,0oo insured Swedish dogs from 1995-2000: II. Breed-specific age and survival patterns and relative risk for causes of death. Acta Vet Scand, 2005. 46(3): pp. 121-36.

80. Fenwick E, et al. Cost-effectiveness acceptability curves - Facts, fallacies and frequently asked questions. Health Economics, 2004. 13(5): pp. 405-415.

81. Riegelman R. Studying a Study \& Testing a Test: Reading Evidencebased Health Research. 6th ed. Health Sciences Research Commons. United States, North America; 2012.

82. Egger M, et al. Systematic reviews in health care: meta-analysis in context. 2nd ed. London: BMJ Books: 2001.

83. American Veterinary Medical Association (AVMA). Animal-Assisted Interventions: Definitions.

https://www.avma.org/KB/Policies/Pages/Animal-AssistedInterventions-Definitions.aspx. Accessed February 17, 2017.

84. Majić T, et al. Animal-assisted therapy and agitation and depression in nursing home residents with dementia: A matched caseecontrol trial. American Journal of Geriatric Psychiatry, 2013. 21(11): pp. 1052-1059.

85. Bono AV, et al. Effects of animal assisted therapy (AAT) carried out with dogs on the evolution of mild cognitive impairment. Giornale di Gerontologia, 2015. 63(1): pp. 32-36.

86. Thodberg K, et al. Therapeutic effects of dog visits in nursing homes for the elderly. Psychogeriatrics, 2016. 16(5): pp. 289-97.

87. Stefanini MC, et al. The use of Animal-Assisted Therapy in adolescents with acute mental disorders: A randomized controlled study. Complement Ther Clin Pract, 2015. 21(1): pp. 42-6.

88. Calvo P, et al. Animal Assisted Therapy (AAT) Program As a Useful Adjunct to Conventional Psychosocial Rehabilitation for Patients with Schizophrenia: Results of a Small-scale Randomized Controlled Trial. Front Psychol, 2016. 7: pp. 631. 
89. Nagengast SL, et al. The effects of the presence of a companion animal on physiological arousal and behavioral distress in children during a physical examination. J Pediatr Nurs, 1997. 12(6): pp. 323-30.

90. Hansen KM, et al. Companion animals alleviating distress in children. Anthrozoös, 1999. 12(3): pp. 142-148.

91. Havener $\mathrm{L}$, et al. The effects of a companion animal on distress in children undergoing dental procedures. Issues Compr Pediatr Nurs, 2001. 24(2): pp. 137-52.

92. Vagnoli L, et al. Can presence of a dog reduce pain and distress in children during venipuncture? Pain Manag Nurs, 2015. 16(2): pp. 89-95.

93. Johnson RA, et al. Animal-assisted activity among patients with cancer: effects on mood, fatigue, self-perceived health, and sense of coherence. Oncol Nurs Forum, 2008. 35(2): pp. 225-32.

94. Krause-Parello CA and Kolassa J. Pet Therapy: Enhancing Social and Cardiovascular Wellness in Community Dwelling Older Adults. Journal of Community Health Nursing, 2016. 33(1): pp. 1-10.

95. Harper CM, et al. Can therapy dogs improve pain and satisfaction after total joint arthroplasty? A randomized controlled trial. Clin Orthop Relat Res, 2015. 473(1): pp. 372-9.

96. Camp MM. The use of service dogs as an adaptive strategy: a qualitative study. Am J Occup Ther, 2001. 55(5): pp. 509-17.

97. Fairman SK and Huebner RA. Service dogs: A compensatory resource to improve function. Occupational Therapy in Health Care, 2000. 13(2): pp. 41-52.

98. Rodriguez KE, et al. Mobility and medical service dogs: a qualitative analysis of expectations and experiences. Disability and Rehabilitation: Assistive Technology, 2019: pp. 1-11.

99. Herlache-Pretzer E, et al. The Impact of Service Dogs on Engagement in Occupation among Females with Mobility Impairments: A Qualitative Descriptive Study. International Journal of Environmental Research and Public Health, 2017. 14(6): p. 649.

100. Burström K, et al. Health-related quality of life by disease and socioeconomic group in the general population in Sweden. Health Policy, 2001. 55(1): pp. 51-69.

101. Wester V, et al. Evaluating the Effectiveness and Cost-Effectiveness of Seizure Dogs in Persons With Medically Refractory Epilepsy in the Netherlands: Study Protocol for a Stepped Wedge Randomized Controlled Trial (EPISODE). Frontiers in Neurology, 2020. 11(3).

102. Kamioka $\mathrm{H}$, et al. Effectiveness of animal-assisted therapy: A systematic review of randomized controlled trials. Complement Ther Med, 2014. 22(2): pp. 371-90.

103. O'haire ME. Animal-assisted intervention for autism spectrum disorder: a systematic literature review. J Autism Dev Disord, 2013. 43(7): pp. 1606-22. 
104. Maber-Aleksandrowicz S, et al. A Systematic Review of AnimalAssisted Therapy on Psychosocial Outcomes in People with Intellectual Disability. Res Dev Disabil, 2016. 49-50: pp. 322-38.

105. Berry A, et al. Use of Assistance and Therapy Dogs for Children with Autism Spectrum Disorders: A Critical Review of the Current Evidence. Journal of Alternative \& Complementary Medicine, 2013. 19(2): pp. 73-80.

106. Paulus JK, et al. Opportunities and challenges in using studies without a control group in comparative effectiveness reviews. Res Synth Methods, 2014. 5(2): pp. 152-61.

107. Evans SR. Clinical trial structures. Journal of Experimental Stroke \& Translational Medicine, 2010. 3(1): pp. 8-18.

108. Ridyard CH and Hughes DA. Methods for the Collection of Resource Use Data within Clinical Trials: A Systematic Review of Studies Funded by the UK Health Technology Assessment Program. Value in Health, 2010. 13(8): pp. 867-872.

109. Leggett LE, et al. Measuring Resource Utilization: A Systematic Review of Validated Self-Reported Questionnaires. Medicine, 2016. 95(10): p. e2759.

110. Van Den Brink M, et al. Self-reports of health-care utilization: Diary or questionnaire? International Journal of Technology Assessment in Health Care, 2005. 21(3): pp. 298-304.

111. Patsy K, et al., Diaries or questionnaires for collecting self-reported healthcare utilisation and patient cost data? CHERE Project Report No 2O, in Research Reports 2O, CHERE, University of Technology, Sydney. 2003.

112. Registercentrum Sydost. Mätning med $R A N D-36 / S F-36$ and $E Q-5 D$. http://rcso.se/wp-content/uploads/2018/02/M\%C3\%A4tningmed-RAND-36 SF-36-och-EQ-5D.pdf. Accessed July 1, 2020.

113. Cherepanov D, et al. Underlying dimensions of the five healthrelated quality-of-life measures used in utility assessment: evidence from the National Health Measurement Study. Medical Care, 2010. 48(8): pp. 718-725.

114. Grieve R, et al. $S F-6 D$ versus EQ-5D: reasons for differences in utility scores and impact on reported cost-utility. Eur J Health Econ, 2009. 10(1): pp. 15-23.

115. Coast J. The appropriate uses of qualitative methods in health economics. Health Economics, 1999. 8(4): pp. 345-353.

116. Socialstyrelsen. Utvärdering av försöksverksamhet med service- och signalhundar. Socialstyrelsen, 2014.

117. Yamamoto M and Hart LA. Professionally- and Self-Trained Service Dogs: Benefits and Challenges for Partners With Disabilities. Frontiers in Veterinary Science, 2019. 6: pp. 179-179.

118. Statistics Sweden (SCB). Statistik om personer med funktionsnedsättning, tabeller 2016-2017 [dataset]. https://www.scb.se/hitta-statistik/statistik-efteramne/levnadsforhallanden/levnadsforhallanden/undersokningarn 
a-av-levnadsforhallanden-ulf-silc/pong/tabell-ochdiagram/statistik-om-personer-medfunktionsnedsattning/tabeller-2016-2017/. Accessed August 4, 2020.

119. Nationella Diabetesregistret. Statistik från Nationella

Diabetesregistret 2019, Andel HbA1c > 78. www.ndr.nu. Accessed August 4, 2020.

120. Astma Och Allergiförbundet. Allergifakta 2016.

file://C:/Users/marlu41/Downloads/allergiafakta\%202016\%20till \%20webb.pdf. Accessed December 11, 2019.

121. Healthline. What you should know about cynophobia. https://www.healthline.com/health/cynophobia. Accessed July 14, 2020.

122. Sveriges Kommuner och Landsting. Statistik om hälso- och sjukvård samt regional utveckling 2015.

http://webbutik.skl.se/bilder/artiklar/pdf/7585-337-

6.pdf?issuusl=ignore. Accessed November 17, 2017.

123. Sveriges Kommuner och Landsting. Arets jämförelse av KPBnyckeltal 2015 [dataset].

https://skl.se/ekonomijuridikstatistik/statistik/kostnadperbrukare $\mathrm{kpb} /$ aretsjamforelseavkpbnyckeltal.803.html. Accessed November 17, 2017.

124. Holmstrom A and Danielsson C. Special transport services and national special transport services 2015. Sveriges officiella statistik. 2016.

125. The Swedish Association of Service Dogs. Kostnadskalkyl för utbildning [In Swedish]. http://www.soshund.se/kostnadskalkylfor-ekipage-i-utbildning/. Accessed November 15, 2017.

126. The Swedish Association of Service Dogs. Personal communication, November 2, 2014.

127. Crowley-Robinson $\mathrm{P}$, et al. A long-term study of elderly people in nursing homes with visiting and resident dogs. Applied Animal Behaviour Science, 1996. 47(1-2): pp. 137-148.

128. Zisselman MH, et al. A Pet Therapy Intervention With Geriatric Psychiatry Inpatients. American Journal of Occupational Therapy, 1996. 50(1): pp. 47-51.

129. Barker SB and Dawson KS. The effects of animal-assisted therapy on anxiety ratings of hospitalized psychiatric patients. Psychiatr Serv, 1998. 49(6): pp. 797-801.

130. Barker SB, et al. Effects of animal-assisted therapy on patients' anxiety, fear, and depression before ECT. J ect, 2003. 19(1): pp. 38-44.

131. Richeson NE and Mccullough WT. A therapeutic recreation intervention using animal-assisted therapy: effects on the subjective well-being of older adults. Annual in Therapeutic Recreation, 2003. 12: pp. 1-64. 
132. Nathans-Barel I, et al. Animal-assisted therapy ameliorates anhedonia in schizophrenia patients. A controlled pilot study. Psychother Psychosom, 2005. 74(1): pp. 31-5.

133. Prothmann A, et al. Dogs in child psychotherapy: Effects on state of mind. Anthrozoös, 2006. 19(3): pp. 265-277.

134. Cole KM, et al. Animal-assisted therapy in patients hospitalized with heart failure. Am J Crit Care, 2007. 16(6): pp. 575-85.

135. Orlandi M, et al. Pet therapy effects on oncological day hospital patients undergoing chemotherapy treatment. Anticancer Res, 2007. 27(6c): pp. 4301-3.

136. Banks MR, et al. Original study: Animal-Assisted Therapy and Loneliness in Nursing Homes: Use of Robotic versus Living Dogs. Journal of the American Medical Directors Association, 2008. 9: pp. 173-177.

137. Martindale BP. Effect of animal-assisted therapy on engagement of rural nursing home residents. American Journal of Recreation Therapy, 2008. 7(4): pp. 45-53.

138. Braun C, et al. Animal-assisted therapy as a pain relief intervention for children. Complement Ther Clin Pract, 2009. 15(2): pp. 105-9.

139. Chu CI, et al. The effect of animal-assisted activity on inpatients with schizophrenia. J Psychosoc Nurs Ment Health Serv, 2009. 47(12): pp. 42-8.

140. Villalta-Gil V, et al. Dog-Assisted Therapy in the Treatment of Chronic Schizophrenia Inpatients. Anthrozoös, 2009. 22(2): pp. 149-159.

141. Moretti F, et al. Pet therapy in elderly patients with mental illness. Psychogeriatrics, 2011. 11(2): pp. 125-129.

142. Beck CE, et al. The effects of animal-assisted therapy on wounded warriors in an Occupational Therapy Life Skills program. US Army Med Dep J, 2012: pp. 38-45.

143. Dietz TJ, et al. Evaluating animal-assisted therapy in group treatment for child sexual abuse. J Child Sex Abus, 2012. 21(6): pp. 665-83.

144. Marcus DA, et al. Animal-assisted therapy at an outpatient pain management clinic. Pain Med, 2012. 13(1): pp. 45-57.

145. Marcus DA, et al. Impact of animal-assisted therapy for outpatients with fibromyalgia. Pain Med, 2013. 14(1): pp. 43-51.

146. Vrbanac Z, et al. Animal assisted therapy and perception of loneliness in geriatric nursing home residents. Coll Antropol, 2013. 37(3): pp. 973-6.

147. Havey J, et al. The Effect of Animal-Assisted Therapy on Pain Medication Use After Joint Replacement. Anthrozoös, 2014. 27(3): pp. 361-369.

148. Nordgren L and Engstrom G. Effects of dog-assisted intervention on behavioural and psychological symptoms of dementia. Nurs Older People, 2014. 26(3): pp. 31-8. 
149. Barker SB, et al. The effect of an animal-assisted intervention on anxiety and pain in hospitalized children. Anthrozoös, 2015. 28(1): pp. 101-112.

150. Calcaterra V, et al. Post-operative benefits of animal-assisted therapy in pediatric surgery: a randomised study. PLoS One, 2015. 10(6): pp. e0125813.

151. Nurenberg JR, et al. Animal-assisted therapy with chronic psychiatric inpatients: equine-assisted psychotherapy and aggressive behavior. Psychiatr Serv, 2015. 66(1): pp. 80-6. 


\section{APPENDIX 1}

\section{Units costs used in the decision-analytic model.}

\begin{tabular}{|c|c|c|c|}
\hline Parameter & Cost (USD) & Unit & Reference \\
\hline \multicolumn{4}{|l|}{ Health-care costs } \\
\hline Emergency care & 1,250 & Per visit & [74] \\
\hline Ambulance & 378 & Per emergency & \\
\hline Visit to physicians (hospital) & 396 & Per visit & [122] \\
\hline Visit to physicians (health center) & 257 & Per visit & [74] \\
\hline Home visit physicians & 514 & Per visit & {$[74,122]$} \\
\hline Telephone contact physician & 86 & Per call & {$[74,122]$} \\
\hline Visit to nurse & 159 & Per visit & [122] \\
\hline Home visit nurse & 317 & Per visit & [122] \\
\hline Telephone contact nurse & 53 & Per call & [122] \\
\hline Visit to physiotherapist & 124 & Per visit & [74] \\
\hline Home visit physiotherapist & 249 & Per visit & {$[74,122]$} \\
\hline Visit to occupational therapist & 195 & Per visit & [74] \\
\hline Home visit occupational therapist & 391 & Per visit & {$[74,122]$} \\
\hline \multicolumn{4}{|l|}{ Municipal services } \\
\hline Home-help services & 54 & Per hour & {$[122,123]$} \\
\hline Personal assistance & 36 & Per hour & [123] \\
\hline Escort/Accompanying person & 36 & Per hour & [123] \\
\hline Transportation service & 42 & Per trip & [124] \\
\hline Informal care & 9 & Per hour & [75] \\
\hline Sick leave & 42 & Per hour & [77] \\
\hline \multicolumn{4}{|l|}{ Dog } \\
\hline Purchase dog & 1,515 & & Patient survey \\
\hline Dog training & 7,746 & & Patient survey \\
\hline Suitability tests & 193 & & [125] \\
\hline Yellow vest & 94 & & [125] \\
\hline Red vest & 117 & & [125] \\
\hline Annual health declaration & 59 & & [126] \\
\hline Annual certification maintenance test & 88 & & [126] \\
\hline Annual costs* & 1,332 & & Patient survey \\
\hline Purchase a fully trained dog & 17,569 & & [126] \\
\hline
\end{tabular}




\section{APPENDIX 2}

\section{Excluded studies due to low quality with reasons for exclusion.}

\begin{tabular}{|c|c|c|c|}
\hline $\begin{array}{l}\text { Exclu- } \\
\text { sion no. }\end{array}$ & $\begin{array}{l}\text { First author } \\
\text { (year) }\end{array}$ & Title & $\begin{array}{l}\text { Reason for quality rated } \\
\text { low }\end{array}$ \\
\hline 1 & $\begin{array}{l}\text { Crowley-Robinson } \\
(1996)[127]\end{array}$ & $\begin{array}{l}\text { A long-term study of elderly people in } \\
\text { nursing homes with visiting and resident } \\
\text { dogs }\end{array}$ & 1,4 \\
\hline 2 & $\begin{array}{l}\text { Zisselman (1996) } \\
{[128]}\end{array}$ & $\begin{array}{l}\text { A Pet Therapy Intervention With Geriatric } \\
\text { Psychiatry Inpatients }\end{array}$ & $2,4,6$ \\
\hline 3 & $\begin{array}{l}\text { Barker (1998) } \\
{[129]}\end{array}$ & $\begin{array}{l}\text { The effects of animal-assisted therapy on } \\
\text { anxiety ratings of hospitalized psychiatric } \\
\text { patients }\end{array}$ & $1,2,3,6$ \\
\hline 4 & $\begin{array}{l}\text { Barker (2003) } \\
{[130]}\end{array}$ & $\begin{array}{l}\text { Effects of animal-assisted therapy on pa- } \\
\text { tients' anxiety, fear, and depression be- } \\
\text { fore ECT }\end{array}$ & $1,2,3,4$ \\
\hline 5 & $\begin{array}{l}\text { Richeson (2003) } \\
\text { [131] }\end{array}$ & $\begin{array}{l}\text { A therapeutic recreation intervention us- } \\
\text { ing animal-assisted therapy: effects on } \\
\text { the subjective well-being of older adults }\end{array}$ & $1,2,3$ \\
\hline 6 & $\begin{array}{l}\text { Nathans-Barel } \\
(2005)[132]\end{array}$ & $\begin{array}{l}\text { Animal-assisted therapy ameliorates an- } \\
\text { hedonia in schizophrenia patients. A con- } \\
\text { trolled pilot study }\end{array}$ & $1,2,3,4$ \\
\hline 7 & $\begin{array}{l}\text { Prothmann (2006) } \\
\text { [133] }\end{array}$ & $\begin{array}{l}\text { Dogs in child psychotherapy: Effects on } \\
\text { state of mind }\end{array}$ & 1,2 \\
\hline 8 & Cole (2007) [134] & $\begin{array}{l}\text { Animal-assisted therapy in patients hos- } \\
\text { pitalized with heart failure }\end{array}$ & 6 \\
\hline 9 & $\begin{array}{l}\text { Orlandi (2007) } \\
{[135]}\end{array}$ & $\begin{array}{l}\text { Pet therapy effects on oncological day } \\
\text { hospital patients undergoing chemother- } \\
\text { apy treatment }\end{array}$ & $1,2,3$ \\
\hline 10 & $\begin{array}{l}\text { Banks (2008) } \\
{[136]}\end{array}$ & $\begin{array}{l}\text { Original study: Animal-Assisted Therapy } \\
\text { and Loneliness in Nursing Homes: Use of } \\
\text { Robotic versus Living Dogs }\end{array}$ & 2,3 \\
\hline 11 & $\begin{array}{l}\text { Martindale (2008) } \\
{[137]}\end{array}$ & $\begin{array}{l}\text { Effect of animal-assisted therapy on en- } \\
\text { gagement of rural nursing home resident }\end{array}$ & $1,4,5$ \\
\hline 12 & $\begin{array}{l}\text { Braun (2009) } \\
{[138]}\end{array}$ & $\begin{array}{l}\text { Animal-assisted therapy as a pain relief } \\
\text { intervention for children }\end{array}$ & $1,2,3$ \\
\hline 13 & Chu (2009) [139] & $\begin{array}{l}\text { The effect of animal-assisted activity on } \\
\text { inpatients with schizophrenia }\end{array}$ & $2,3,5$ \\
\hline 14 & $\begin{array}{l}\text { Villalta-Gil (2009) } \\
{[140]}\end{array}$ & $\begin{array}{l}\text { Dog-Assisted Therapy in the Treatment of } \\
\text { Chronic Schizophrenia Inpatients }\end{array}$ & $2,5,7$ \\
\hline 15 & $\begin{array}{l}\text { Moretti (2011) } \\
{[141]}\end{array}$ & $\begin{array}{l}\text { Pet therapy in elderly patients with men- } \\
\text { tal illness }\end{array}$ & 1,5 \\
\hline 16 & Beck (2012) [142] & $\begin{array}{l}\text { The effects of animal-assisted therapy on } \\
\text { wounded warriors in an Occupational } \\
\text { Therapy Life Skills program }\end{array}$ & $1,2,3,6$ \\
\hline 17 & Dietz (2012) [143] & $\begin{array}{l}\text { Evaluating animal-assisted therapy in } \\
\text { group treatment for child sexual abuse }\end{array}$ & $1,2,3,4$ \\
\hline 18 & $\begin{array}{l}\text { Marcus (2012) } \\
{[144]}\end{array}$ & $\begin{array}{l}\text { Animal-assisted therapy at an outpatient } \\
\text { pain management clinic }\end{array}$ & $1,2,3$ \\
\hline 19 & $\begin{array}{l}\text { Marcus (2013) } \\
{[145]}\end{array}$ & $\begin{array}{l}\text { Impact of animal-assisted therapy for } \\
\text { outpatients with fibromyalgia }\end{array}$ & $1,2,3$ \\
\hline
\end{tabular}




\begin{tabular}{|c|c|c|c|}
\hline 20 & $\begin{array}{l}\text { Vrbanac (2013) } \\
{[146]}\end{array}$ & $\begin{array}{l}\text { Animal assisted therapy and perception } \\
\text { of loneliness in geriatric nursing home } \\
\text { residents }\end{array}$ & $1,2,3$ \\
\hline 21 & $\begin{array}{l}\text { Havey (2014) } \\
{[147]}\end{array}$ & $\begin{array}{l}\text { The effect of animal-assisted therapy on } \\
\text { pain medication use after joint replace- } \\
\text { ment }\end{array}$ & $1,2,3$ \\
\hline 22 & $\begin{array}{l}\text { Nordgren (2014) } \\
\text { [148] }\end{array}$ & $\begin{array}{l}\text { Effects of dog-assisted intervention on } \\
\text { behavioral and psychological symptoms } \\
\text { of dementia }\end{array}$ & 2,5 \\
\hline 23 & $\begin{array}{l}\text { Barker (2015) } \\
\text { [149] }\end{array}$ & $\begin{array}{l}\text { The Effect of an Animal-Assisted Inter- } \\
\text { vention on Anxiety and Pain in Hospital- } \\
\text { ized Children }\end{array}$ & 2,3 \\
\hline 24 & $\begin{array}{l}\text { Calcaterra (2015) } \\
{[150]}\end{array}$ & $\begin{array}{l}\text { Post-operative benefits of animal-as- } \\
\text { sisted therapy in pediatric surgery: a ran- } \\
\text { domized study }\end{array}$ & 2,7 \\
\hline 25 & $\begin{array}{l}\text { Nurenberg (2015) } \\
\text { [151] }\end{array}$ & $\begin{array}{l}\text { Animal-assisted therapy with chronic psy- } \\
\text { chiatric inpatients: equine-assisted psy- } \\
\text { chotherapy and aggressive behavior }\end{array}$ & 4 \\
\hline \multicolumn{4}{|c|}{$\begin{array}{l}\text { Matters causing low quality rating: 1) Lack of randomization, 2) Lack of adequate control group(s), 3) } \\
\text { Lack of control for confounders, 4) Insufficiently described experimental design, 5) Underpowered } \\
\text { study, 6) Minute treatment effects, 7) High dropout rate. }\end{array}$} \\
\hline
\end{tabular}




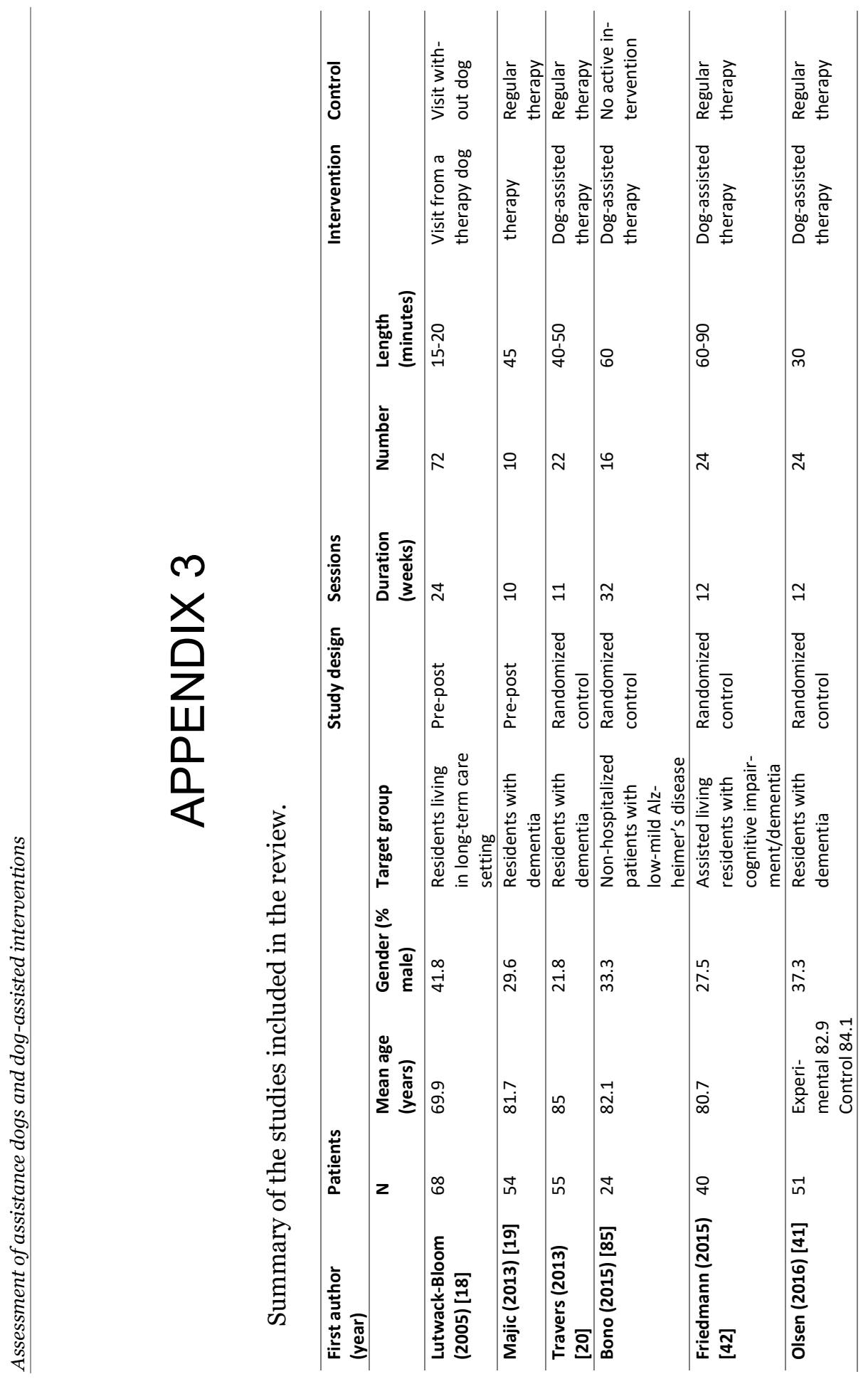




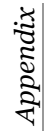

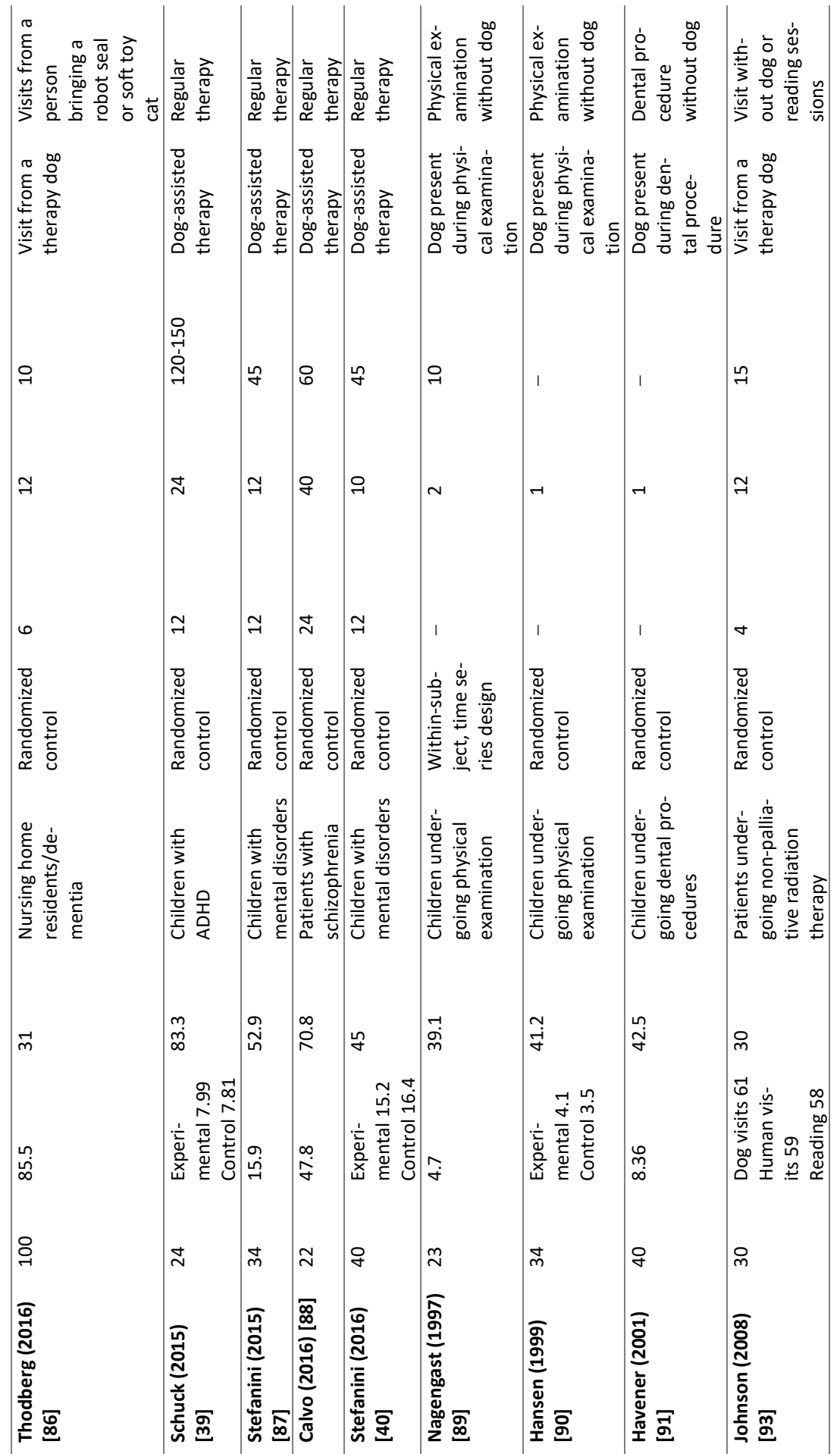




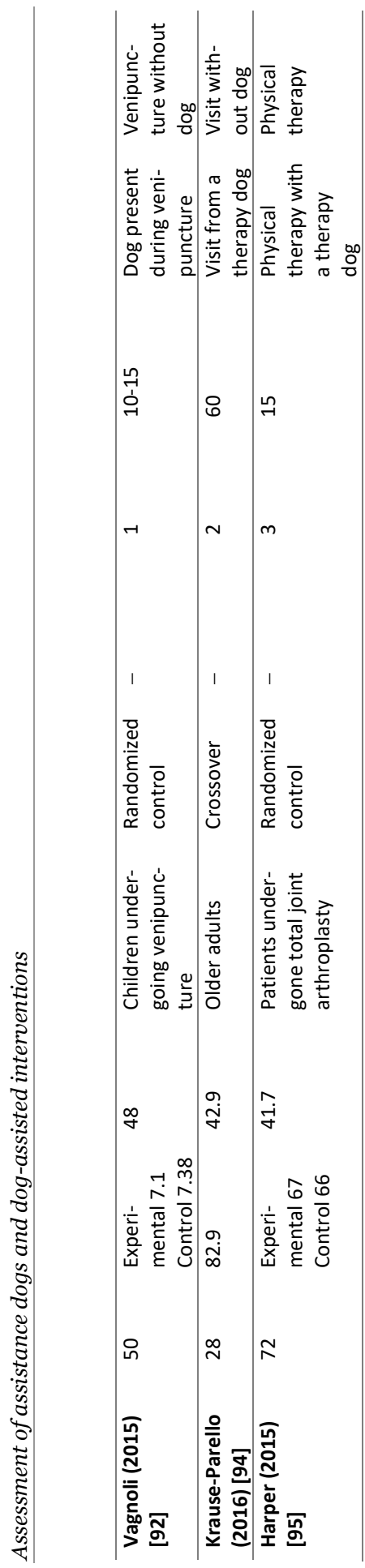




\section{Papers}

The papers associated with this thesis have been removed for copyright reasons. For more details about these see:

http://urn.kb.se/resolve?urn=urn:nbn:se:liu:diva-169010 


\section{0}

\section{FACULTY OF MEDICINE AND HEALTH SCIENCES}

Linköping University Medical Dissertation No. 1743, 2020

Department of Health Medicine and Caring Sciences

Linköping University

SE-581 83 Linköping, Sweden

www.liu.se
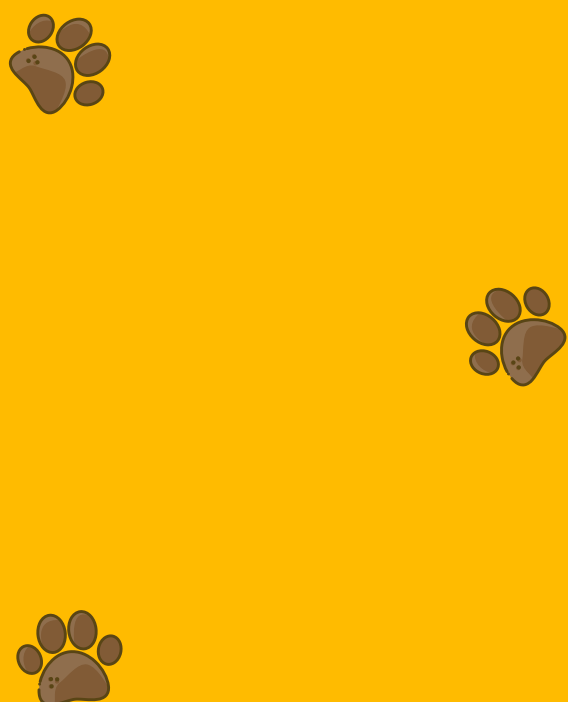